\title{
Engineering Scale Development of the Vapor-Liquid-Solid (VLS) Process for the Production of Silicon Carbide Fibrils
}

September 1993

Report Prepared by

William E. Hollar, Jr.

The Carborundum Company

Technology Division

P.O. Box 832

VED

DEC 201993

OSTI

Niagara Falls, New York 14302

Wendell H. Mills

BP America

4440 Warrensville Center Road

Cleveland, Ohio 44128

under
Subcontract Number 86X-SD861C

for

OAK RIDGE NATIONAL LABORATORY

Oak Ridge, Tennessee 37831 managed by

MARTIN MARIETTA ENERGY SYSTEMS, INC.

for the

U.S. Department of Energy

under Contract No. DE-AC05-84OR21400 
This report has been reproduced directly from the best available copy.

Available to DOE and DOE contractors from the Office of Scientific and Technical Information, P.O. Box 62, Oak Ridge, TN 37831; prices available from (615) 576-8401, FTS 626-8401.

Available to the public from the National Technical Information Service, U.S. Department of Commerce, 5285 Port Royal Rd., Springfield, VA 22161.

This report was prepared as an account of work sponsored by an agency of the United States Government. Neither the United States Government nor any agency thereof, nor any of their employees, makes any warranty, expressed or implied, or assumes any legal liability or responsibility for the accuracy, completeness, or usefulness of any information, apparatus, product, or process disclosed, or represents that its use would not infringe privately owned rights. Reference herein to any specific commercial product, process, or service by trade name, trademark, manufacturer, or otherwise, does not necessarily constitute or imply its endorsement, recommendation, or favoring by the United States Government or any agency thereof. The views and opinions of authors expressed herein do not necessarily state or reflect those of the United States Government or any agency thereof. 


\section{Engineering Scale Development of the Vapor-Liquid-Solid (VLS) Process for the Production of Silicon Carbide Fibrils}

September 1993

Research Sponsored by the U.S. Department of Energy

Fossil Energy

Advanced Research and Technology Development Materials Program

Report Prepared by

William E. Hollar, Jr.

The Carborundum Company

Technology Division

P.O. Box 832

Niagara Falls, New York 14302

Wendell H. Mills

BP America

4440 Warrensville Center Road

Cleveland, Ohio 44128

under

Subcontract Number 86X-SD861C

for

OAK RIDGE NATIONAL LABORATORY

Oak Ridge, Tennessee 37831

managed by

MARTIN MARIETTA ENERGY SYSTEMS, INC.

for the

U.S. Department of Energy

under Contract No. DE-AC05-84OR2141 J

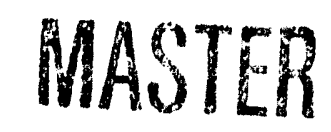




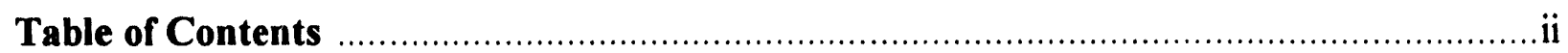

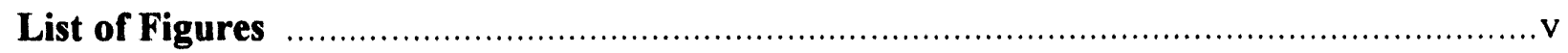

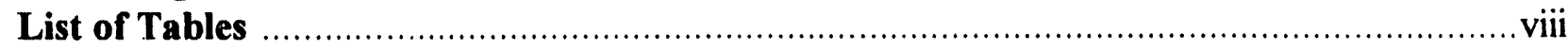

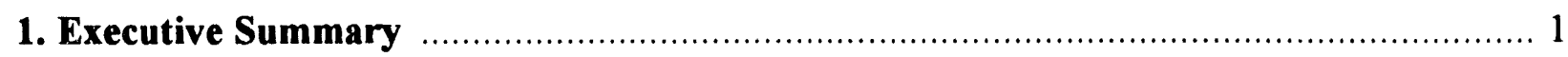

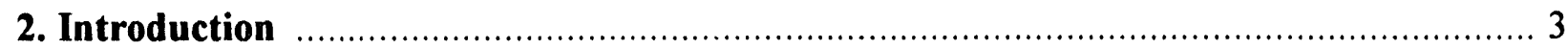

2.1 The History of VLS SiC Fibril Process Development ................................... 3

2.2 Process Chemistry ............................................................................... 4

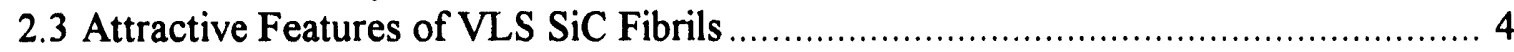

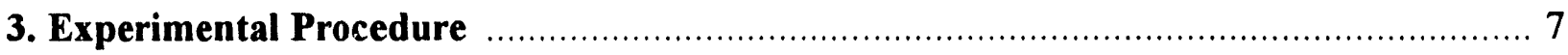

3.1 Growth Experiments .......................................................................... 7

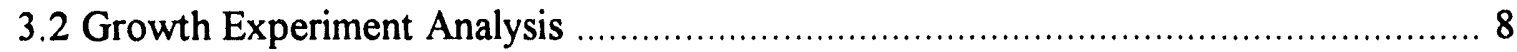

3.3 Process Gas Analysis ........................................................................... 9

3.4 Miscellaneous Characterization ............................................................. 9

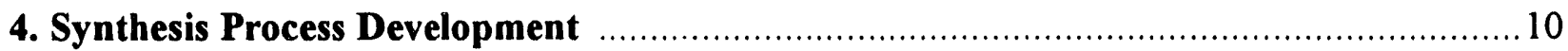

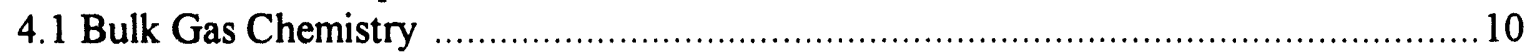

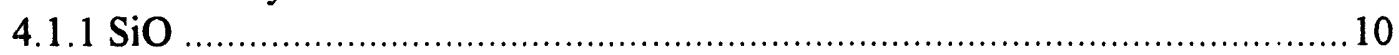

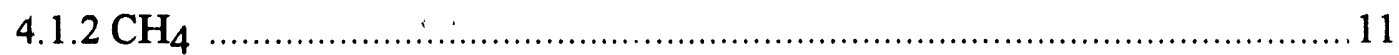

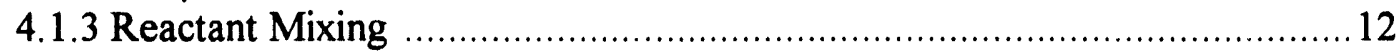

$4.2 \mathrm{SiC}$ Fibril Growth Behavior ..................................................................... 13

4.3 Effect of Reactor Height on SiC Fibril Growth Rates ....................................... 14

4.4 Nucleation Behavior ..................................................................................... 15

4.5 Effect of Process Variables on Reactant Supply Reactions ............................... 16

4.5.1 Temperature Effects ..................................................................... 16

4.5.1.1 Methane Supply ....................................................... 16

4.5.1.2 SiO Supply ................................................................ 19

4.5.2 Process Gas Flow Rate .............................................................. 19

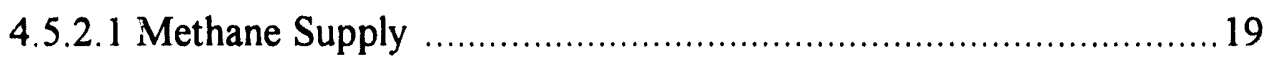

4.5.2.2 SiO Supply .............................................................. 19

4.5.3 Methane Partial Pressure ................................................................. 19

4.5.3.1 Methane Supply .......................................................... 19

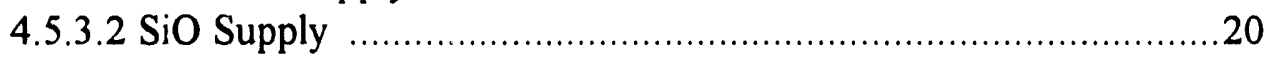

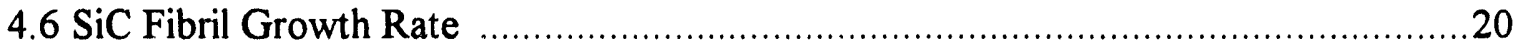

4.7 Effect of Synthesis Mrocess Conditions on Fibril Characteristics ............................24

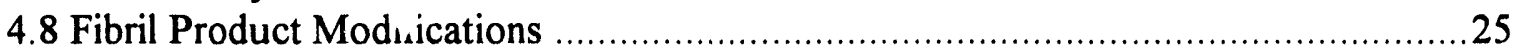

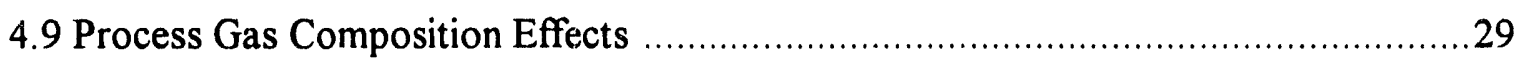

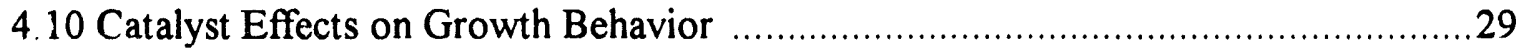

4.1. Baseline Process Conditions and Process Reproducibility ..................................30

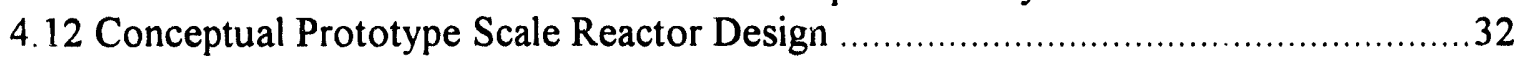




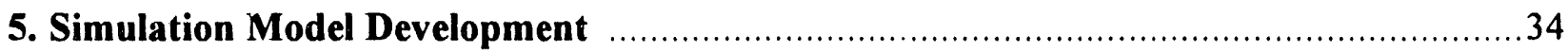

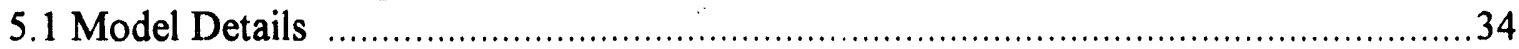

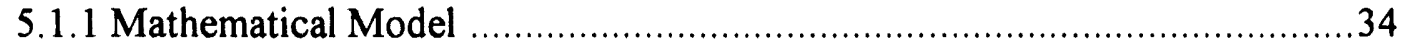

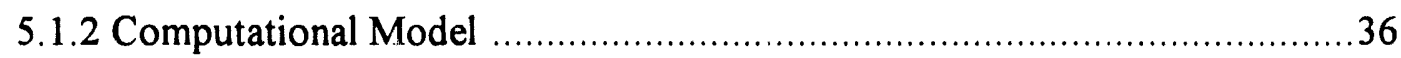

5.2 Comparison of Model and Experimental Results ….............................................37

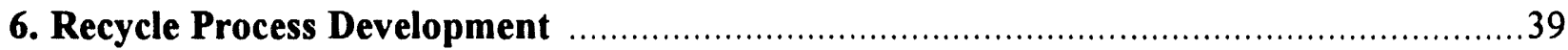

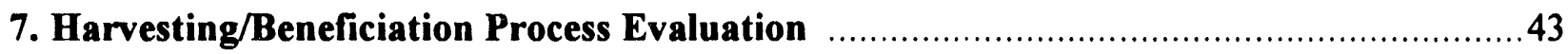

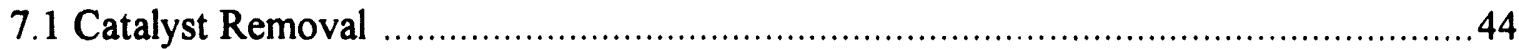

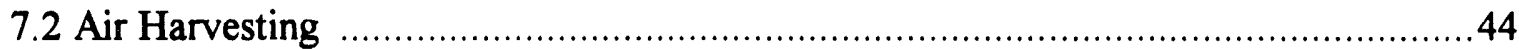

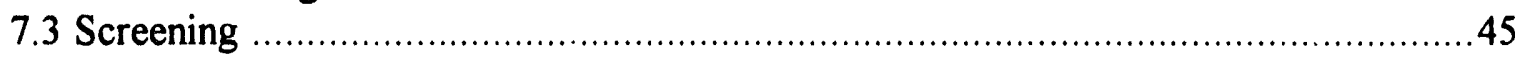

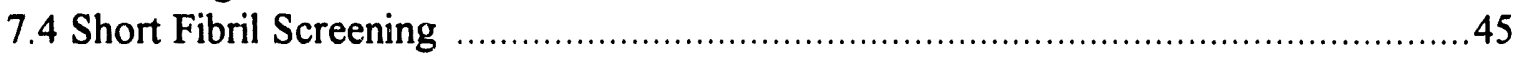

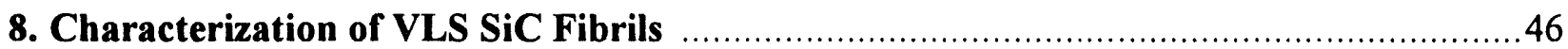

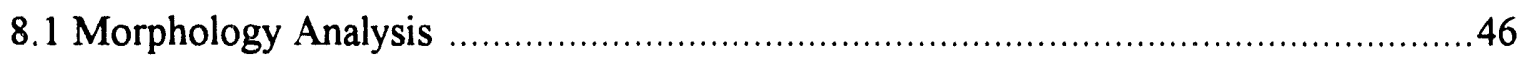

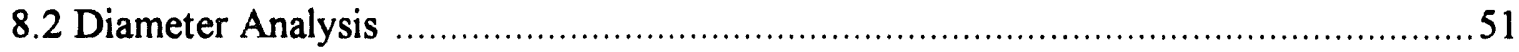

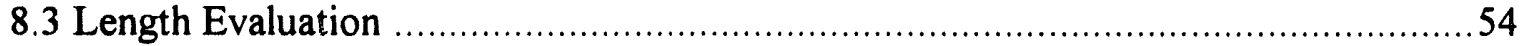

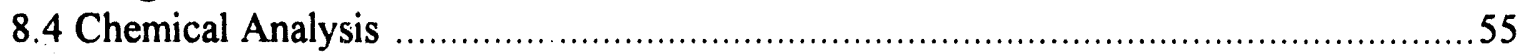

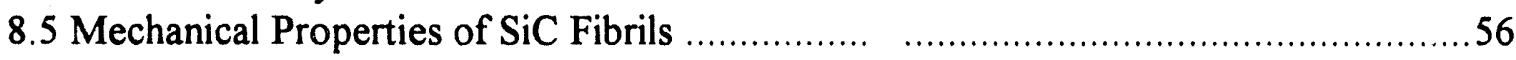

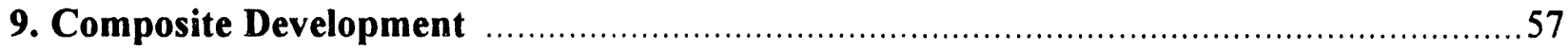

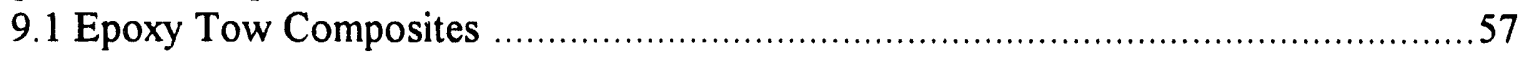

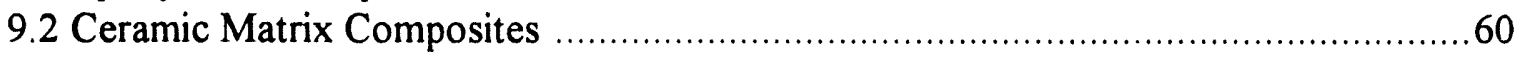

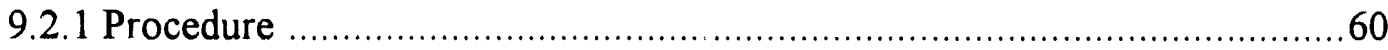

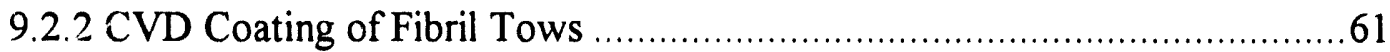

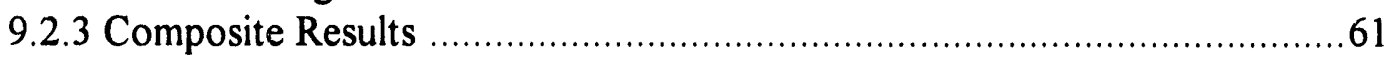

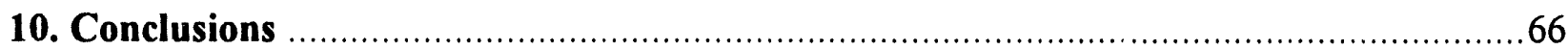

11. Acknowledgments

12. References 


\section{Appendices}

1. Correction Procedures for SiC Formation at the Generator A-1

2. Methane Decomposition Kinetic Measurements ........................................

3. Derivation of the Cell Model .................................................................

4. Activation Energies for SiO Formation ............................................

5. Kinetic Data for Fibril Formation Rate Constant ......................................

6. Statistical Experimental Design Results ..............................................A-14

7. Simulation Model Equations ..........................................................

8. Recycle ivia erial Balance ...............................................................

9. Diameter Distribution Data and Correlation Results ................................ A-23

10. Single Fiber Composite Testing Results ..............................................A-27

11. Epoxy Composite Mechanical Testing Results ........................................A-28

12. Summary of MER Process Research Experiments ...................................A-29

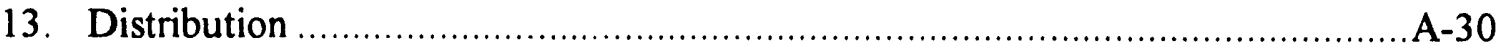




\section{List of Figures}

Page

1. VLS SiC Fibril Synthesis Reaction Mechanisms …………................................... 5

2. Carborundum SiC Fibril Reactor Design Concept …........................................ 6

3. Schematic of VLS SiC Fibril Synthesis Experimental Apparatus ……………........ 7

4. Growth Experiment Temperature/Time Profile ……..................................... 8

5. SiO Generator Weight Loss Versus Distance into the Reactor ...............................11

6. Time Dependence of $\mathrm{SiO}$ and $\mathrm{SiC}$ Fibril Formation Reactions .............................14

7. SEM Micrographs Illustrating the Effect of Process Conditions on Fibril

Nucleation Behavior (Magnification 20x) 17

8. $\quad 35 \mathrm{~mm}$ Photographs Showing the Effect of Process Conditions on Nucleated Fibril Length and Site Density 18

9. Effect of Reactor Position on Reactant Partial Pressures and SiC Fibril

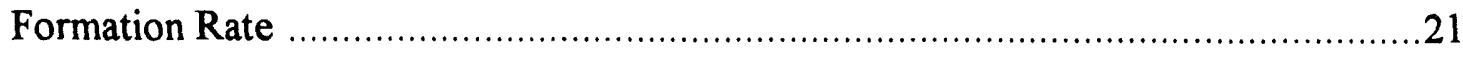

10. Effect of Synthesis Process Conditions on Fibril Growth Rate Profiles ...................22

11. Effect of Methane Concentration and Temperature on Total Fibril Growth (Process Gas Flow Rate $=27$ slpm)

12. Effect of Methane Concentration and Temperature on Total Fibril Growth (Process Gas Flow Rate $=13.5 \mathrm{slpm}$ )

13. Photographs Comparing Fibril Product Grown at Different Process Conditions ........26

14. Long SiC Fibrils Grown Under the Product Modification Task ............................28

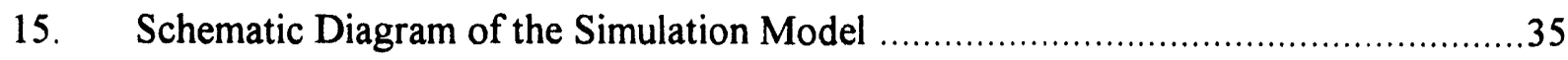

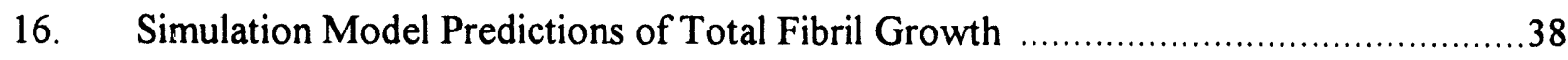

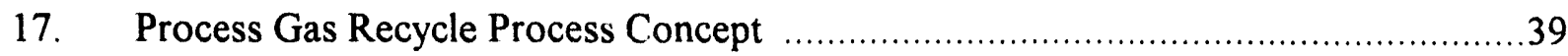

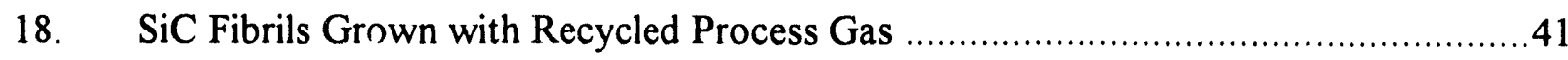


19. Recycle Process Gas Composition as a Function of Time …................................42

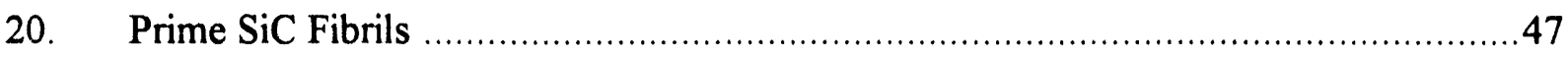

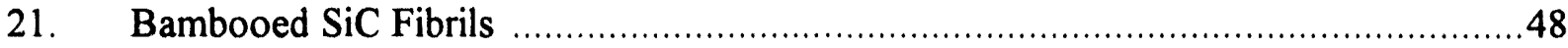

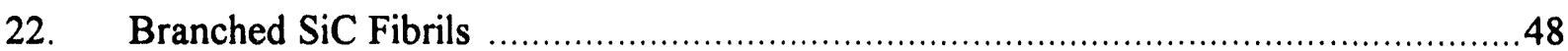

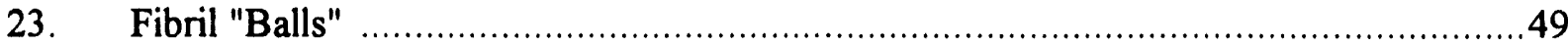

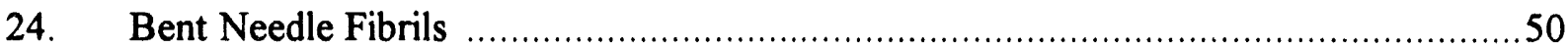

25. Experimental and Calculated Fibril Diameter Distributions …...........................52

26. Effect of Synthesis Process Conditions on Average Diameter Parameter (X') ..........53

27. Effect of Synthesis Process Conditions on Diameter Dispersion Parameter (n) .........53

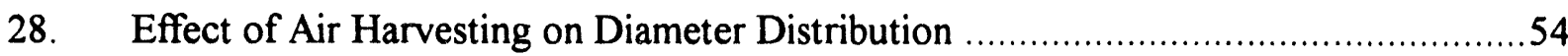

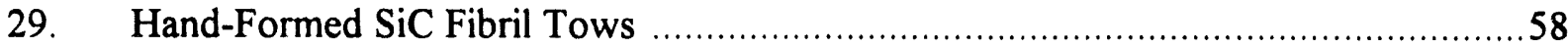

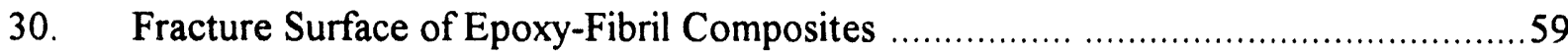

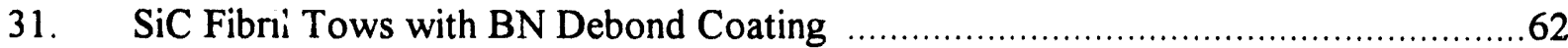

32. Four-Point Bend Testing Results on Monolithic Mullite and Fibril Reinforced Mullite Composites Fabricated by Hot Pressing ...................................63

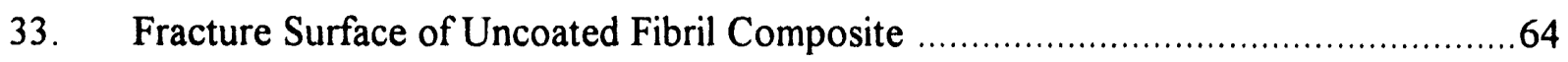

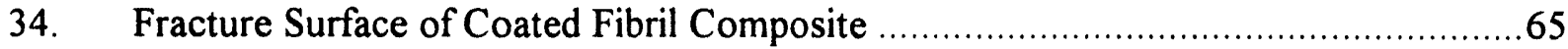

A-1.1 CO Evolution During Fibril Growth Experiment ……...........................................

A-1.2 Spreadsheet for SiO Correction by $\mathrm{CO}$ Analysis .................................................

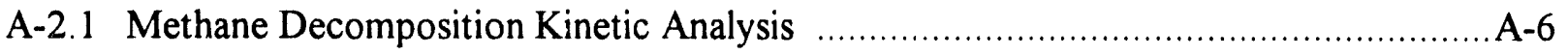

A-2.2 Effect of Temperature and Process Gas Composition on Methane Decomposition Rate Constants 


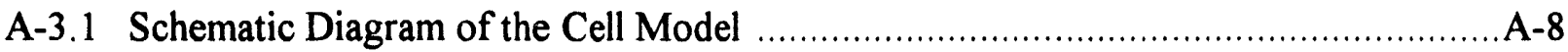

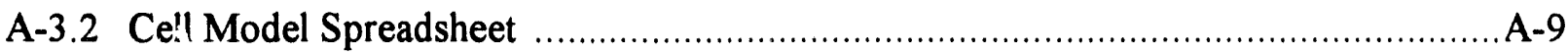

A-6.1 Generator Weight Loss as a Function of Synthesis Process Conditions ....................A-15

A-6.2 SiO Utilization as a Function of Synthesis Process Conditions …..........................A-16

A-6.3 $\mathrm{CH}_{4}$ Utilization as a Function of Synthesis Process Conditions …........................ A-17

A-6.4 Average Fibril Diameter as a Function of Synthesis Process Conditions ……...........A-18

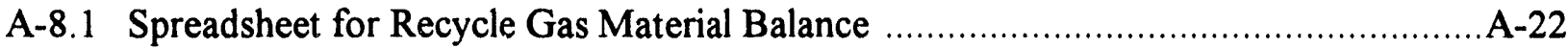

A-9.1 Effect of $n$ on Diameter Distribution for Fixed X' using the RRB Equation ..............A-24

A-9.2 Effect of $\mathrm{X}^{\prime}$ on Diameter Distribution for Fixed $\mathrm{n}$ using the RRB Equation ..............A-24

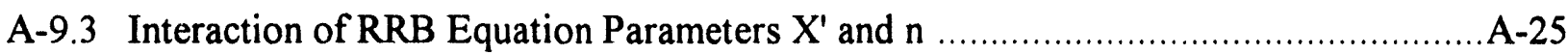

A-9.4 Relationship Between Experimental Mean Diameter and RRB Parameter X' ...........A-25

A-9.5 Relationship Between Experimental Diameter Distribution Width and

RRB Parameter $n$

A-10.1 Single Fiber Compos: • Test Results - Experimental Data and Model Predictions .....A-27

A-11.1 Tensile Test Results for Fibril Tow Reinforced Epoxy ……….............................. A-28 


\section{List of Tables}

\section{Page}

1. Attractive SiC Fibril Characteristics ….................................................... 5

2. Methane Decomposition Kinetic Parameters ….............................................. 12

3. Stages and Goals of the SiC Fibril Growth Process ..........................................

4. Macroscopic Nucleation Experimental Results .............................................. 16

5. Effect of Process Conditions on Important Fibril Synthesis Reactions ....................24

6. Experimental Results - Fibril Product Modification Campaign ............................25

7. Baseline Synthesis Process Conditions ....................................................... 31

8. Process Reproducibility at the Baseline Process Condition ..................................32

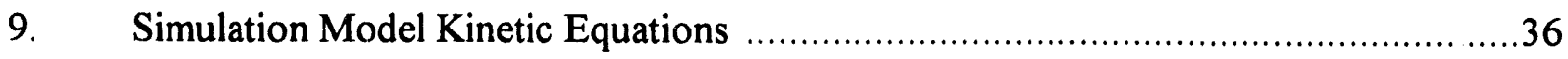

i0. Comparison of Recycle and Standard Growth Experimental Results .....................40

11. SiC Fibril Postprocessing Steps …........................................................43

12. Settled Density of Different Length Fibril Product .........................................55

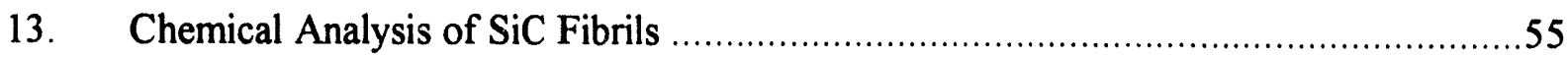

14. Literature Data on SiC Fibril Mechanical Properties .......................................56

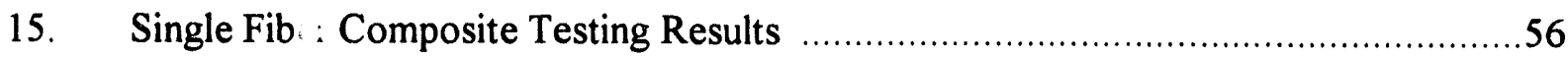

16. Hot Pressing Conditions and Fibril Composite Properties ..................................60

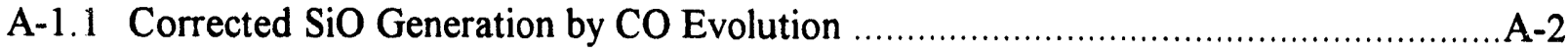

A-1.2 Effect of Process Conditions on Corrected SiO by Generator Chemical Analysis ......A-4

A-4.1 Activation Energies for the SiO Formation Reaction .......................................12

A-5.1 Regression Analysis for Fibril Formation Rate Constant ..................................A-13 
A-8.2 Comparison of Experimental and Calculated Gas Flow and Composition Parameters for Recycle Experiment A-21

A-9.1 Correlation of Fibril Diameter Distribution Ceia Using the RRB Equation A-23

A-12.1 Optimum Result - MER Process Research Program A-29 


\section{Engineering Scale Development of the Vapor-Liquid-Solid (VLS) Process for the Production of Silicon Carbide Fibrils*}

\section{Executive Summary}

Vapor-Liquid-Solid (VLS) SiC fibrils have attractive physical, mechanical, and thermal properties for use as reinforcements in ceramic matrix composite (CMC) material systems. These properties include high tensile strength and modulus, unmatched creep resistance, and good oxidation resistance. High production costs and limited availability of material for composite evaluation at the present production scale have slowed full evaluation and utilization of $\mathrm{SiC}$ fibrils in composite systems.

The Carborundum Company has completed a program designed to determine the process scaleup parameters and to produce material for evaluation in a CMC. Scaleup of reactor capacity is necessary to lower production costs and increase availability of this material. The work focused on determining the factors that determine the viability of this scaleup. Fibril manufacturing process steps such as process gas recycle and postprocessing of fibril product impact the production costs. Preliminary evaluation of these steps has been completed to determine their impact on production costs and the technical feasibility of the manufacturing process.

Reactor scaleup parameters have been evaluated in a reactor configuration with a vertical dimension twice that of the Los Alamos National Laboratory (LANL) reactor. This configuration allowed evaluation of growth process limitations caused by variations of the reactant concentrations with increasing reactor height. The effect of $\mathrm{SiO}$ and $\mathrm{CH}_{4}$ supply rates on the fibril growth rate and characteristics has been evaluated. Variations in the reactant supply with reactor position have been identified as the controlling scaleup characteristic. Modification of the synthesis process conditions relative to the LANL process conditions was necessary to achieve uniform fibril growth in a taller reactor.

A computer simulation model has been developed to consolidate critical scaleup data in a form suitable for reactor design and process optimization. The model uses the PHOENICS computer package to simulate flow dynamics and mass transfer within a single reactor channel. Kinetic data obtained in the development reactor have been incorporated into the model. The model requires minimal adjustable parameters to simulate the effects of critical process variables such as temperature and reactant supply.

The cost of hydrogen in the fibril synthesis process can become a controlling production cost factor in the absence of a process gas recycle system. An external recycle system was designed, installed, and commissioned. Growth experiments with recycled process gas confirmed that $\mathrm{SiC}$ fibrils can be grown using recycled gas. Preliminary evaluation indicated $t^{\text {that }}$ both the fibril growth rate and product characteristics were similar to the baseline process without a recycle system.

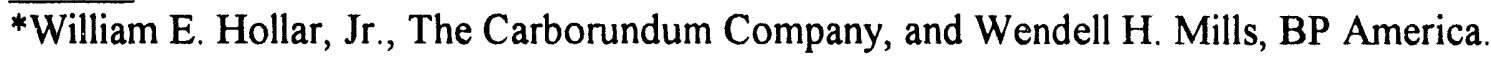


Fibril postprocessing requirements depend on the fibril characteristics required for the composite application. Chemical leaching was developed as a means of removing residual metal catalyst. Successful removal of undesirable impurities was demonstrated without visible degradation of the fibril surfaces. Several process concepts were evaluated for beneficiation of the fibril product based on the fibril length requirements. Typical yields in the range of $40-60 \%$ were found for the beneficiation processes. These were similar to the results observed in LANL's prime beneficiated product. Yield is an important parameter, since manufacturing costs will be inversely proportional to yield.

Fibril characterization has been an important component of the process development and scaleup effort. The primary focus has been on physical characterization by microscopy to determine product morphology and dimensions. Synthesis process conditions strongly affect fibril physical characteristics; characterization is necessary to determin : tradeoffs between process productivity and product characteristics. A quantitative technique has been developed for measuring and correlating fibril diameter distributions. This technique should serve as a powerful tool in achieving improved or tailored diameter distributions for specific applications. Mechanical strength evaluation has been performed by single fiber composite testing. These experiments have confirmed the high strength of VLS SiC fibrils reported by other researchers.

Hand-formed tows have been used to fabricate an oxide-matrix composite containing a low volume loading of long aligned fibrils. These experiments demonstrated that fibrils could be CVD. -oated in a low-density tow and a dense composite could be fabricated.

The results of this work indicate that reactor scaleup will be possible. Improved understanding of the relationship between reactant supply and the fibril growth process has been obtained. In addition, side reactions involving the reactants have been evaluated, leading to improved understanding of reactor design requirements. These data were consolidated in the form of the simulation model, producing, a powerful tool for reactor design and optimization.

In addition, the feasibility of recycling process gas has been demonstrated and the impact of postprocessing on yields has been determined. The information generated during this program indicates that the production costs for the fibril will be competitive with current costs and cost projections for other high-performance, high-temperature reinforcements on a cost-performance basis.

The viability of the fibril as a reinforcement can only be evaluated by understanding the relationship between production costs and composite performance. To improve understanding of this relationship, the following near-term work is suggested:

1. Demonstrate the application of fibrils as a high-performance reinforcement.

2. Improve understanding of the relationship between macroscopic growth conditions and microscopic fibril characteristics.

3. Evaluate improved reactor designs for scaleup.

4. Evaluate the relationship between fibril cost and composite performance. 


\section{Introduction}

\subsection{The History of VLS SiC Fibril Process Development}

Research and development of the VLS process for SiC fibrils has been performed over the past twenty-five years. Earliest efforts focused on defining the mechanism for the formation of VLS $\mathrm{SiC}$ fibrils[1]. Small quantities of fibrils (i.e., less than $1 \mathrm{~g}$ ) were produced in this study. Early efforts at scaling up the process included work by General Technology Corporation[2]. This scaleup effort advanced the manufacturing technology, but commercialization of the process was unsuccessful primarily due to high projected costs relative to other commercially available reinforcements.

Enhanced demands for reinforcement performance in ceramic matrix composites[3] have renewed interest in the fibrils. High-temperature materials applications require reinforcements with increased temperature stability, creep resistance, and strength. The SiC fibril remains a strong candidate by virtue of its single crystal structure which yields high strength, thermal resistance, and oxidation resistance.

In response to these requirements, a major research and development effort was conducted at LANL during the 1980 's[4]. Process improvements developed through this program have improved the commercial viability of the fibril. The important contributions of the LANL program included increased understanding of several key process variables: gas mixing, catalystsubstrate interactions, and Si reactant supply on the growth process performance. Process and reactor design improvements resulted in an order of magnitude increase in growth rates[4]. Development of postprocessing steps and fibril characterization techniques was also completed[5].

A concurrent program for the commercial scaleup of the process was also attempted, based on a continuous furnacing process concept[6]. This concept was unsuccessful primarily due to an insufficient understanding of the process to support a new reactor design and furnacing concept. The requirement of gas mixing for the reproducible production of prime fibrils appeared to be the primary cause for the difficulties encountered.

Carborundum's efforts have focused on transferring the LANL technology and increasing the understanding of key scaleup parameters in order to evaluate reactor scaleup feasibility. The specific targets of this program were to:

- determine the design of a prototype scale reactor capable of producing $100-500$ pounds/year of SiC fibrils

- improve the productivity of the process through increases in growth rate and yield

- demonstrate a process gas recycle system

- demonstrate a beneficiation process for postprocessing of fibrils 


\subsection{Process Chemistry}

The basic process chemistry has been described in more detail elsewhere[7,8]. Figure 1 shows a schematic of reaction mechanisms for the process. Both $\mathrm{C}$ and $\mathrm{Si}$ are required to precipitate the $\mathrm{SiC}$ fibril. Most of the development work has used in-situ batch generation of $\mathrm{SiO}$ as the $\mathrm{Si}$ source[4]. The fundamental understanding of this reaction is low and has been the subject of a dissertation[9]. Control of $\mathrm{SiO}$ supply via this reaction is difficult[4]; however, no viable alternatives to SiO have been demonstrated. Methane is the typically used carbon source[2,4]. The thermodynamics of the reactant gas and liquid catalyst droplet have been described elsewhere[8,9]. Order of magnitude calculations have been used to postulate potential rate limiting steps in the fibril growth process[7]. $\mathrm{SiO}$ and $\mathrm{CH}_{4}$ delivery appeared to be the probable rate limiting mechanisms. Other efforts have indicated the importance of uniform reactant delivery in producing desired growth[10]. This is another indication that reactant delivery (molar supply rate plus uniformity of the gaseous environment) is a controlling factor in the growth process.

Figure 2 is a reactor design schematic diagram. Process gas containing $\mathrm{H}_{2} / \mathrm{N}_{2} / \mathrm{CO} / \mathrm{CH}_{4}[7]$ is introduced at the base of the reactor and flows in vertically rectangular channels. SiO is produced in-situ at locations termed generators[4]. The growth of fibrils by the VLS process is promoted and controlled by the introduction of a source for liquid metal catalyst droplets. The catalyst source can be supplied by a variety of techniques[4,11]. Fibrils grow approximately perpendicular to the gas flow in the LANL/Carborundum reactor configuration. The individual fibrils tend to lengthen with time until encountering a geometrical barrier (substrate, other fibrils) or until deactivation occurs.

\subsection{Attractive Features of VLS SiC Fibrils}

Table 1 summarizes some key characteristics of $\mathrm{SiC}$ fibrils which make them an attractive reinforcement for ceramic matrix composites. These characteristics include mechanical and thermal properties unmatched by other continuous SiC reinforcements. The VLS reaction mechanism imparts some control over the product physical characteristics. Diameter is proportional to the catalyst diameter, while fibril length can be modified through changes in reactor geometry and growth cycle time. This control over fibril dimensions represents critical advantage over the commercially available Vapor-Solid (VS) SiC whiskers, which have small diameter and limited lengths. When compared on an individual basis, the mass of a SiC fibril can be four orders of magnitude larger than a SiC whisker. 


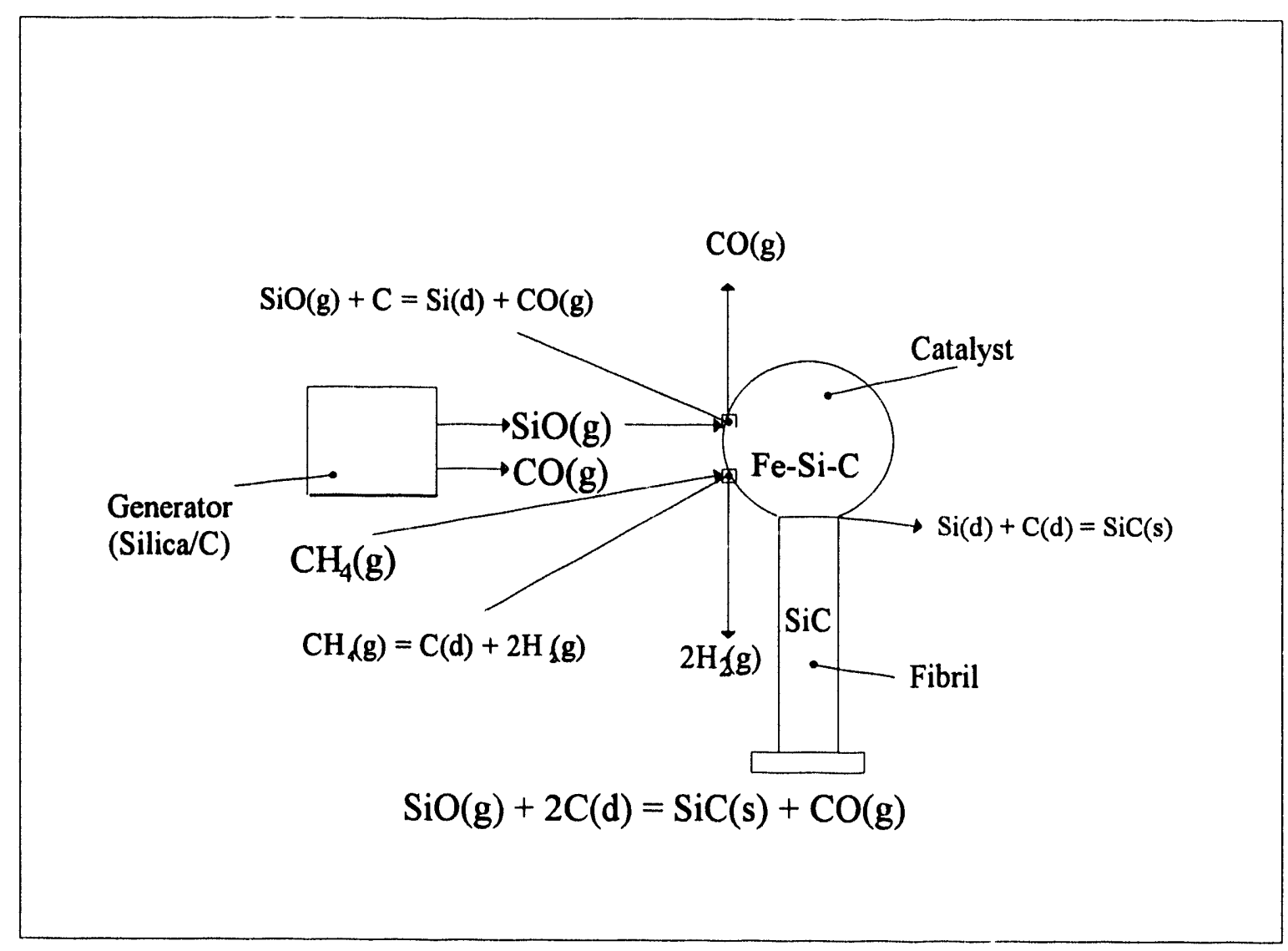

Figure 1 VLS SiC Fibril Synthesis Reaction Mechanisms

Table 1 Attractive SiC Fibril Characteristics

\begin{tabular}{|c|c|c|}
\hline Characteristic & Examples & Attractive Fibril Features \\
\hline Physical & $\begin{array}{c}\text { Morphology } \\
\text { Length } \\
\text { Diameter } \\
\end{array}$ & $\begin{array}{c}\text { Straight, smooth, rounded } \\
\text { triangular } \\
\text { Lengths to } 7 \mathrm{~cm} \\
\text { Diameter: } 5-10 \mu \mathrm{m}\end{array}$ \\
\hline Chemical & $\begin{array}{l}\text { Bulk Chemistry } \\
\text { Trace Impurities }\end{array}$ & $\begin{array}{c}\text { Single Crystal } \beta-\mathrm{SiC} \\
\text { Trace Impurities }<1 \%\end{array}$ \\
\hline Mechanical & Tensile Strength & Tensile Strength $\geq 6 \mathrm{GPa}$ \\
\hline Thermal & $\begin{array}{c}\text { Creep Resistance } \\
\text { Oxidation Resistance }\end{array}$ & $\begin{array}{c}\text { Creep Parameter } m=1 \\
(T=1673 \mathrm{~K})\end{array}$ \\
\hline
\end{tabular}




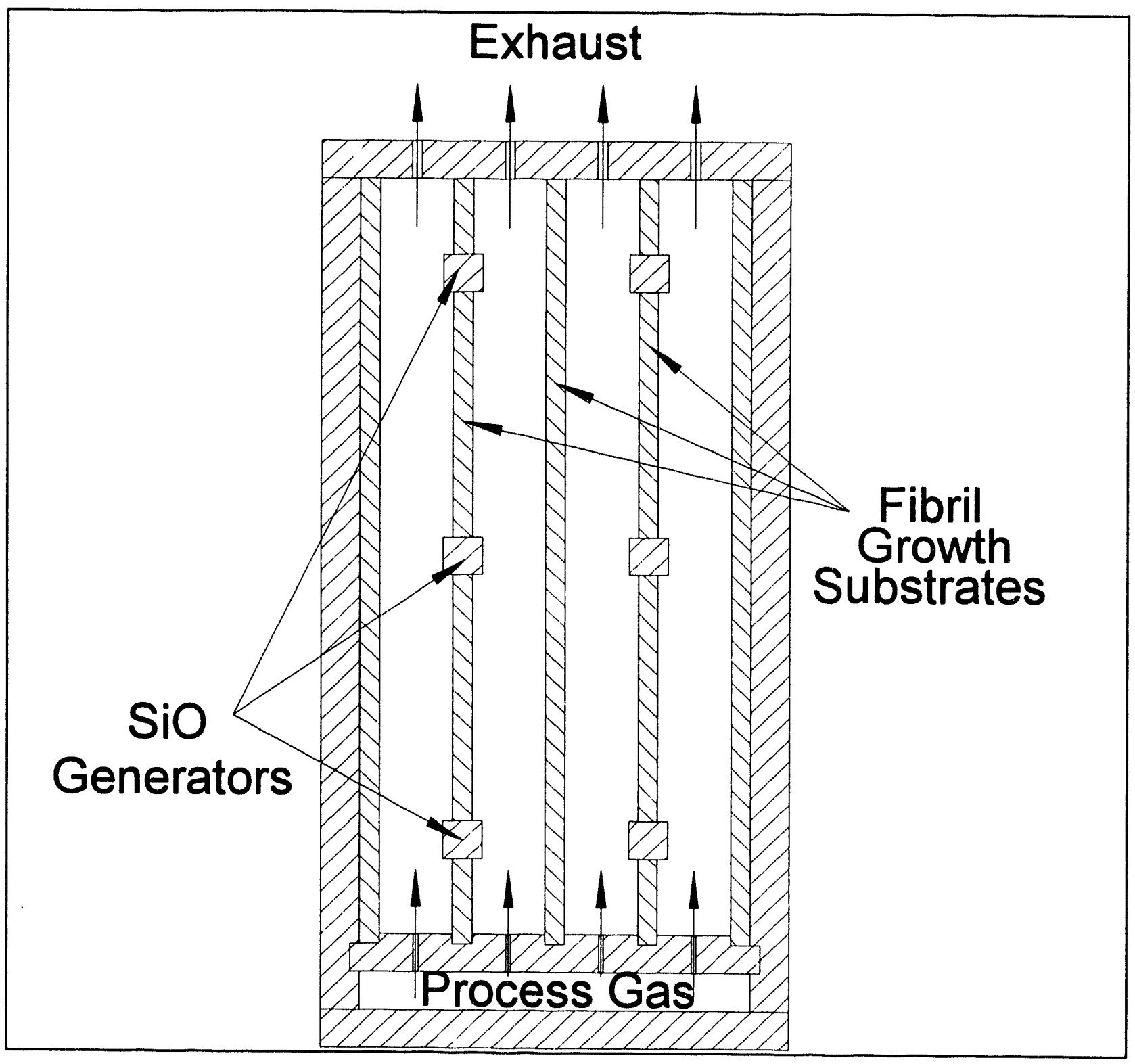

Figure 2 Carborundum SiC Fibril Reactor Design Concept 


\section{Experimental Procedure}

\subsection{Growth Experiments}

A schematic of the fibril synthesis system is shown in Figure 3. Fibril growth substrates were prepared by coating $15.2 \mathrm{~cm}$ by $30.4 \mathrm{~cm}$ graphite substrates with a catalyst precursor. Two catalysts were used in the present study: iron sol catalyst[11] and -325 mesh FeSi particles. The FeSi catalyst was applied using a technique similar to the LANL procedure[4]. SiO generator bricks were prepared by dip coating refractory ceramic brick supports (K-30) in a slurry of carbon black and colloidal silica. These "generators" were placed at discrete locations within the reactor. The growth experiments were conducted in a specially-designed graphite-element furnace. The reactor was located in a cylindrical graphite crucible. Reactor temperatures were typically measured by Type B thermocouples at two locations--the outside of the graphite crucible containing the reactor assembly and the bottom of the crucible. The furnace insulation was purged with nitrogen.

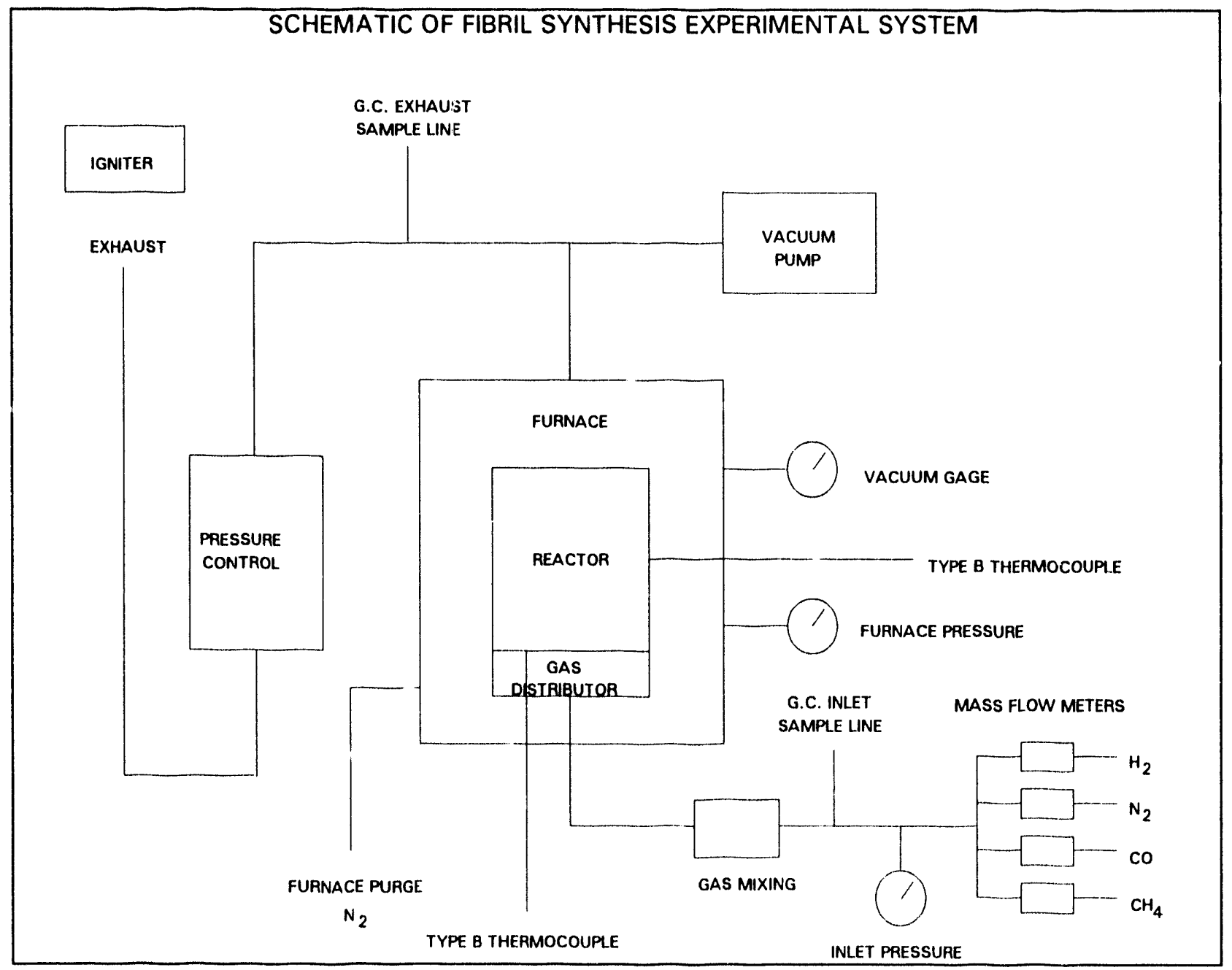

Figure 3 Schematic of VLS SiC Fibril Synthesis Experimental Apparatus 
The process gas consisting of $\mathrm{H}_{2}(80 \%-90 \%), \mathrm{CO}(0 \%-10 \%), \mathrm{N}_{2}(0 \%-15 \%)$, and $\mathrm{CH}_{4}$ $(0.1 \%-1 \%)$ was supplied by regulating the individual component flow rates with mass flow meters.

The furnace heating cycle consisted of three phases--heat-up, nucleation, and growth, as illustrated in Figure 4. A 4.5 hour cycle time to the nucleation temperature was used. The nucleation/growth times and process conditions were varied during the experimental program, depending on the desired experimental conditions. The furnace was allowed to cool overnight prior to fibril harvesting.

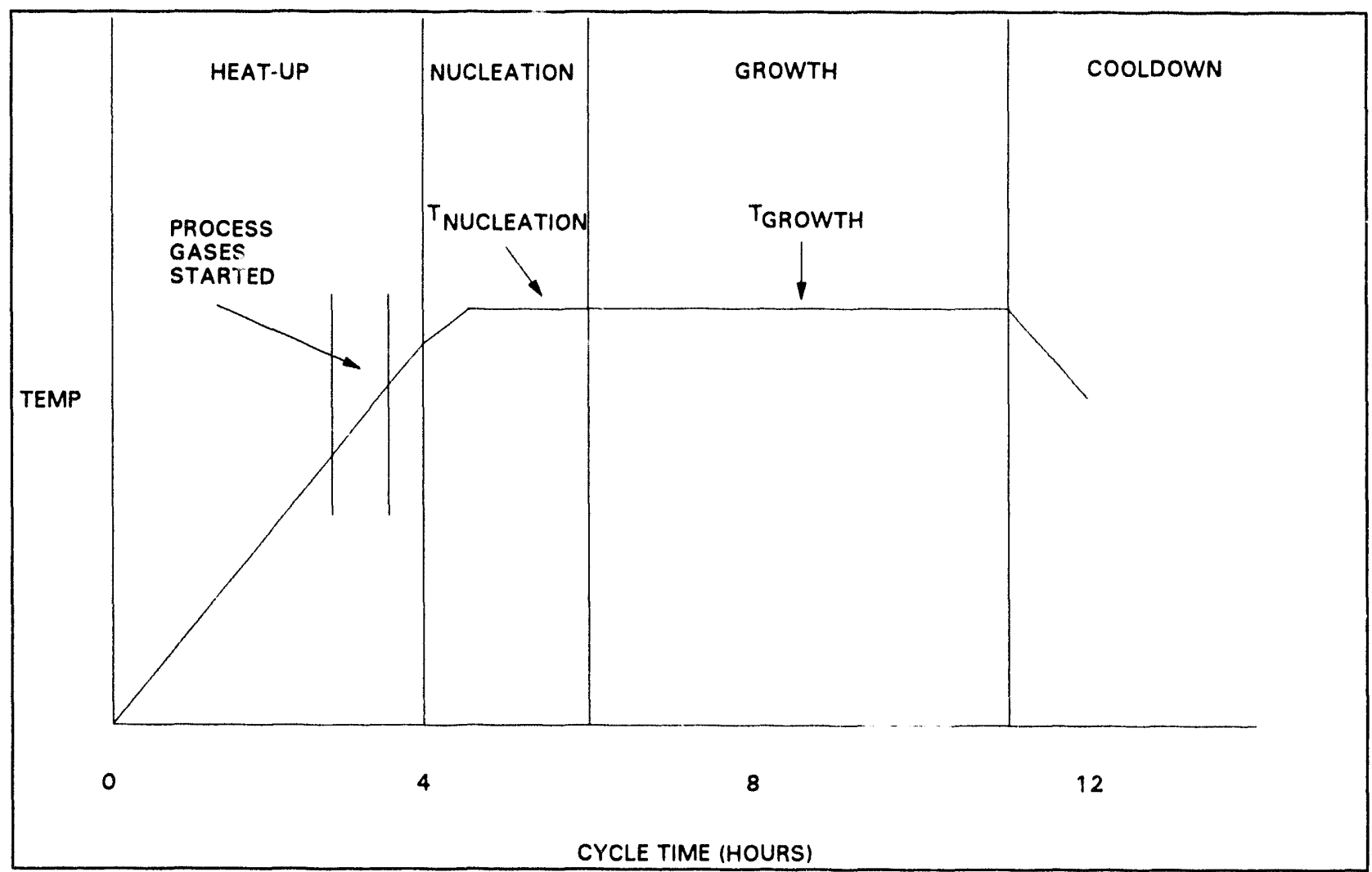

Figure 4 Growth Experiment Temperature-Time Profile

The furnace and cooling water temperatures, process gas flow rates, input furnace power, and furnace pressures were evaluated periodically throughout each experiment. Inlet and exhaust gas compositions were monitored by gas chromatography (GC) and infrared $\mathrm{CO}$ analysis.

\subsection{Growth Experiment Analysis}

The growth substrates were removed from the reactor and the fibril morphology and length as a function of position were recorded. The fibrils on individual substrates were typically harvested by scraping with a razor blade. This technique produced the best accountability of the total SiC 
formation. Two substrates were chosen (typically substrates five and six), and fibrils were razor harvested in specific areas as a function of position (height) into the reactor. This procedure allowed for the evaluation of the variation of the growth rate with position. The generator bricks were collected and weighed to $\mathrm{pr}$ ide an estimate of the total $\mathrm{SiO}$ generation $[4,9,12]$. In latter stages of the program, $35 \mathrm{~mm} \mathrm{p}$.. .ographs of the as-synthesized fibrils were obtained to record the effects of synthesis process conditions on fibril length and morphology.

\subsection{Process Gas Analysis}

Process gas analysis played an important role in the analysis of the growth process[4]. A gas chromatograph (GC) (Varian Model 3700) with Carbosieve ${ }^{\mathrm{TM}}$ columns was used. Calibration gases containing each process gas component were used to calibrate the response factors for the four major component gases. The sampling system was designed to allow sampling of both the inlet and exhaust gas streams. The interval between samples was thirty minutes, which led to 10 20 gas composition measurements per experiment.

An infrared CO monitor (Carbon Monoxide Gas Analyzer, Infrared Industries, Model 703D) was used for continuously measurement of the $\mathrm{CO}$ concentrations. Good agreement between the GC and IR monitor $\mathrm{CO}$ readings was found.

\subsection{Miscellaneous Characterization}

Much of this task utilized scanning electron microscopy (SEM) and optical microscopy to evaluate the characteristics of as-synthesized and postprocessed fibrils. The SEM was an AMRAY Model 1400. Optical microscopy was performed on a Wild Model 420, using magnifications from 50 to $160 \mathrm{x}$.

Diameter measurements were performed using a Zeitz Model SP4000 optical microscope. Diameter data analysis was performed using custom software on an IBM PC.

Fibril chemical analysis was performed. Total $\mathrm{C}$ and total $\mathrm{Si}$ were measured by combustion analysis and X-ray spectrophotometry, respectively. Trace impurities such as $\mathrm{Fe}, \mathrm{Al}$ and other transition metals were analyzed by emission spectroscopy and atomic absorption. Several experiments were conducted in which reacted generator bricks were evaluated by total and free carbon analysis. Free carbon was measured by combustion analysis. 


\section{Synthesis Process Development}

Order of magnitude calculations indicated that growth rate limitations were related to the supply of the two key reactants - - $\mathrm{CH}_{4}$ and $\mathrm{SiO}$ [7]. Much of the development effort focused on determining the effect of reactant delivery rates on the fibril growth rates. Reactant delivery rates were modified through changes in the synthesis process conditions--primarily temperature, process gas flow rate, and methane partial pressure. Reactant delivery was also affected by the degree of mixing within the reactor, since mixing and mass transfer processes determined the uniformity of the reactant gas concentrations. Synthesis process conditions determined the reactor performance in terms of:

- macroscopic behavior (growth rate, reactant utilization)

- microscopic behavior (product physical characteristics)

Development experiments demonstrated that evaluation of macroscopic and microscopic responses was required to identify operating conditions which maximized desirable product characteristics and fibril growth rate.

\subsection{Bulk Gas Chemistry}

\subsubsection{SiO}

Earlier studies showed the importance of the SiO supply rate on the fibril growth rate[4]. SiO was generated in-situ at specific locations within the reactor using $\mathrm{SiO}$ "generators." The generators were placed at specific locations within the reactor to control the SiO concentration throughout the reactor height. The SiO was formed by the carbothermal reduction of silica by carbon according to the reaction:

$$
\mathrm{C}(\mathrm{s})+\mathrm{SiO}_{2}(\mathrm{~s})=\mathrm{SiO}(\mathrm{g})+\mathrm{CO}(\mathrm{g})
$$

Since both products are gaseous, the weight loss of the generator is proportional to the total amount of $\mathrm{SiO}$ formed[4]. There is the potential for side reactions at the generator site[9]. The most important is:

$$
\mathrm{SiO}(\mathrm{g})+2 \mathrm{C}(\mathrm{s})=\mathrm{SiC}(\mathrm{s})+\mathrm{CO}(\mathrm{g})(2)
$$

This reactic $n$ can reduce the $\mathrm{SiO}$ available for fibril formation. Several techniques were developed under the present program to estimate the importance of this reaction[12]. Results based on these analyses are summarized in Appendix 1.

Carbothermal generation of $\mathrm{SiO}$ as a silicon source has two major drawbacks:

- it is a batch process and can exhibit time-dependent behavior

- there is no $\mathrm{SiO}$ in the inlet gas, which places greater importance on the mixing of the process gas stream and the $\mathrm{SiO}$ 
The ramifications of these features will be discussed later. Process variables which impact SiO formation and delivery include flow rate, temperature, and process gas composition.

One unique characteristic of $\mathrm{SiO}$ generation in the Carborundum reactor was that the generation rate was position dependent. This was demonstrated by a continuous variation in the generator weight loss as a function of height into the reactor. Figure 5 shows the individual brick weight losses as a function of position. The generator weight loss was at a maximum near the center of the reactor. This behavior was probably caused by a combination of mass transfer and temperature effects. The process gas at the inlet was slightly cooler than the gas in the remainder of the reactor and may have reduced the $\mathrm{SiO}$ formation rate at the bottom generator. The remaining generators form $\mathrm{SiO}$ at rates which depend on the mass transfer driving force into the free stream. The driving force for $\mathrm{SiO}$ vaporization decreased with increasing distance into the reactor, thereby reducing the SiO formation rate with increasing height.

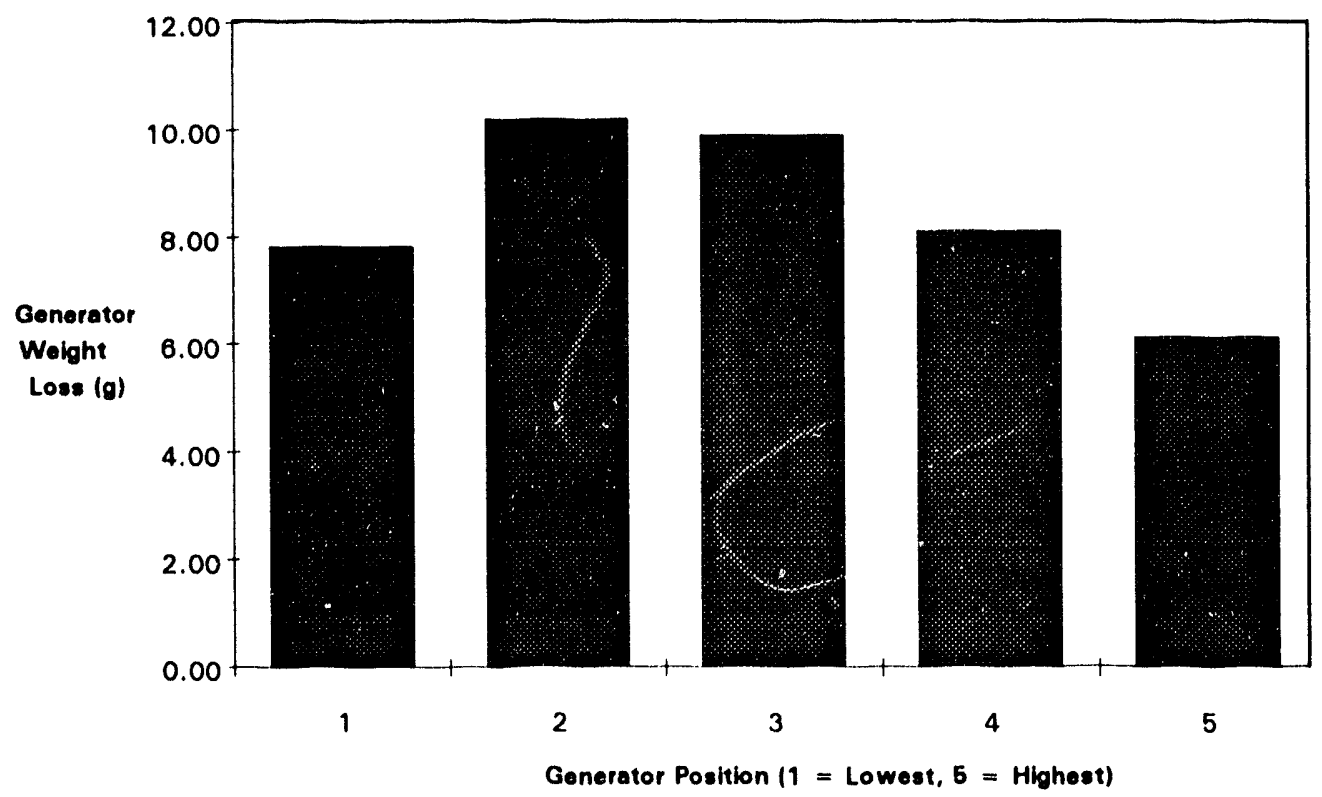

Figure $5 \mathrm{SiO}$ Generator Weight Loss Versus Distance into the Reactor

\section{$4.1 .2 \mathrm{CH}_{4}$}

Methane was the carbon source for the fibril formation reaction. It was supplied in the process gas at relatively low mole fractions $(<1 \%)$. The methane concentration was at a maximum at the bottom of the reactor and decreased with increasing distance into the reactor. Methane was supplied to the reactor at a constant rate (unlike the SiO). However, the present reactor concept has no provision for additional methane inputs at other positions within the reactor, which can lead to methane depletion effects.

A major difficulty associated with the methane was its instability at the synthesis process conditions. Methane can decompose according to the reaction:

$$
\mathrm{CH}_{4}(\mathrm{~g})=\mathrm{C}(\mathrm{s})+2 \mathrm{H}_{2}(\mathrm{~g})(3)
$$


The equilibrium constant for this reaction is 974 at $1700 \mathrm{~K}$. The detailed mechanism for methane decomposition at high temperatures is complex, involving free radical intermediates and other hydrocarbon species[13]. The methane decomposition side reaction has an important impact on the growth rate as a function of position.

The kinetics of the methane decomposition reaction were evaluated by GC measurements of inlet and exhaust gas composition under typical synthesis process conditions. A more detailed description of the procedure is contained in Appendix 2. The important features of the reaction kinetics are described in Table 2 . The methane disappearance reaction can be described by a first order kinetic expression and has a significant activation energy (of the order of $250 \mathrm{~kJ} / \mathrm{gmole}$ ).

\section{Table 2 Methane Decomposition Kinetic Parameters}

$$
\begin{aligned}
& \mathrm{dCH}_{4} / \mathrm{dt}=-\mathrm{k}_{\mathrm{d}}{ }^{*} \mathrm{pCH}_{4} \\
& \mathrm{k}_{\mathrm{d}}=\mathrm{k}_{\mathrm{d}}(\mathrm{T} \text {, gas composition }) \\
& k_{d}(T)=k_{d, 0} * \exp \left(-\Delta E_{d} / R T\right) \\
& k_{d, 0}=3.9 \times 10^{7} \mathrm{~s}^{-1} \\
& \Delta \mathrm{E}_{\mathrm{d}}=258 \mathrm{~kJ} / \mathrm{gmole}
\end{aligned}
$$

\subsubsection{Reactant Mixing}

The differences between the delivery of $\mathrm{CH}_{4}$ and $\mathrm{SiO}$ placed an increased importance on the mixing of these components. Acceptable mixing was difficult to achieve due to the laminar flow conditions. Reactor channel Reynolds numbers of 1 to 20 were typical. Understanding of this mixing requirement was a critical development in the LANL program[4]. LANL pioneered the application of "turbulent jet mixing" in the VLS SiC fibril process[10]. This development along with improved uniform gas distributor design allowed for impressive increases in growth rates and product uniformity in the LANL reactor.

The turbulent jet mixing has several potential drawbacks when transferred to a taller reactor. There is the potential for reduced effectiveness of the concept with increasing reactor height, since it depends on the interaction of the $\mathrm{SiO}$ generators with the process gas inlet jets. Early simulation model results[7] indicated that this interaction would be limited to the bottom $10 \mathrm{~cm}$ of the reactor (one third of the Carborundum development reactor height). Another potential disadvantage is the relatively high pressure drops required to sustain turbulent jet mixing, which may be difficult to attain in a larger scale reactor. 
An alternative mixing concept was developed to address these concerns. This concept was called oscillatory flow mixing; it is based on the observation of researchers that improved heat and mass transfer characteristics in laminar flow situations can occur when periodic flow perturbations occur in the presence of a flow destabilizing gecmetry. Oscillating fluid flows near solid objects in the flow path can cause enhanced rates of heat and mass transfer. Two characteristics of the flow oscillations control the transport rate enhancement--the amplitude, or the ratio of the peak and average fluid flow rate, along with the oscillation frequency.

The generators serve the role of the flow-destabilizing structures in the fibril reactor design. A flow oscillator was developed based on a mechanical bellows to produce periodic perturbations in the process gas flow. This device was designed to allow independent changes in the frequency and the amplitude of the oscillations. The oscillatory flow conditions were optimized for fibril synthesis based on a statistical experimental matrix using the frequency and amplitude as variables. These experiments were evaluated based on their effect on fibril growth rate. An amplitude ratio of 1.7 and a frequency of $0.5 \mathrm{~s}^{-1}$ were chosen as the standard oscillatory condition; for fibril growth.

\subsection{SiC Fibril Growth Behavior}

Critical synthesis scaleup data includes the effects of the following variables on fibril growth rates and characteristics:

- time

- position

- synthesis process conditions

Time effects result from two sources. Previous reports have documented the existence of a distinct fibril nucleation period[14,15]. During this time period fibril lengthening and mass growth rates are low. Nucleation is followed by a growth period in which the fibril lengthening rate and mass growth rate increases. The other potential time effect arises from the batch characteristics of the $\mathrm{SiO}$ reaction[4]. Solid reactant depletion $\left(\mathrm{SiO}_{2}\right.$ and $\left.\mathrm{C}\right)$ or changes in the reactant physical characteristics can result in time-dependent variations in the SiO supply rate[9].

Figure 6 shows the effect of time on the total $\mathrm{SiC}$ fibril and $\mathrm{SiO}$ formation. These measurements were obtained by discrete time series experiments. The $\mathrm{SiO}$ generation rate appeared relatively constant up to 7 hours. After 7 hours the SiO generation rate decayed; this probably resulted in a concurrent decrease in fibril growth rate. This constant $\mathrm{SiO}$ generation rate was different than observations made at LANL[4]. This difference may have resulted from the increase in process gas flow rates or from the modified mixing process. 


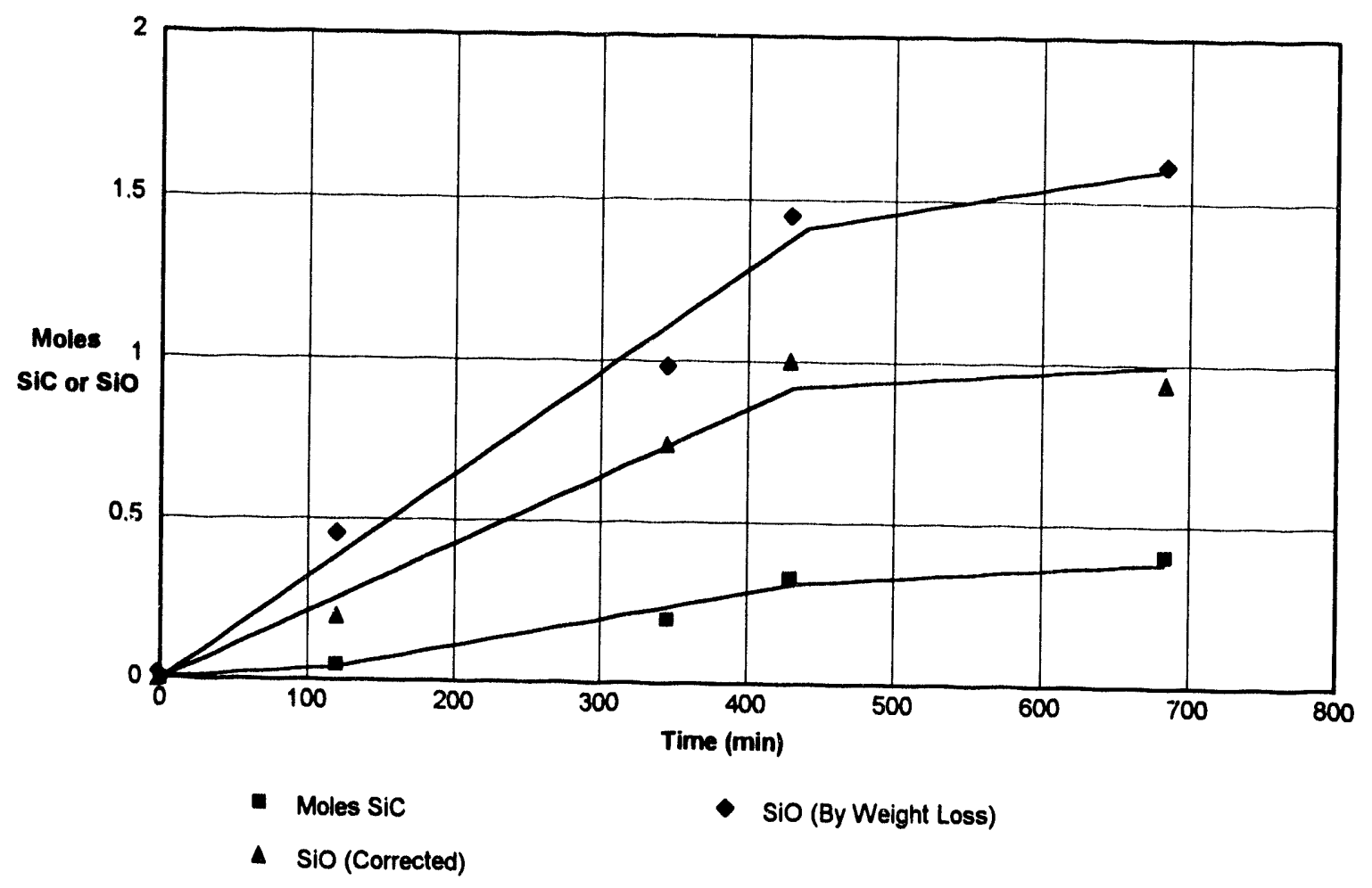

Figure 6 Time Dependence of SiO and SiC Fibril Formation Reactions

\subsection{Effect of Reactor Height on SiC Fibril Growth Rates}

Early synthesis experiments identified the existence of reproducible variations in the fibril growth rate with distance into the reactor. The primary trend was that growth rate was maximized in the bottom of the reactor. There was a continuous decrease in the growth rate with increasing distance into the reactor. Subsequent analysis identified spatial variations in $\mathrm{SiO}$ and $\mathrm{CH}_{4}$ concentrations.

A "cell model" was developed as a means of analyzing the fibril growth kinetics, SiO formation kinetics, and methane concentration variations with distance into the reactor. The basic premise of this approach was that the variation in growth rate with distance into the reactor could be evaluated by determining the reactant concentrations as a function of distance. The cell model assumed that the reactor volume around each $\mathrm{SiO}$ generator acted as an individual mixed flow reactor. Material balances for $\mathrm{SiO}, \mathrm{CH}_{4}$, and $\mathrm{SiC}$ fibrils were calculated within each cell using generator weight loss, local fibril growth rates, and calculated $\mathrm{CH}_{4}$ concentrations. Appendix 3 summarizes the cell model derivation and its use in evaluating growth experiment results.

The cell model was used to evaluate reaction rate constants by correcting for continuous variations of the process gas composition with increasing distance into the reactor. The cell model approach allowed for improved estimation of local chemical conditions and their impact on critical reactions. It also produced a better understanding of the vertical scaleup parameters. 


\subsection{Nucleation Behavior}

Figure 4 showed the time dependence of the fibril growth reaction at a fixed process condition. These results confirmed the existence of an induction period prior to the growth cycle. During this period, minimal fibril lengthening and mass growth rates were observed. This result led to a modified strategy for synthesis process optimization through separate evaluation of the process conditions required for the nucleation and growth stages of the process. The goals for each stage are summarized in Table 3.

Table 3 Stages and Goals of SiC Fibril Growth Process

\begin{tabular}{|c|c|c|}
\hline Period & $\begin{array}{c}\text { Time Period of } \\
\text { Cycle (hr) }\end{array}$ & Goals \\
\hline Nucleation & $0-2$ & $\begin{array}{c}\text { Maximize active site density } \\
\text { Minimize defect formation }\end{array}$ \\
\hline Growth & $2-7$ & $\begin{array}{c}\text { Maximize lengthening and mass formation } \\
\text { rate } \\
\text { Minimize defect formation }\end{array}$ \\
\hline
\end{tabular}

Nucleation optimization experiments were performed using two variables--temperature and $\mathrm{CH}_{4}$ partial pressure. The results were analyzed by macroscopic and microscopic techniques.

SEM analysis was used for qualitative evaluation of nucleation effectiveness as determined by active site density, catalyst utilization, and fibril characteristics. Figure 7 compares low magnification views of fibrils nucleated at different temperatures and methane partial pressures.

There were several significant trends. Increasing temperature increased the active site density. For the low-temperature, low-methane condition, there were a substantial fraction of inactive catalyst sites. As the temperature was increased, the fraction of active sites increased. Increasing the methane partial pressure appeared to have a deleterious effect on the nucleated product characteristics. Higher methane concentrations increased the amount and severity of bent needle fibrils at the substrate surface. The fibrils nucleated at high temperatures and high methane partial pressures showed this trend clearly.

Table 4 and Figure 8 summarize the macroscopic parameter for the nucleation cycle. Total fibril mass increased with increasing temperature and increasing methane, similar to trends exhibited by the growth cycle. An undesirable effect of increasing the methane concentration was reduced iibril length, especially on the solid substrates. 
Table 4 Macroscopic Nucleation Experimental Results

\begin{tabular}{|c|c|c|c|c|c|}
\hline $\begin{array}{c}\text { Temperature } \\
(\mathrm{K})\end{array}$ & $\mathrm{CH}_{4}(\%)$ & $\begin{array}{c}\text { Total } \mathrm{SiC}_{\mathrm{f}} \\
(\mathrm{g})\end{array}$ & $\begin{array}{c}\text { Generator } \\
\text { Wt. Loss }(\mathrm{g})\end{array}$ & $\begin{array}{c}\mathrm{CH}_{4} \\
\text { Utilization }\end{array}$ & $\begin{array}{c}\text { SiO } \\
\text { Utilization }\end{array}$ \\
\hline 1673 & 0.4 & 1.62 & 21.38 & 0.07 & 0.14 \\
\hline 1673 & 0.8 & 4.45 & 24.67 & 0.09 & 0.32 \\
\hline 1723 & 0.4 & 2.54 & 32.77 & 0.11 & 0.14 \\
\hline 1723 & 0.4 & 2.26 & 26.43 & 0.10 & 0.14 \\
\hline 1723 & 0.6 & 3.53 & 36.44 & 0.10 & 0.17 \\
\hline 1773 & 0.4 & 2.96 & 38.76 & 0.13 & 0.14 \\
\hline 1773 & 0.8 & 6.34 & 45.67 & 0.13 & 0.25 \\
\hline
\end{tabular}

The best combination of active site density and desirable fibril characteristics was observed at a nucleation condition at $1698 \mathrm{~K}$ and $0.4 \% \mathrm{CH}_{4}$. This nucleation condition was used in subsequent process optimization experiments.

\subsection{Effect of Process Variables on Reactant Supply Reactions}

Analysis of the fibril growth experiments indicated that the process variables with the strongest influence on the fibril growth behavior included:

- temperature

- process gas flow rate

- methane partial pressure

The effects of these variables on the fibril growth process have been explored in the context of their influence on $\mathrm{CH}_{4}$ decomposition, $\mathrm{SiO}$ formation, and the resulting impact on $\mathrm{SiC}$ fibril formation reactions.

\subsubsection{Temperature Effects}

\subsubsection{Methane Supply}

The methane decomposition reaction was characterized in the absence of $\mathrm{SiO}$ and $\mathrm{SiC}$ fibril formation reactions. These experiments indicated that the methane decomposition kinetics were first order in methane. The decomposition reaction activation energy was $230-270 \mathrm{~kJ} / \mathrm{gmole}$ at the baseline process conditions. This reflected a reaction rate that increased rapidly with increasing temperature. Increasing in the temperature reduced the methane available for fibril formation. 
(

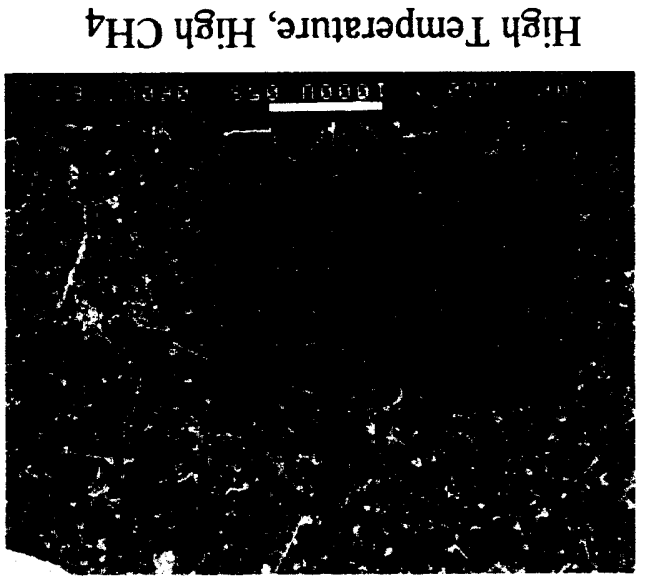

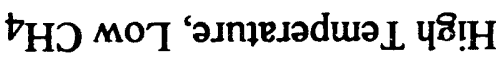

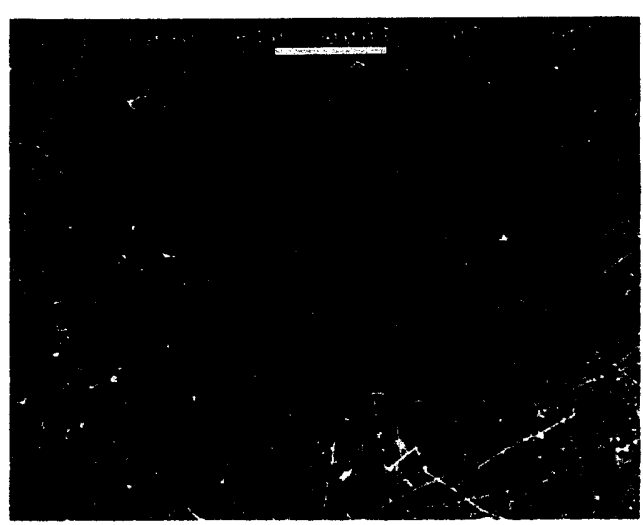

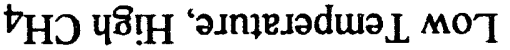

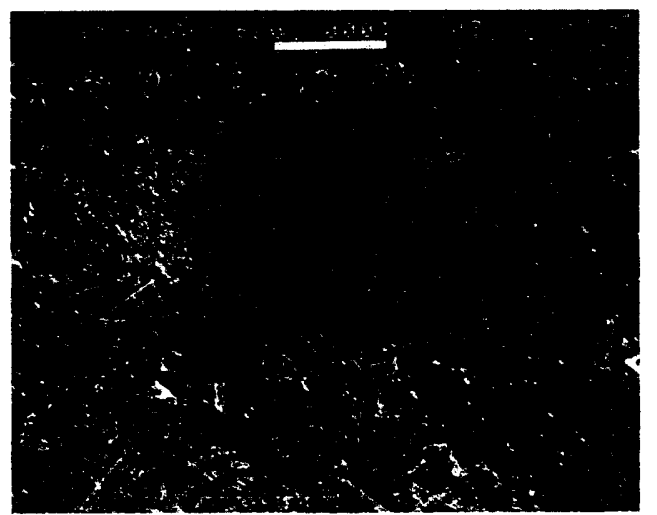

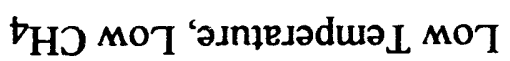

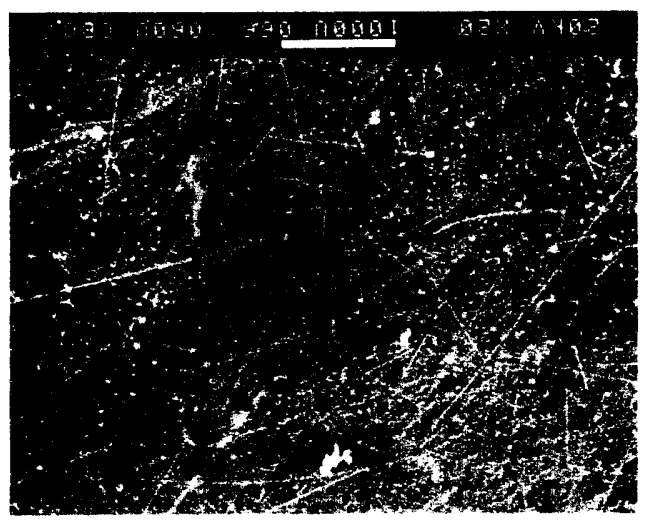




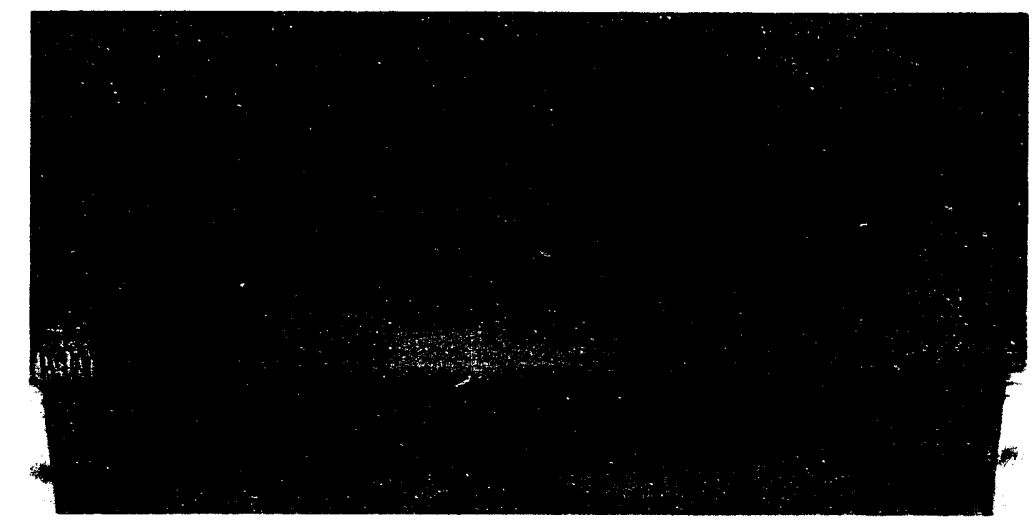

Low Temperature, Low $\mathrm{CH}_{4}$

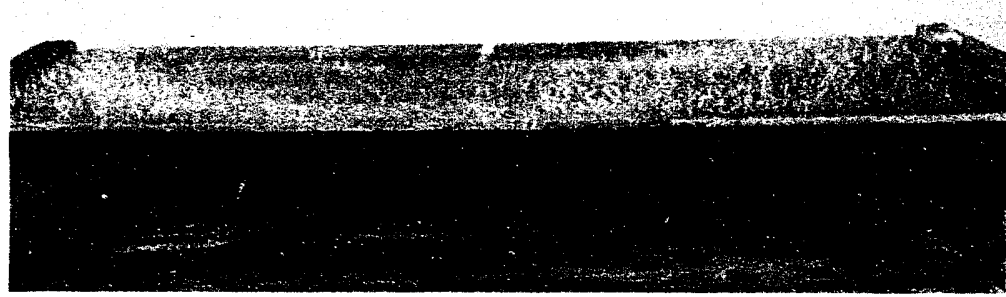

Low Temperature, High $\mathrm{CH}_{4}$

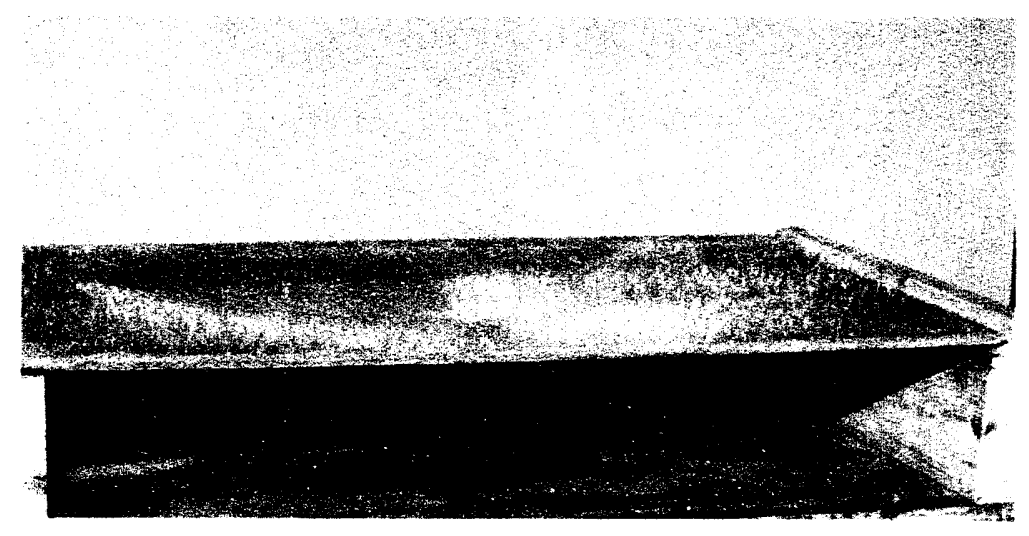

High Temperature, Low $\mathrm{CH}_{4}$

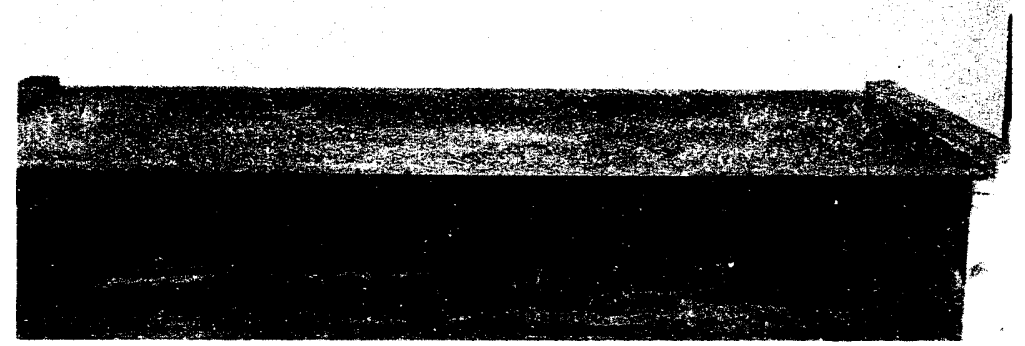

High Temperature, High $\mathrm{CH}_{4}$

Figure 8 35-mm Photographs Showing the Effect of Process Conditions on Nucleated Fibril Length and Site Density 


\subsubsection{SiO Supply}

Increased temperature increased the generator weight loss and the $\mathrm{SiO}$ generation rates. Correction of $\mathrm{SiO}$ formation via $\mathrm{CO}$ analysis confirmed this trend. $\mathrm{SiC}$ formation at the generator was shown to reduce the $\mathrm{SiO}$ available for SiC fibril formation[12]. An activation energy of 240 $420 \mathrm{~kJ} / \mathrm{gmole}$ was found for the SiO formation reaction. The calculation procedures for obtaining activation energies have been summarized in Appendix 4.

Process gas analysis of the reactor effluent can mask detailed features of the SiO generation process due to the continuous variation of reactant concentration with distance into the reactor. An alternative method for evaluating $\mathrm{SiC}$ formation at the generator was developed using total and free carbon analysis of the reacted generator. This procedure is described in Appendix 1. Corrections based on this procedure confirmed that $\mathrm{SiC}$ formation at the generator reduced the available SiO; the correction was on the order of $10-50 \%$.

Each approach indicated that the activation energy for the $\mathrm{SiO}$ formation reaction was larger than that for the methane decomposition reaction. SiO formation rates increased more rapidly with increasing temperatures than methane decomposition rates.

\subsubsection{Process Gas Flow Rate}

\subsubsection{Methane Supply}

Increasing the process gas flow rate increased the total methane supply by two different mechanisms. For a fixed process gas composition, increasing the flow rate increased the total methane supply. Analysis of growth experiments indicated that the total fibril growth was proportional to the total methane additicn. The process gas flow rate also influenced the amount of methane lost by decomposition. Based on first order decomposition kinetics[16], increased flow rates led to corresponding decreases in the residence time and reduced the consumption of methane by the decomposition reaction.

\subsubsection{SiO Supply}

The flow rate effect on $\mathrm{SiO}$ generation rates was determined by mass transfer considerations. Increased process gas flow rates reduced the bulk gas partial pressure of $\mathrm{SiO}$ and increased the driving force for vaporization of SiO. This resulted in slight increases in the total SiO formed.

\subsubsection{Methane Partial Pressure}

\subsubsection{Methane Supply}

The total mass supply of methane at a fixed process gas flow rate increased linearly with increasing methane partial pressure and resulted in increased availability of methane for fibril formation. 


\subsubsection{SiO Supply}

Increasing methane mass supply rates increased the $\mathrm{SiC}$ fibril formation rate and increased the consumption of $\mathrm{SiO}$. This resulted in a slight increase in the $\mathrm{SiO}$ formation driving force and a corresponding small but measurable increase in generator weight loss.

\subsection{SiC Fibril Growth Rate}

Fibril growth rate kinetics were evaluated based on cell model predictions of local reactant concentrations. The dependence of $\mathrm{SiC}$ fibril formation on the gas phase reactant concentration was assumed to follow an expression of the form:

$$
\mathrm{dSiC}_{\mathrm{f}} / \mathrm{dt}=\mathrm{f}\left(\mathrm{p}_{\mathrm{SiO}}, \mathrm{p}_{\mathrm{CH} 4}\right)
$$

The analysis focused on the growth portion of the process. The effects of the nucleation period were subtracted from the growth process using $\mathrm{SiO}$ generator weight losses and $\mathrm{SiC}$ fibril formation rates from a two hour nucleation experiment. SiC fibril formation rate constants were decoupled from the influence of nucleation period by this procedure. The analysis focused on the 27 slpm subset of the statistical design experiments.

Four kinetic expressions for $\mathrm{SiC}$ formation were evaluated:

$$
\begin{gathered}
\mathrm{dSiC}_{\mathrm{f}} / \mathrm{dt}=\mathrm{k}_{\mathrm{w}}{ }^{*} \mathrm{pSiO}^{*} \mathrm{p}_{\mathrm{CH} 4}(5) \\
\mathrm{dSiC}_{\mathrm{f}} \mathrm{dt}=\mathrm{k}_{\mathrm{w}}{ }^{*} \mathrm{pSSiO}^{*}\left(\Delta \mathrm{pCH}_{4}\right)(6) \\
\mathrm{dSiC}_{\mathrm{f}} / \mathrm{dt}=\mathrm{k}_{\mathrm{w}}{ }^{*} \mathrm{pSSO}^{*}\left(\mathrm{pCH}_{4}\right)^{2}(7) \\
\mathrm{dSiC}_{\mathrm{f}} / \mathrm{dt}=\mathrm{k}_{\mathrm{w}}{ }^{*} \mathrm{pSSiO}^{*}\left(\Delta \mathrm{pCH}_{4}\right)^{2}
\end{gathered}
$$

First order rate expressions produced the poorest correlation of results. Equations (7) and (8) gave the best correlation for the growth data over the range of process conditions investigated. Equation (7) was chosen since it was a simpler expression and did not rely on an accurate knowledge of local SiO concentrations. Appendix 5 summarizes the kinetic analysis results. There was not a clear trend in the rate constant $\mathrm{k}_{\mathrm{W}}$ as a function of temperature. It should be noted that $\mathrm{k}_{\mathrm{W}}$ was not an intrinsic rate constant since it depends on the catalyst concentration and catalyst breakup behavior (active catalyst site density and surface area). 
Fibril growth rate varied with distance into the reactor. This variation was the result of changes in the reactant concentrations as a function of position. Figure 9 shows the variation in $\mathrm{SiO}$ and $\mathrm{CH}_{4}$ partial pressures and fibril growth rate as a function of distance into the reactor for the baseline process conditions. There were several important trends:

- $\mathrm{CH}_{4}$ concentration was at a maximum at the inlet and decayed sharply with increasing distance. This decrease was primarily the result of the methane decomposition reaction. The $\mathrm{SiC}$ fibril formation reaction typically consumed $10-20 \%$ of the total supplied methane.

- There was no SiO in the inlet gas. SiO partial pressure increased approximately linearly with height as the result of incremental addition of $\mathrm{SiO}$ at each generator. $20 \%-40 \%$ of the total $\mathrm{SiO}$ was consumed by the fibril formation reaction; unreacted $\mathrm{SiO}$ accumulated in the process gas.

- SiC fibril formation rates were highest at the reactor bottom and decreased from the middle to the top of the reactor. In general, growth rates in the reactor bottom appeared to be limited by $\mathrm{SiO}$, while growth rates in the top appeared to be limited by methane. The methane supply behavior appeared to more strongly influence the SiC fibril growth rate as a function of position.
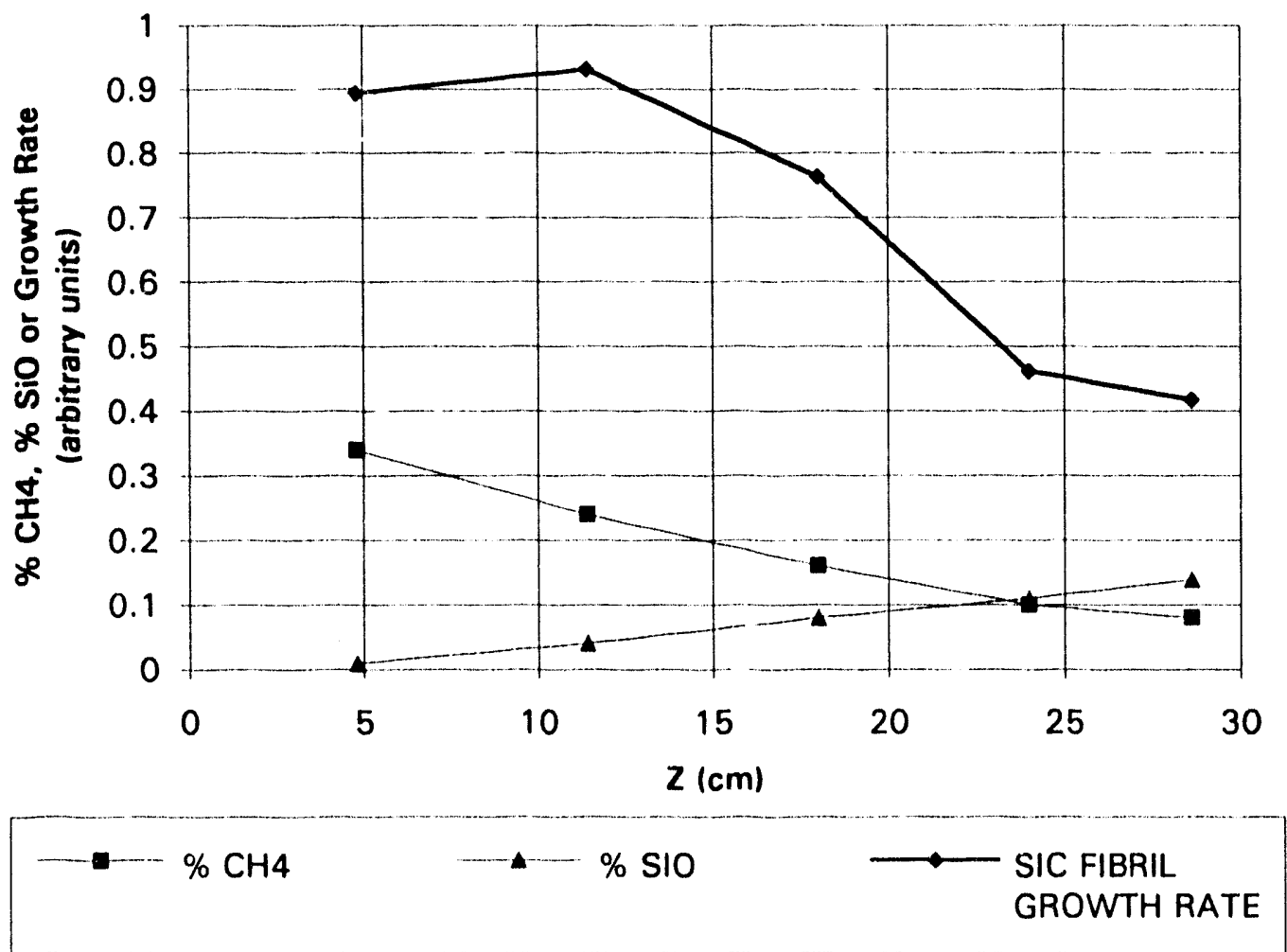

Figure 9 Effect of Reactor Position on Reactant Partial Pressures and $\mathrm{SiC}$ Fibril Formation Rate 
There was a substantial change in the gas phase composition and the $\mathrm{C} / \mathrm{Si}$ ratio from the bottom to the top of the reactor. The ratio of $\mathrm{CH}_{4}$ to $\mathrm{SiO}$ changed by nearly an order of magnitude over this distance. Figure 10 shows the effect of temperature, methane partial pressure, and process gas flow rate on the fibril growth rate profiles. The following trends were noted:

- Increasing the methane partial pressure at a constant flow rate led to a corresponding increase in the fibril growth rates.

- Halving the process gas flow rate decreased the fibril growth rate and substantially reduced growth rates in the top half of the reactor.

- Decreasing the temperature reduced the amount of SiO formed and led to reduced fibril growth rates. It also changed the shape of the growth rate profile. For a temperature of $1673 \mathrm{~K}$, the fibril growth rate increased with increasing height. In this case, the growth process was silicon-limited throughout the reactor.

A statistical experimental design[17] was developed to evaluate the effects of the three most significant process variables: methane concentration, temperature, and process gas flow rate/mixing technique. The response variables included macroscopic and microscopic parameters such as total fibril growth rate, total generator wright loss, product diameter, and product morphology. Experimental data not discussed in the report body have been summarized in Appendix 6.

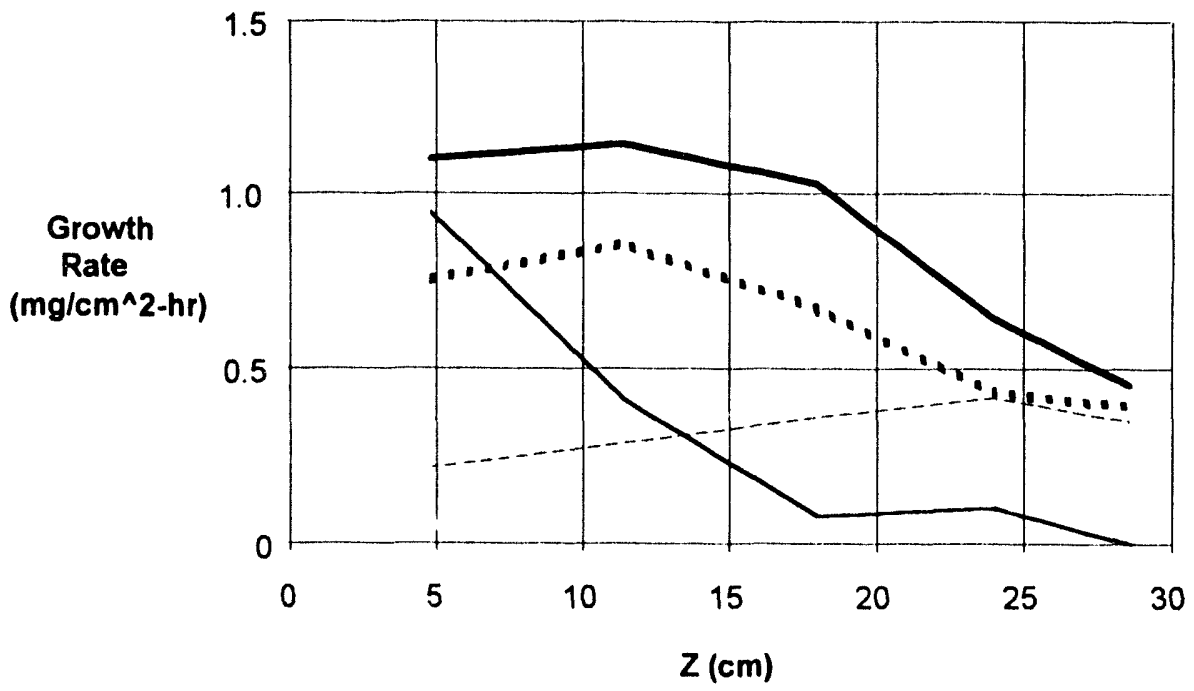

\begin{tabular}{lllll}
\hline $1698 \mathrm{~K}$ & $1673 \mathrm{~K}$ & $\cdots \ldots$. & \\
$0.4 \% \mathrm{CH} 4$ & $0.4 \% \mathrm{CH} 4$ & $0.4 \% \mathrm{CH} 4$ & $0.6 \% \mathrm{CH} 4$ \\
$13.5 \mathrm{slpm}$ & $27 \mathrm{slpm}$ & $27 \mathrm{slpm}$ & $27 \mathrm{slpm}$
\end{tabular}

Figure 10 Effect of Synthesis Process Conditions on Fibril Growth Rate Profiles

Figure 11 shows the effect of temperature and methane partial pressure on the total fibril growth at a process gas flow rate of $27 \mathrm{slpm}$. Two major trends were noted. Total SiC fibril formation increased with increasing temperature and increasing methane partial pressure. The temperature effect was a combination of two effects. SiO generation increased with increasing temperature, 
which led to an increased fibril growth rate. This effect was reduced by increased rates of methane decomposition caused by increasing temperatures. Increasing the methane partial pressure increased growth rates, as would be expected from the fibril growth rate dependence on $\mathrm{PCH} 4$ to the second power.

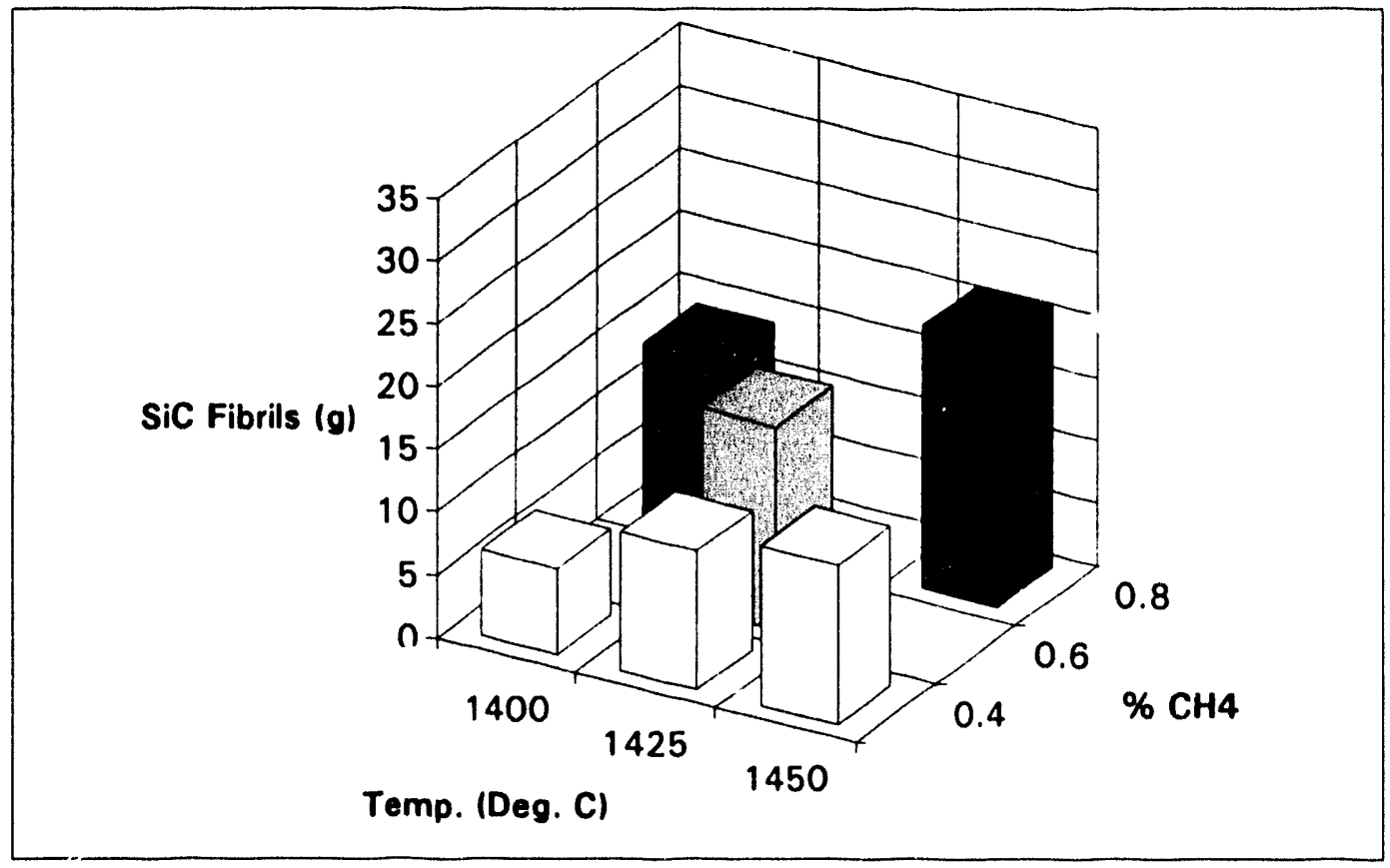

Figure 11 Effect of Methane Concentration and Temperature on Total Fibril Growth (Process Gas Flow Rate $=27 \mathrm{slpm}$ )

Figure 12 shows a similar plot obtained at a process gas flow rate of $13.5 \mathrm{slpm}$. Trends in the fibril growth rate with increasing temperature and methane concentration were similar to the higher flow rate case. In general, there was an overall decrease in the total fibril mass by a factor of two. This indicated a linear relationship between total fibril growth and total process gas flow rate for a fixed methane concentration.

Table 5 summarizes the important fibril synthesis reaction mechanisms and the impact of the temperature and process gas flow rate on these reactions. 


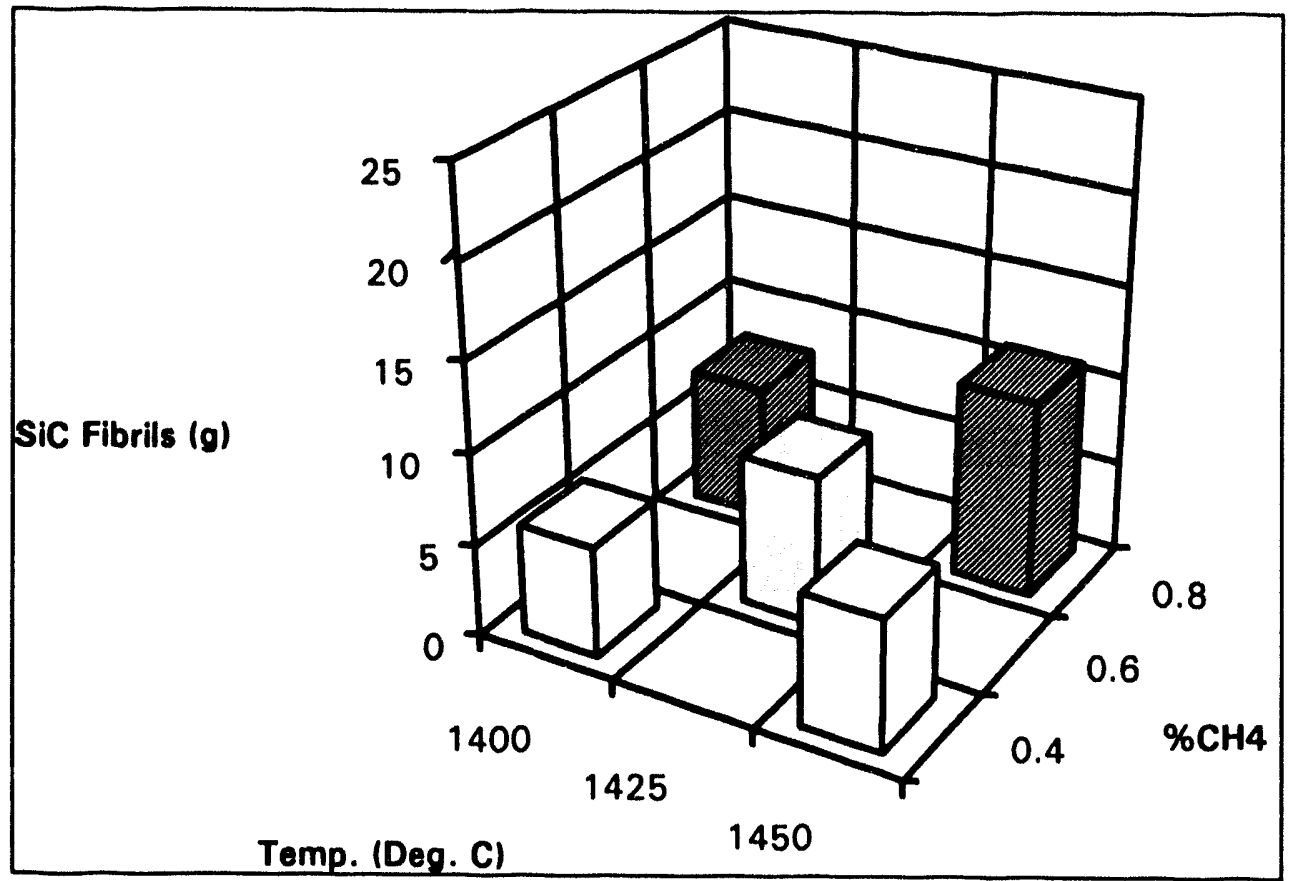

Figure 12 Effect of Methane Concentration and Temperature on Total Fibril Growth (Process Gas Flow Rate $=13.5 \mathrm{slpm}$ )

Table 5 Effect of Process Conditions on Important Fibril Synthesis Reactions

\begin{tabular}{|c|c|c|c|}
\hline Reaction & $\begin{array}{c}\text { Kinetic } \\
\text { Expression }\end{array}$ & T Effect & Flow Effects \\
\hline SiO formation & $\begin{array}{c}\text { st order in } \\
\mathrm{pSiO}\end{array}$ & $\begin{array}{c}280-400 \\
\mathrm{~kJ} / \mathrm{gmole}\end{array}$ & Mass transfer \\
\hline $\mathrm{CH}_{4}$ decomposition & $\begin{array}{c}1 \mathrm{st} \text { order in } \\
\mathrm{pCH}_{4}\end{array}$ & $\begin{array}{c}230-260 \\
\mathrm{~kJ} / \mathrm{gmole}\end{array}$ & $\begin{array}{c}\text { Residence time } \\
\text { Mass supply } \\
\text { rate }\end{array}$ \\
\hline SiC fibril formation & $\begin{array}{c}1 \text { st order in } \\
\text { pSiO } \\
\text { 2nd order in } \\
\mathrm{pCH}_{4}\end{array}$ & $\begin{array}{c}\text { Nn clear } \\
\text { impact }\end{array}$ & $\begin{array}{c}\text { Mass supply of } \\
\text { reactants }\end{array}$ \\
& & \\
\hline
\end{tabular}

\subsection{Effect of Synthesis Process Conditions on Fibril Characteristics}

Synthesis process conditions affected both the fibril growth rate and the fibril characteristics. Methane concentration had a large effect on the fibril characteristics. High methane concentrations produced undesirable fibril morphologies such as fibril balls and bent needles. Figure 13 shows photographs of as-synthesized fibrils on a growth substrate and corresponding low magnification SEM micrographs. A photograph of prime fibrils grown at the final baseline process condition has been shown for comparison. These figures clearly illustrate the substantial impact of the methane partial pressure on fibril characteristics. 
Increasing temperature and increasing methane concentrations produced increased amounts of fibril balls, which appear as white, fuzzy growths at the tips of the needles.

These growths are undesirable because of their high content of small diameter fibrils. Diameter analysis results presented later in this report confirm this observation--high methane concentrations promoted a wider diameter distribution and smaller average diameter. The best condition for maximizing the product diameter and promoting a narrow diameter distribution was $1698 \mathrm{~K}$ and $0.4 \% \mathrm{CH}_{4}$. This corresponded to an acceptable process condition for minimizing undesirable fibril characteristics.

\subsection{Fibril Product Modifications}

A series of experiments were performed to identify process conditions and reactor designs which could modify the diameter and length of the fibril product. The goal was to evaluate the flexibility of the fibril growth process for tailoring fibril product characteristics for specific applications.

Table 6 summarizes the experimental approach and the controlling process variables. Fibril diameter was affected by process gas composition, nucleation conditions, and catalyst chemistry/concentration. Fibril length was most strongly impacted by reactor geometry; an increased substrate spacing was necessary to grow long fibril product. Long fibrils were also promoted by use of the FeSi catalyst and reduced process gas flow rates. Figure 14 shows long fibrils grown as part of this task.

Table 6 Experimental Results - Fibril Product Modification Campaign

\begin{tabular}{|c|c|c|}
\hline Product Characteristic & $\begin{array}{c}\text { Process Variables } \\
\text { Evaluated }\end{array}$ & $\begin{array}{c}\text { Controlling Process } \\
\text { Variables }\end{array}$ \\
\hline Diameter & $\begin{array}{c}\text { Catalyst Concentration } \\
\text { Catalyst Composition } \\
\text { Process Gas Composition }\end{array}$ & $\begin{array}{c}\text { Catalyst Concentration } \\
\text { Process Gas Composition }\end{array}$ \\
\hline Length & $\begin{array}{c}\text { Process Gas Flow Rate } \\
\text { Catalyst Chemistry } \\
\text { Reactor Geometry }\end{array}$ & All \\
& \multicolumn{2}{|c}{} \\
\hline
\end{tabular}

The fibril length requirements for yarn forming and composite applications will impact the fibril production cost. These preliminary long fibril growth experiments indicated that the growth rate per unit area for the long fibril reactor configuration was equal to the rate in the standard reactor configuration. The reduced number of substrates associated with the long fibril reactor configuration led to a reduction in total fibril growth per unit reactor volume which would indicate increased production costs per unit mass for long fibril product. This result was a preliminary indication of the tradeoffs between the cost and fibril length for different composite application. 

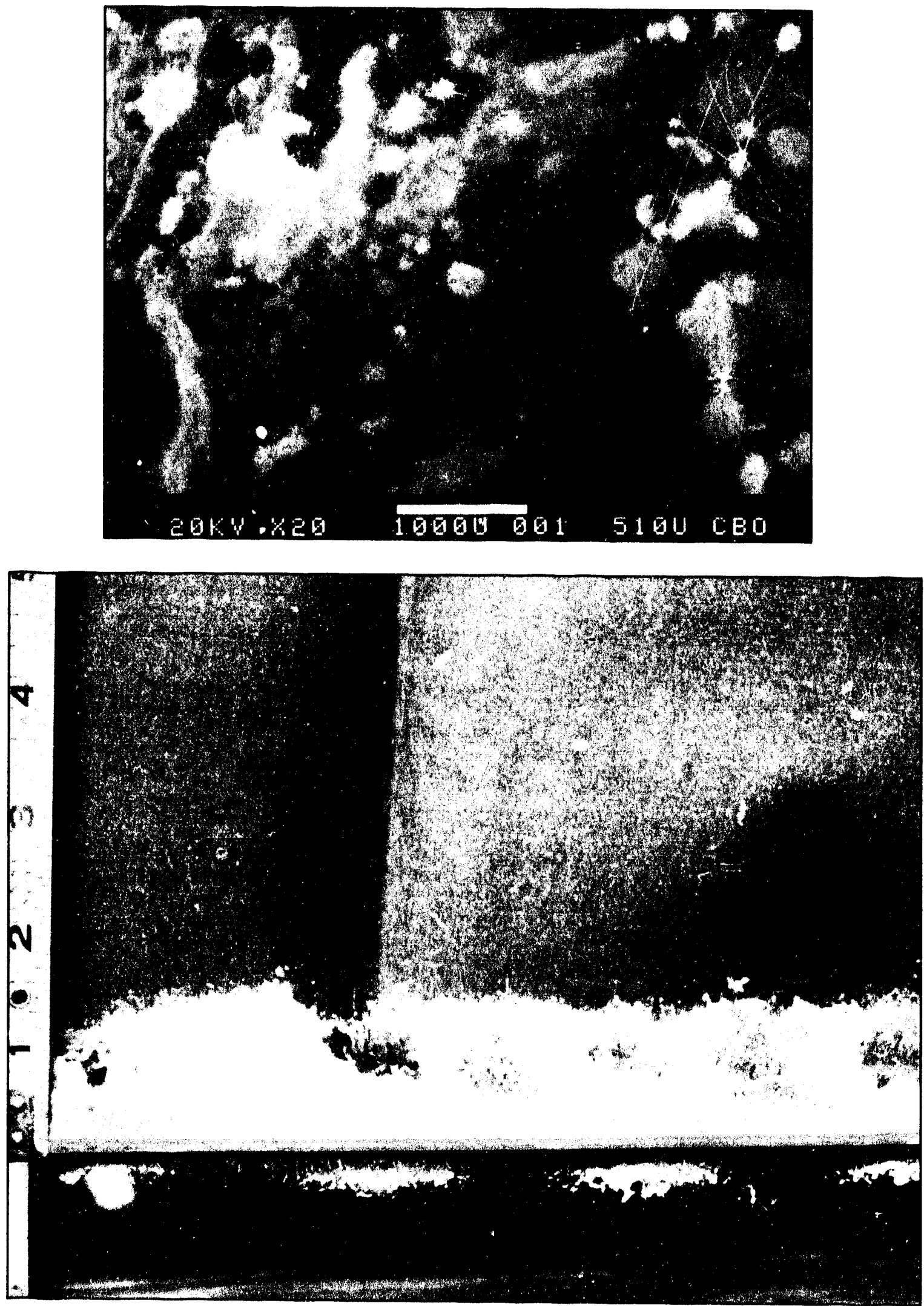

Figure 13a Photographs Comparing Fibril Product Grown at High $\mathrm{CH}_{4}$ Process Conditions 

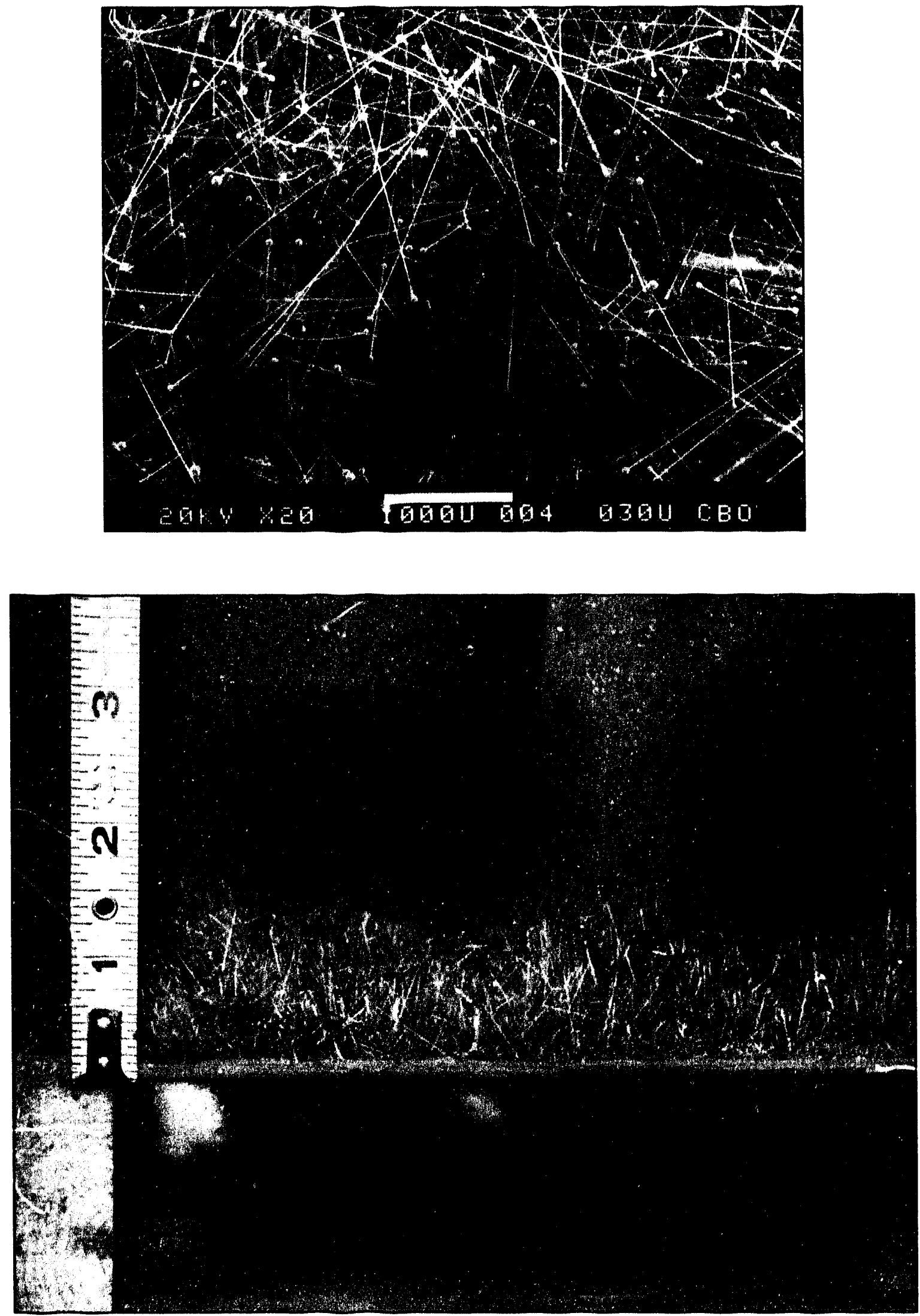

Figure 13b Photographs Comparing Fibril Product Grown at Baseline Process Conditions 

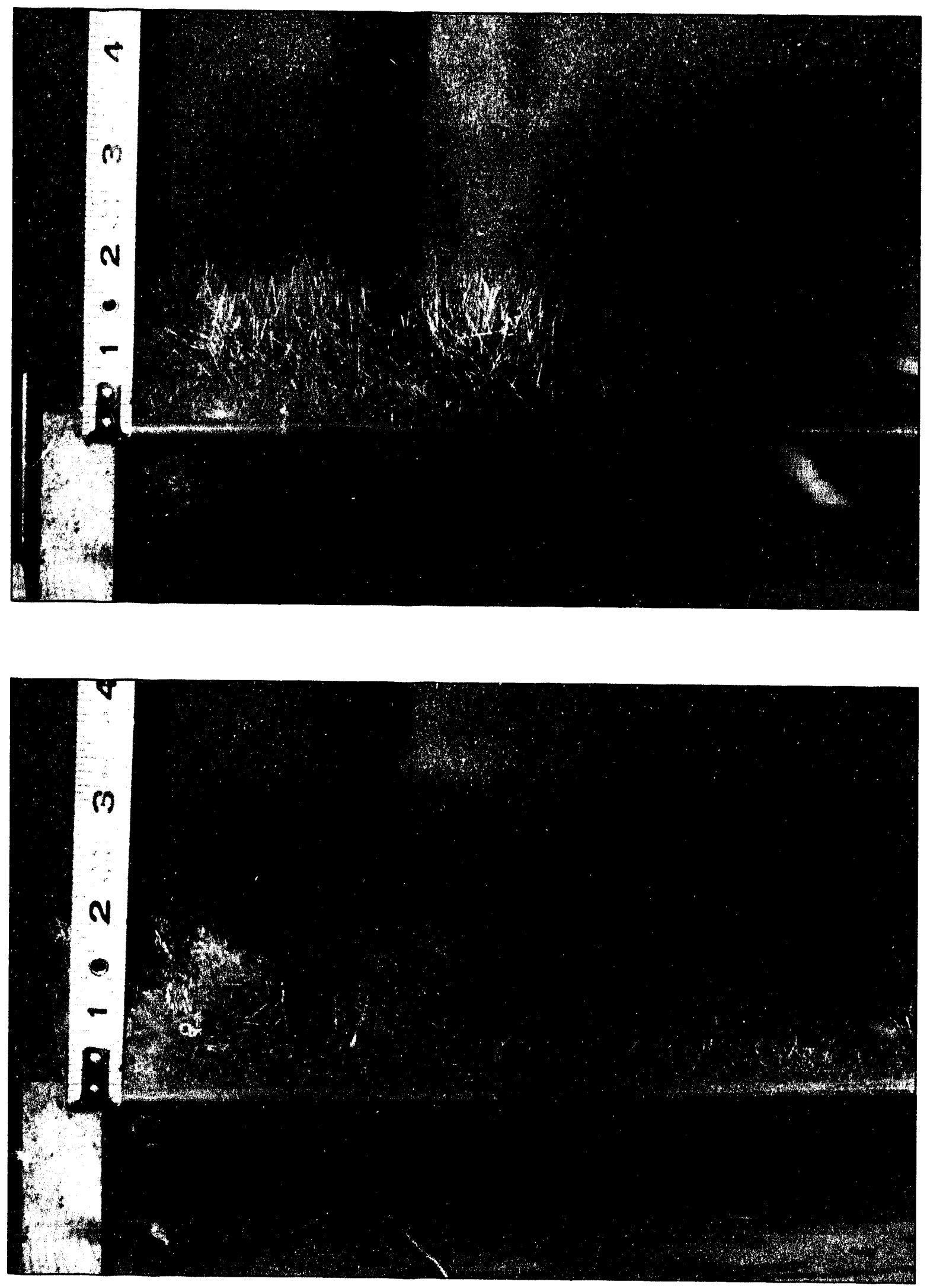

Figure 14 Long SiC Fibrils Grown Under the Product Modification Task 


\subsection{Process Gas Composition Effects}

The effects of the $\mathrm{N}_{2}$ and $\mathrm{CO}$ mole fractions in the process gas on the fibril growth process were evaluated. These effects on the growth rate and product morphology were mainly qualitative and are summarized below.

Primary effects of increasing nitrogen included:

- increased fraction of needle-like product at a fixed process condition

- improved length uniformity

- improved growth rates

Very low nitrogen contents promoted carbon-rich growth in the form of small diameter white fibrils. This result was similar to that reported by others[18].

The $\mathrm{CO}$ concentration effects appeared primarily in the fibril morphology. The primary effects were as follows:

- Absence of $\mathrm{CO}$ in the process gas prevented fibril growth

- CO concentrations around 3\% led to Si-rich products

- CO concentrations around $10 \%$ led to highly distorted fibrils

- CO concentrations in the $5-8 \%$ range appeared optimum for the current growth process

Mosi of these trends agree with earlier published data[18].

\subsection{Catalyst Effects on Growth Behavior}

The catalyst-substrate interactions control many of the microscopic characteristics of the SiC fibril growth process. These interactions remain insufficiently understood despite their importance. The LANL development effort was the first to place a major emphasis on this aspect of the synthesis process. They devoted a significant effort toward qualitative analysis of the impact of the catalyst physio-chemical characteristics, the substrate characteristics, and the nucleation conditions on the nucleation process.

Catalyst-substrate interactions were not the major focus of the present program. However, several general observations were made during the experimental program. Three different catalyst systems were evaluated:

- iron sol catalyst

- FeSi particles

- stainless steel flakes

The iron sol catalyst application method is a Carborundum-patented technique for producing catalyst droplets through the uniform application of fine iron oxide particles in the form of a sol[11]. The ultimate catalyst particle dimensions are related to the drying/breakup behavior of the oxide coating[19]. FeSi and stainless steel particles were applied in the more traditional methodology developed by an earlier program[2] and used by LANL[4]. 
A major difference between the current development effort and the LANL work was the substrate surface chemistry. The current program used reacted graphite substrates (i.e., substrates with a $\mathrm{SiC}$ reaction layer formed on the surface by its reaction with $\mathrm{SiO}$ ). These substrates were reused without special treatment other than light sanding of the surface between experiments. This choice contrasted with the LANL process, where fresh graphite substrates were used to produce optimum growth process characteristics. Preliminary economic analysis indicated that substrate lifetime would be a significant cost factor. It was felt that optimizing the concept with (reacted) substrate surfaces would be more viable for further scaleup.

Several trends were noted (for a fixed growth period and synthesis process condition):

- The iron sol catalyst produced the highest bulk growth rates

- FeSi tended to promote faster nucleation and earlier growth than the iron sol catalyst

- Doubling the concentration of the FeSi catalyst in the catalyst precursor increased the growth rate to nearly that of the iron sol catalyst but simultaneously increased the amount of undesirable surface growths

- Stainless steel flakes produced unacceptably Si-rich growths on reacted substrates

The iron sol catalyst exhibited variable performance depending on the mixing. In its absence, the fibrils grown tended to be Si-rich morphologies. FeSi catalyst produced prime fibrils with or without oscillatory mixing. The stainless steel flake catalyst appeared to interact strongly with the reacted substrate surface, producing short, dark, large diameter fibrils. Oscillatory mixing did not affect this response.

In future development efforts, improved characterization of the relationship between the microscopic growth behavior and nucleation/process conditions will be required to guide product and process improvements.

\subsection{Baseline Process Conditions and Process Reproducibility}

The process optimization and product modification experiments led to a choice of the baseline process condition for the current reactor design. VLS SiC fibrils grown under this process condition exhibited the following attractive features:

- the product morphology was primarily $4 \mathrm{~A}-6 \mathrm{~A}$ needle-like material

- the bulk growth rate was $0.55-0.65 \mathrm{mg} / \mathrm{cm}^{2} / \mathrm{hr}$

- product number average diameter was $5-8 \mu \mathrm{m}$, and the fraction of product $<3 \mu \mathrm{m}$ was typically less than $10 \%$

- the amount of bambooed and branched fibrils appeared to be minimized at these conditions

These synthesis process conditions promoted the best combination of growth rate and desirable product characteristics. They are summarized in Table 7. 
Table 7 Baseline Synthesis Process Conditions

\begin{tabular}{|c|c|}
\hline Process Variable & Baseline Process Condition \\
\hline Temperature & $1698 \mathrm{~K}$ \\
\hline Total Process Gas Flow Rate & $27 \mathrm{slpm}$ \\
\hline Process Gas Composition & 78.6 \\
\hline$\% \mathrm{H}_{2}$ & 15.0 \\
\hline$\% \mathrm{~N}_{2}$ & 6.0 \\
\hline$\% \mathrm{CO}$ & 0.4 \\
\hline$\% \mathrm{CH}_{4}$ & Fe sol or FeSi - standard concentration \\
\hline Catalyst & Frequency $=0.5 \mathrm{~s}-1 ;$ Amplitude ratio $=1.7$ \\
\hline Oscillatory Mixing & $100-120 \mathrm{~g}$ \\
\hline Total SiO Generator Feed Mass & $943 \mathrm{~cm}^{2}$ \\
\hline Total Generator Surface Area & Reacted $\mathrm{HLM} \mathrm{Graphite}$ \\
\hline Substrate Material & \\
\hline
\end{tabular}

While this process condition produced prime fibril product at a reasonable growth rate, there were several characteristics of the fibril product which could be improved. These include:

- product length uniformity on a substrate

- variations in product characteristics of fibrils synthesized on different type substrates (i.e. generator versus solid)

- increased average product length

- reduction of surface growth

It is expected that all of these characteristics can be improved through reactor design modifications and improved understanding of the microscopic behavior of the piocess.

Establishment of the baseline process conditions required a preliminary evaluation of the process reproducibility. Macroscopic process reproducibility was the primary focus - growth rate, $\mathrm{SiO}$ formation, and reactant utilization. Several of the microscopic product characteristics were also evaluated, including average fibril length and fibril diameter. The results are summarized in Table 8. Total production of $\mathrm{SiC}$ fibrils was reproducible for a fixed nucleation condition and catalyst system. Out of nine experiments, only one appeared to produce poorer quality fibrils than expected.

An effective means of evaluating run-to-run variations of the product characteristics was to examine 35-mm photos of as-synthesized growth substrates for a series of experiments. This procedure showed minor variations in fibril characteristics from experiment to experiment clearly. 
Table 8 Process Reproducibility at the Baseline Process Condition

\begin{tabular}{|c|c|c|c|c|c|}
\hline $\begin{array}{c}\text { Experiment } \\
\text { Number }\end{array}$ & Catalyst & $\begin{array}{c}\text { Total } \mathrm{SiC}_{\mathrm{f}}^{*} \\
(\mathrm{~g})\end{array}$ & $\begin{array}{c}\text { Total Gen. } \\
\text { Wt. Loss }(\mathrm{g})\end{array}$ & $\begin{array}{c}\text { Mean } \\
\text { Diameter } \\
(\mu \mathrm{m}) \\
(\# \text { Avg/ } \sigma)\end{array}$ & Comment \\
\hline 95 & $\mathrm{Fe} \mathrm{sol}$ & 13.7 & 86.5 & & \\
\hline 139 & $\mathrm{Fe} \mathrm{sol}$ & 15.8 & 84.3 & $5.4 / 2.7$ & \\
\hline 140 & $\mathrm{Fe} \mathrm{sol}$ & 14.0 & 86.0 & & \\
\hline 153 & $\mathrm{Fe} \mathrm{sol}$ & 12.2 & 82.4 & $6.9 / 3.6$ & $\begin{array}{c}\text { Poor } \\
\text { product } \\
\text { quality }\end{array}$ \\
\hline 145 & $\mathrm{Fe} \mathrm{sol}$ & 13.0 & 74.0 & $7.6 / 2.7$ & Low Si nuc. \\
\hline 147 & $\mathrm{Fe} \mathrm{sol}$ & 11.7 & 76.6 & $7.7 / 2.9$ & Low C nuc. \\
\hline 146 & $\mathrm{FeSi}$ & 11.0 & 79.9 & $7.3 / 3.0$ & \\
\hline 148 & $\mathrm{FeSi}$ & 12.6 & 77.7 & $6.7 / 3.5$ & \\
\hline 152 & $\mathrm{FeSi}$ & 10.8 & 56.9 & $7.4 / 3.4$ & \\
\hline
\end{tabular}

* Calculated from the total razor harvest of substrates 5 and 6

Most of the experiments produced fibril product of a similar appearance. The primary experiment to experiment variations were identified as follows:

There were variations in product length at various locations; this was most likely the result of variations in the product diameter. This would result in specific locations appearing more Si-rich--shorter, darker in appearance and larger in diameter than the average product.

Fibril balls would appear at the end of the fibril at the end of the longest fibrils. This appeared to occur most frequently in the bottom half of the reactor and near the $\mathrm{SiO}$ generator sites, which indicated that long fibrils nucleated undesirable secondary growths under reactant-rich conditions.

Continued efforts on establishing process reproducibility will be required. These efforts should include on establishing the macroscopic and microscopic reproducibility of the synthesis process as the current reactor is utilized on a production mode. These production campaigns will produce the database necessary to identify the process reproducibility and requirements to achieve this goal.

\subsection{Conceptual Prototype Scale Reactor Design}

The advantage of using a sectional model approach (the approach used by LANL and Carborundum) is that the current development reactor design can directly be scaled up to a larger size reactor, assuming certain criteria (i.e. similarity) is maintained. Thus, a prototype scale reactor could be designed and operated based on the development reactor design and process concept. 
Based on the scaleup data, improved reactor designs can be envisioned. The experimental results indicated that reactant concentrations varied with reactor height. A number of reactor design modifications can improve this situation, including modified SiO generator design and multiple process gas inputs. A symmetric reactor/generator configuration can be used to reduce the differences in the product characteristics between solid and generator substrates.

Several key results from this experimental program will become critical design considerations in the prototype scale reactor. A primary concern will be to maintain chemical similarity in the development and prototype scale reactors. Careful design of the process gas delivery system will be necessary, with particular attention to the existence and impact of the methane decomposition reaction. Another important design criteria will be to maintain of thermal similarity during scaleup. Several aspects of the furnace heating and thermal behavior can affect this similarity. For example, modified heating profiles will be required to achieve uniform, rapid heating rates in larger reactors. The sensitivity of the fibril nucleation to changes in the heating cycle has not been explored. Previous reports have indicated that this can impact the fibril quality [20]. Uniform heating of the reactor will be a primary design consideration in the prototype scale reactor. It will be important to maintain a fixed temperature drop across the reactor which allows for prime fibril growth at both the interior and exterior of the reactor. 


\section{Simulation Model Development}

A simulation model was developed as a tool for compiling scaleup data in a form suitable for reactor design and process development. The approach included incorporation of development reactor kinetic data into the simulation model and evaluation of its effectiveness for predicting the effects of the process conditions on the fibril growth rate. Preliminary model confirmation was performed; these results indicated that the current model can predict variations in the growth rate as a function of position and synthesis process conditions using a single set of rate constants consistent with parameters obtained in the development reactor.

\subsection{Model Details}

Successful simulation of the fibril growth process involved both a mathematical and a computational model. The mathematical model was a system of equations describing the physical process itself. The computational model was a set of approximations to these equations solvable on a computer. The resulting solutions of the computational model produced simulations of the process under different operating scenarios. These simulations can be used in the design of experiments, reactor design, and determination of process conditions for optimal SiC fibril growth.

\subsubsection{Mathematical Model}

The reactor geometry is depicted in Figure 15. A two-dimensional (2D) model of the flow and reactions was developed for a single channel. The model assumed that the process gas inlets and exhausts were a single equi-areal strip; this served as an approximation to the series of discrete inlet and exhaust holes. This was a reasonable approximation and produced only a small deviation in flow near the inlets and exhausts of the reactor. The main components of the reactions, fibril growth, and overall reactor flow were not adversely affected by the 2D assumption.

To calculate $\mathrm{SiC}$ fibril growth rates at the reactor walls, mass flow rate equations were solved for each chemical species relevant in the reaction process. These equations required detailed velocities of the vapor flow throughout the reactor and, therefore, the full set of momentum, continuity, and mixture ideal gas law equations were solved. Standard viscosity and species diffusivity correlations for mixtures were used in these equations and were obtained from the literature. The controlling differential and physical property equations are summarized in Appendix 7.

The species mass flow rate equations required source terms because of the chemical reactions at the substrate surface, at the $\mathrm{SiO}$ generator surface, and in the reactor volume. These sources of reactant supply and consumption were added to the individual species mass balance equation, with the mass generated into the reactor being added to the overall continuity equation. The model allowed for either direct input of kinetic constants or their automatic calculation from experimental growth and generator $\mathrm{I}_{\mathrm{u}} \mathrm{e}$ data. The kinetic equations describing the sources are summarized in Table 9. They were based on kinetic data determined in the development reactor. 
35

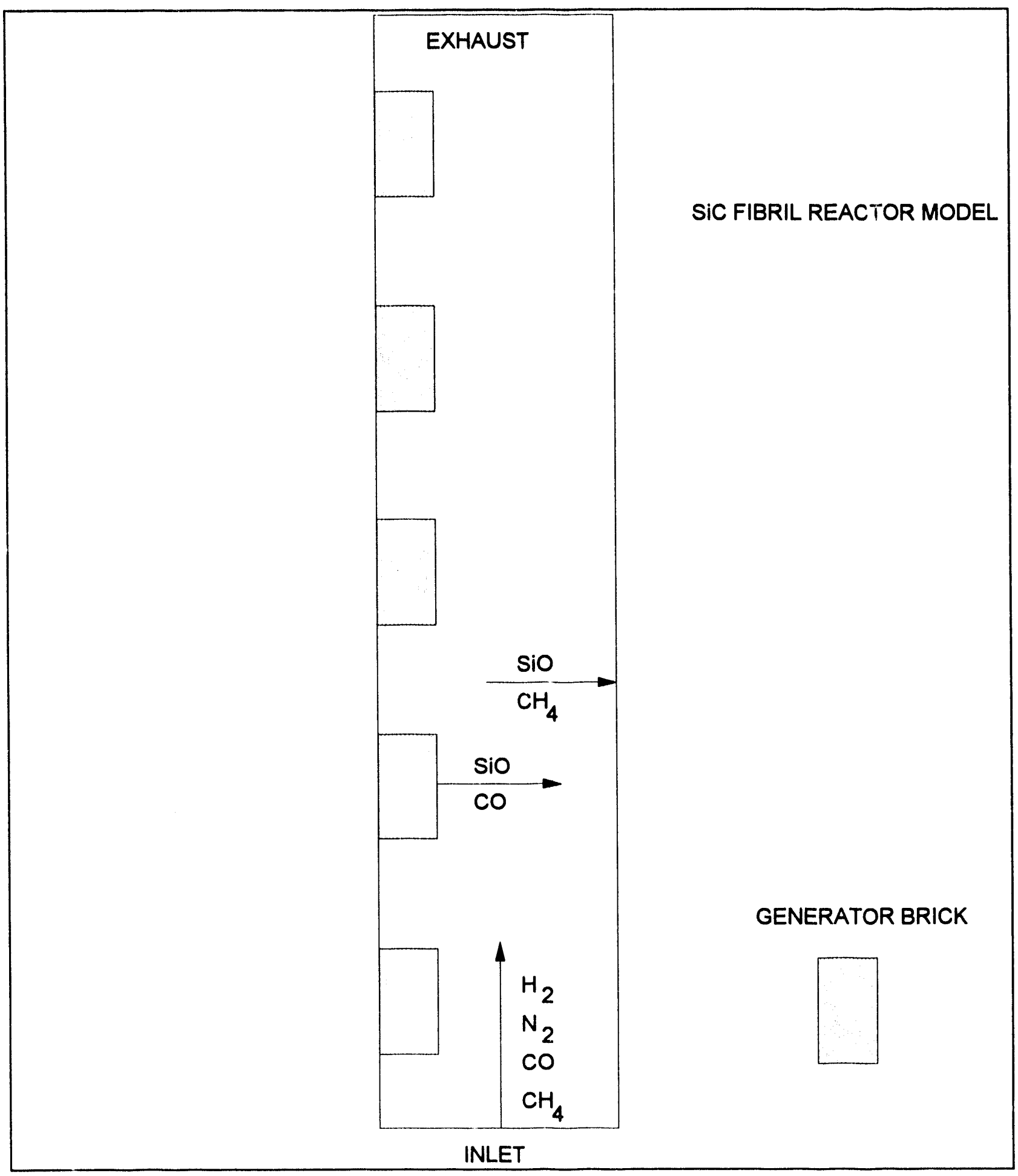

Figure 15 Schematic Diagram of the Simulation Model 
Table 9 Simulation Model Kinetic Equations

$\underline{\text { SiC Fibril Formation }}$

$$
\mathrm{dSiC} / \mathrm{dt}=\mathrm{k}_{\mathrm{w}} \mathrm{PSiO}\left(\mathrm{pCH}_{4}\right)^{2}
$$

$\underline{\text { SiO Formation }}$

$$
\mathrm{dSiO} / \mathrm{dt}=\mathrm{k}_{\mathrm{gen}}\left(\mathrm{pSiO}^{*}-\mathrm{pSiO}\right)
$$

Methane Decomposition

$$
\mathrm{dCH}_{4} / \mathrm{dt}=-\mathrm{k}_{\mathrm{d}} \mathrm{PCH} 4
$$

The following assumptions were made in the mathematical model:

- isothermal

- two-dimensional

- laminar flow

- single-phase--the solid $\mathrm{SiC}$ phase was not modeled and fibril growth was simulated as a disappearance at the substrate surface

\subsubsection{Computational Model}

The mathematical equations described above were solved via the PHOENICS Computational Fluid Dynamics simulator [21]. This simulator solves arbitrary convection-diffusion partial differential equations with arbitrary sources. It also solves momentum and continuity equations for velocities and pressures. Hybrid upwind difference is used to obtain finite difference equations, and these are solved as fully implicit resulting in a system of non-linear equations. The pressure correction is solved using a modified SIMPLER algorithm.

The 2D region was discretized in a fine grid for accurate solutions and the equations were stabilized for convergence using the versatile stabilizing features built into PHOENICS. A typical simulation required about 10 CPU minutes on a HP 750 workstation which enabled fast optimization of reactor designs. 


\subsection{Comparison of Model and Experimental Results}

Figure 16 illustrates the simulation model predictions of the total fibril mass as a function of temperature and methane partial pressure at a fixed process gas flow rate. The model successfully simulated the effects of temperature, process gas flow rate, and $\mathrm{CH}_{4}$ partial pressure on total fibril growth. While there was deviation in the absolute values of total mass of $\mathrm{SiC}$, the important result was that the predicted trends in the fibril growth rate with changing process conditions were very similar to the experimental results. The model also simulated the fibril growth rate as a function of reactor height, an achievement not demonstrated by earlier versions of the model.

Continued efforts on the model confirmation are planned. The focus will be optimization of model parameters to produce closer quantitative agreement of $\mathrm{SiC}$ formation rates as a function of process conditions and reactor geometry. The confirmed model will be useful for the design of alternative reactor configurations, scaleup reactor designs, and as a guide for future process development. 


\section{Effect of Process Conditions on SiC Fibril Growth}

(Experimental Results)

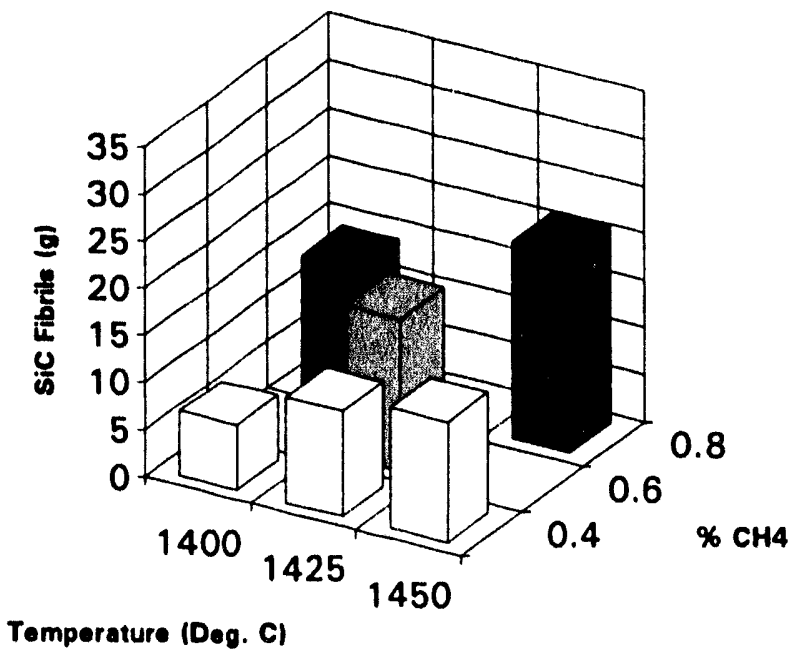

Effect of Process Conditions on SiC Fibril Growth (Simulation Model Predictions)

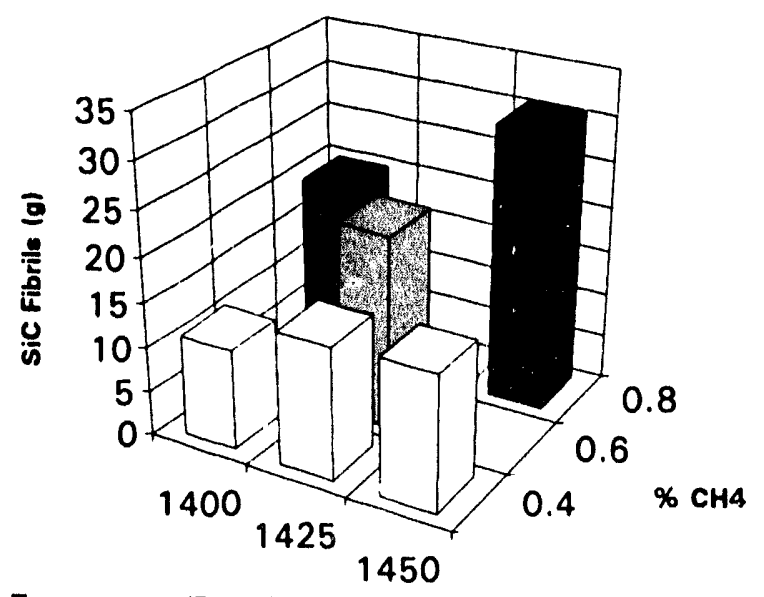

Tomperature (Deg. C)

Figure 16 Simulation Model Predictions of Total Fibril Growth 


\section{Recycle Process Development}

A preliminary economic evaluation[22] indicated that process gas costs were a significant production cost factor. Process development experiments have indicated that higher process gas flow rates than the LANL process concept[4] will be necessary to sustain fibril growth rates in scaleup reactors. This fact further increases the potential process gas cost impact. Hydrogen is the principal cost driver for the process gas. A system for recycling or reusing substantial fractions (high recycle ratios) of the process gas has been developed in response to the economic impact of the process gas.

The process concept is shown in Figure 17. The gas exiting the furnace was cooled, filtered, and recompressed. The inlet gas composition was adjusted to replace missing or off-spec components. The system bleed stream removed a fixed fraction of the gas to maintain a steady gas composition and to prevent buildup of undesirable components which could lead to deleterious (poisoning) effects on the fibril growth reaction. The process gas composition was monitored using the $\mathrm{GC}$ and $\mathrm{CO}$ gas analyzer.

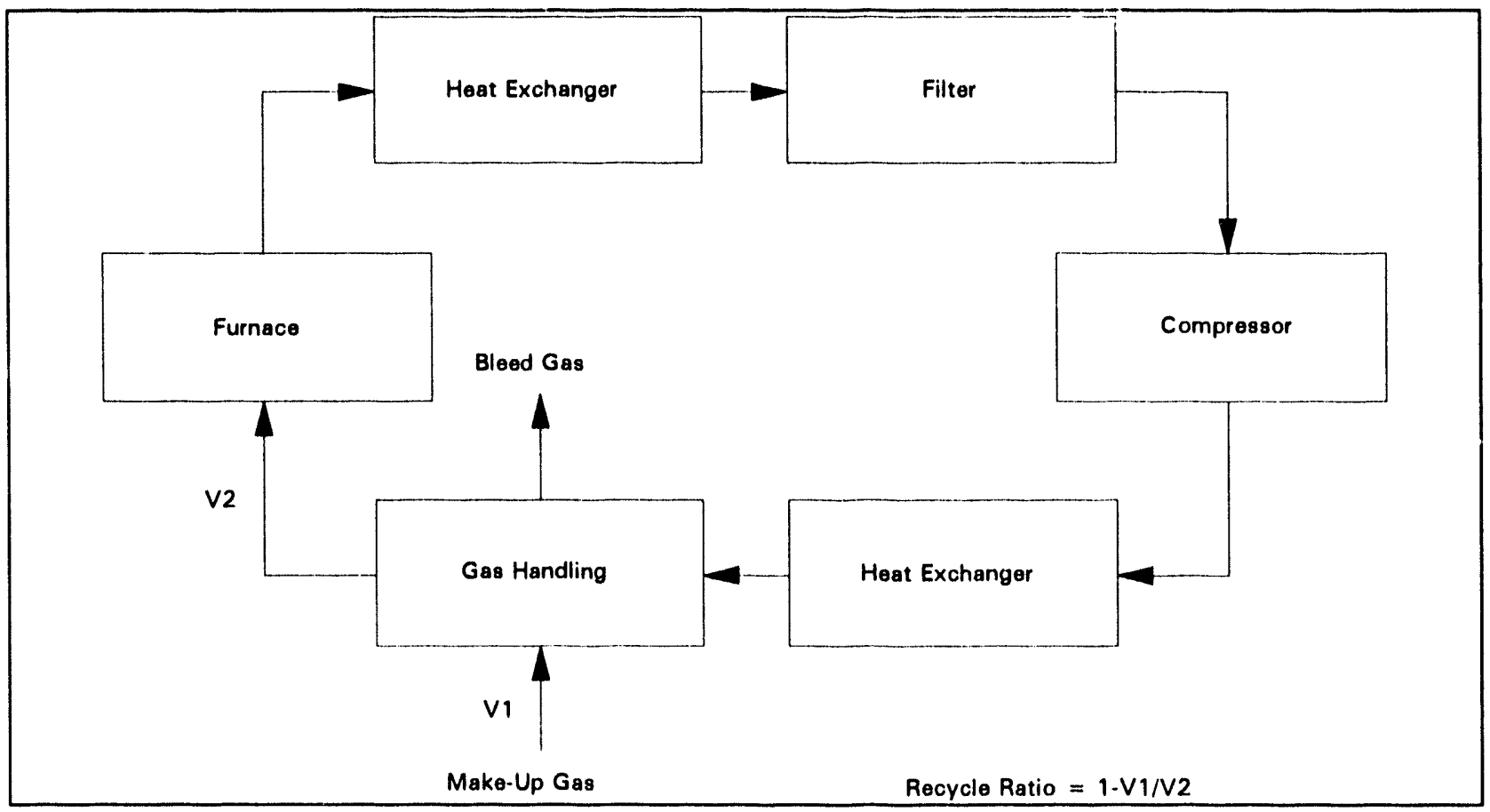

Figure 17 Process Gas Recycle Process Concept

There were two critical operating concerns for the system. The first potential issue was that conti. iuous recycling of the gas stream could lead to the formation of species which adversely impact the growth process. These species could form by continuous cycling of the process gas temperature. Such species could include methane decomposition by-products, water, and/or carbon dioxide.

Processing of the condensable compounds in the furnace exhaust gas was the other critical design consideration. Unreacted $\mathrm{SiO}$ in the gas stream condenses readily upon cooling, producing a fine, fumed mixture of $\mathrm{Si}$ and $\mathrm{SiO}_{2}$. This condensate can block piping and exhaust tubes, causing unscheduled shutdowns and operating difficulties. Carbon by-products from methane 
decomposition can also react to form solids. Careful design of the exhaust system and proper filtration of the furnace exhaust gas was critical for achieving acceptable furnace operability.

The recycle experimental program was broken into two experimental campaigns. Preliminary efforts focused on equipment shakedown and demonstration of the mechanical system operability. This included demonstration of critical equipment--filter, compressor, and heat exchanger systems. Successful demonstration of the hardware design was completed. Steady state gas compositions were achieved within one to two hours of system startup.

The second set of experiments were conducted under typical fibril synthesis process conditions. The results have been summarized in Table 10 . Table 10 compares fibril growth rate performance in the presence and absence of recycled process gas. Use of $80 \%$ recycled gas did not appear to adversely impact growth rate or product characteristics. There were two visible differences in the product grown on several interior substrates--it was shorter and more Si-rich in appearance. The product appeared similar to material synthesized under low $\mathrm{CO}$ process conditions. Modification of the recycle startup procedure would prevent nucleation at $\mathrm{CO}$-lean conditions and should improve product characteristics. Figure 18 shows examples of as-synthesized SiC fibrils grown with recycled gas. A recycle ratio of $80 \%$ was used for this experiment, which is close to the target of $90 \%$. Current recycle limitations are the result of the furnace design--a minimum amount of nitrogen purge is necessary to prevent excessive heat loss through the insulation. Future furnace designs should be based on a furnace purge flow using the recycled process gas, which would likely allow for recycle ratios $>90 \%$.

Table 10 Comparison of Recycle and Standard Growth Experimental Results

\begin{tabular}{|c|c|c|c|c|c|c|}
\hline $\begin{array}{c}\text { Recycle } \\
\text { Ratio }\end{array}$ & $\begin{array}{c}\text { Cycle } \\
\text { Time (hr) }\end{array}$ & $\begin{array}{c}\text { Total SiC } \\
(\mathrm{g})\end{array}$ & $\begin{array}{c}\text { Gen. Wt. } \\
\text { Loss }(\mathrm{g})\end{array}$ & SiO Util. & $\mathrm{CH}_{4}$ Util. & $\begin{array}{c}\text { Product } \\
\text { Morph. }\end{array}$ \\
\hline 0 & 7 & 15.6 & 86.7 & 0.32 & 0.19 & $4 \mathrm{~A}-5 \mathrm{~A}$ \\
\hline 0.8 & 6 & 14.0 & 70.9 & 0.36 & 0.20 & $4 \mathrm{~A}-7 \mathrm{~A}$ \\
\hline 0.8 & 6 & 12.0 & 69.5 & 0.31 & 0.17 & $4 \mathrm{~A}-7 \mathrm{~A}$ \\
\hline
\end{tabular}

Figure 19 shows the time dependence of the process gas composition in terms of two key components--exhaust $\mathrm{CO}$ and inlet $\mathrm{CH}_{4}$. This figure demonstrates that a stable gas composition can be achieved. Process and product reproducibility would be difficult to maintain without this level of stability. The figure illustrates the existence of an induction period between the recycle startup and the attainment of a steady state gas composition. This information was important from the standpoint of identifying strategies for process control during the nucleation cycle.

Appendix 8 summarizes the approach for calculating gas phase material balances for fibril growth experiments utilizing the recycle system. 

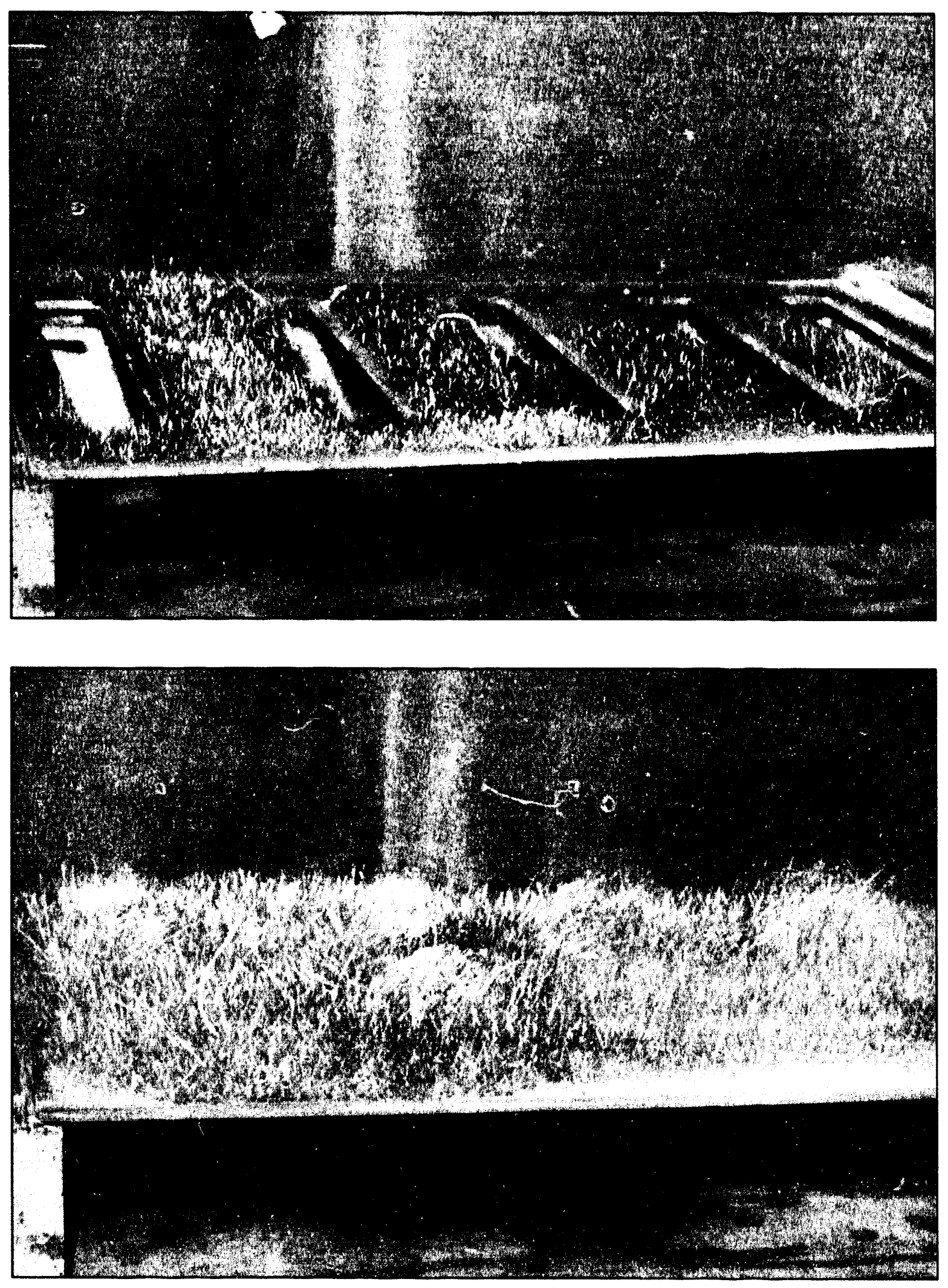

Figure 18 SiC Fibrils Grown with Recycled Process Gas 


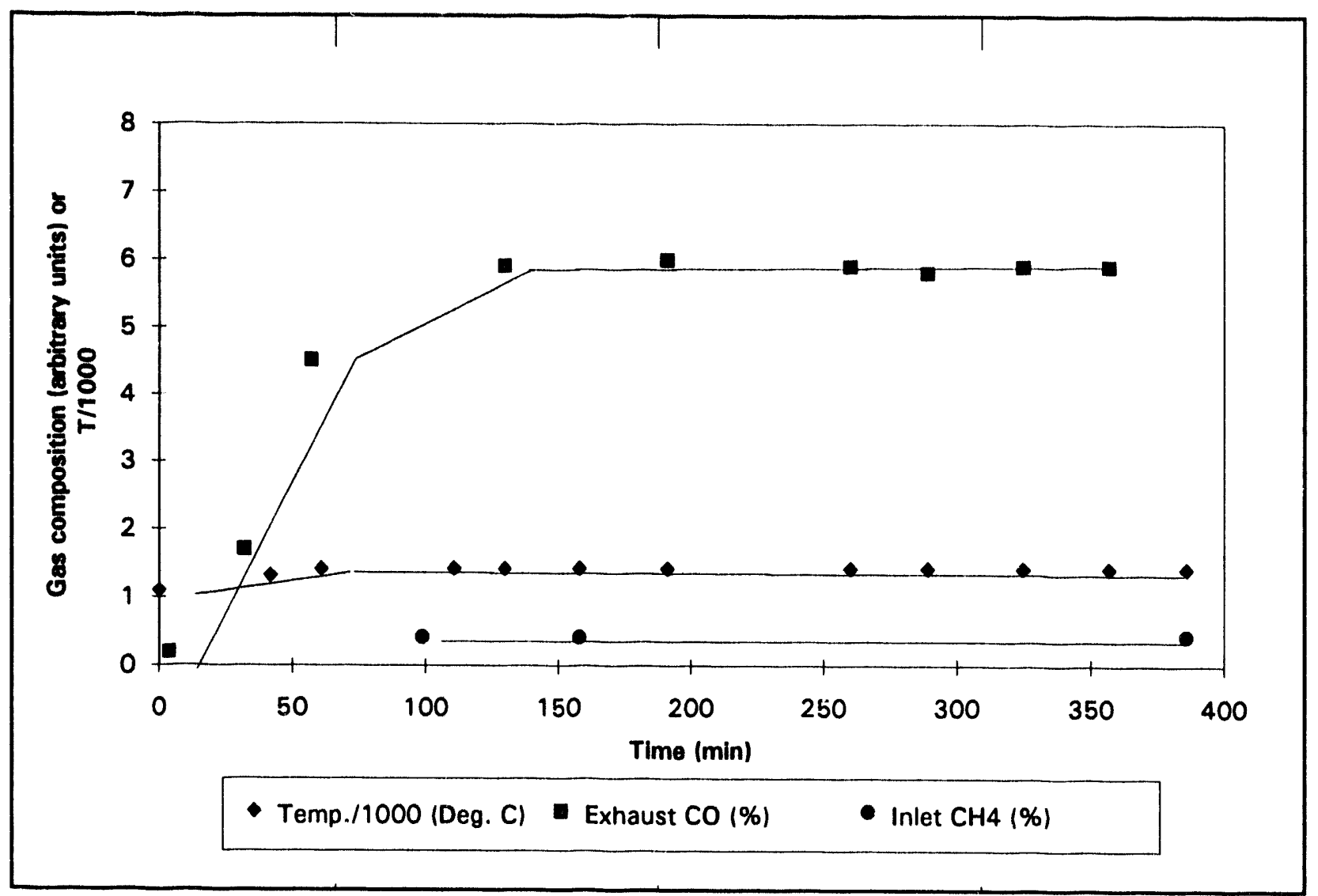

Figure 19 Recycle Process Gas Composition as a Function of Time 


\section{Harvesting/Beneficiation Process Evaluation}

As-synthesized fibrils typically require further processing for composite applications. These beneficiation or postprocessing steps are necessary to achieve the desired physical and chemical characteristics for the specific composite application. There were several goals for the fibril beneficiation process:

- remove residual catalyst

- remove undesirable by-product fibrils

- place the fibrils in a form suitable for subsequent processing

To achieve the final goal, the postprocessing step(s) cannot degrade the fibril characteristics for the composite application. The optimum physical form for subsequent processing needs to be considered in the beneficiation process concept. Table 11 summarizes postprocessing routes explored in the present program. Four process steps were evaluated based on the expected product length requirements for different types of composite applications. Leaching will probably be required for most composite applications, as it is expected that residual metal catalyst will have an adverse impact on composite properties. The remaining beneficiation processes would be chosen based on the fibril length specification.

Table 11 SiC Fibril Postprocessing iteps

\begin{tabular}{|c|c|c|c|}
\hline Postprocessing Step & $\begin{array}{c}\text { Average Fibril } \\
\text { Product Length }\end{array}$ & Typical Yield (\%) & Comment \\
\hline Chemical Leaching & Any & $80-90$ & $\begin{array}{c}\text { Removes residual } \\
\text { catalyst } \\
\text { Required for all } \\
\text { postprocessing } \\
\text { concepts }\end{array}$ \\
\hline $\begin{array}{c}\text { Air Harvest } \\
\text { (LANL) }\end{array}$ & Long $(>5 \mathrm{~mm})$ & $40-60$ & $\begin{array}{c}\text { Separate long, } \\
\text { medium, and short } \\
\text { fibrils }\end{array}$ \\
\hline Screen & Medium $(1-5 \mathrm{~mm})$ & $30-60$ & $\begin{array}{c}\text { Fibril attrition limits } \\
\text { use for long fibril } \\
\text { processing }\end{array}$ \\
\hline $\begin{array}{c}\text { Blend/Screen } \\
\text { (LANL) }\end{array}$ & Short $(0.1-1 \mathrm{~mm})$ & $40-70$ & $\begin{array}{c}\text { Some catalyst } \\
\text { removal, attrition of } \\
\text { fibril length }\end{array}$ \\
\hline
\end{tabular}




\subsection{Catalyst Removal}

Chemical leaching was evaluated as a means of catalyst removal[12]. The leaching step used an acid solution to dissolve impurities. In a typical leaching experiment, the fibril sample was allowed to soak in a static acid bath containing a large excess of acid. A typical leaching experiment would use a solid to liquid mass ratio of 1:80. There was a noticeable evolution of gas bubbles during leaching. Upon completion of the experiment, the supernatant acid was decanted and neutralized. The remaining fibrils were rinsed several times to remove residual acid. The presence of dissolved impurities in the leachate was confirmed by wet chemical analysis of the unneutralized leachate.

Table 13 (see Section 8.4) summarizes the effect of acid leaching on the residual impurity content. The chemical analysis indicated a significant reduction in all impurity concentrations by leaching. This process has not been optimized from the standpoint of leaching rate or final impurity levels. Future development efforts should target specification of these parameters.

The leaching process did not appear to degrade the fibril surface. This conclusion was based on microscopic evaluation of leached product.

\subsection{Air Harvesting}

Air harvesting techniques originally developed by LANL[4,5] appear to be the best concept for the collection of long ( $>5 \mathrm{~mm}$ ) fibrils required for the successful production of fibril yarns. This concept used a high velocity air jet aimed at the base of the fibrils to liberate them from the substrate. This procedure caused the longest fibrils to peel off the substrate as a mat; application of a small amount of polymer solution in the form of an aerosol aided in maintaining the coherence of the mat. A fraction of the fibrils tended to blow free from the substrate and the fibril mat. These fibrils contained a combination of short and medium length product of large diameter. The remainder of the fibrils remained attached to the substrate surface. This product consisted of a mixture of short, small diameter fibrils and medium length fibrils.

This harvesting procedure has several attractive features. The fibril mat appeared to be an acceptable form for subsequent yarn-forming operation. Air harvesting appeared to beneficiate the product by concentrating long, prime fibrils from undesirable morphologies. The medium and short fibrils from the remaining fractions can be collected and beneficiated by screening. This technique appeared to be a relatively sensitive technique for evaluating the effect of synthesis process conditions on average product length and should serve as a useful tool for evaluating future process development experiments. 


\subsection{Screening}

Initial beneficiation process development focused on a wet screening process to separate long and short fibrils [12]. The process consisted of razor harvesting of the fibrils, dispersion in ethylene glycol, and batch screening on a 20 -mesh screen. This process concept had several drawbacks:

- The dispersion process led to shortening of the product

- Screening yield was not impacted by synthesis process conditions or product length

- Undesirable fibrils appeared to be captured by the screened fibrils

The shortening of the fibrils was the primary issue with this concept. Successful fabrication of fibril yarns will require a minimum average fibril length. The dispersion process appeared to shorten the product to an average length of $<1 \mathrm{~cm}$ which may not be sufficient.

The contamination of desirable fibrils with product such as bent needles in the batch processing was another concern. Very clean fibrils could be achieved, but only after required multiple dispersion/screening steps which resulted in substantial yield reduction. This concept may have utility for producing a medium length product (i.e., $1-5 \mathrm{~mm}$ average length) using some type of continuous screening process.

\subsection{Short Fibril Screening}

This process was developed by LANL to produce shortened fibrils for discontinuous fibrilreinforced composites[5]. The concept consisted of high shear mixing to reduce the average fibril length, followed by screening on 100-mesh and 325-mesh screens. The primary product was the +100 -mesh product, which contained mostly prime fibril product. As shown in Table 11, the LANL procedure produces yields of prime product similar to the process concepts evaluated under the present program. This process concept would be chosen for postprocessing of fibrils for discontinuous reinforced composites.

Typical yields for each process are similar to the ranges found at LANL. They were also observed to vary widely from experiment to experiment. It was difficult to separate the effects of the growth process from variability in the beneficiation process. Postprocessing yields are an important economic parameter, since low yields translate to increased production costs. Future efforts should determine the reproducibility of the yield for a fixed synthesis process condition, as well as the potential for further improvements in the yield. Each of the beneficiation process concepts appear amenable to scaleup and automated operation. 


\section{Characterization of VLS SiC Fibrils}

\subsection{Morphology Analysis}

The physical characterization of VLS SiC fibrils was an important prog am task, since these characteristics were affected by the synthesis process conditions. The primary physical characteristics include diameter, length, and morphological characteristics. Microscopy $[1,4,18]$ has identified the presence of a wide variety of fibril morphologies which grow under specific process conditions. However, characterization efforts have typically been qualitative. The current program has attempted to incorporate and develop techniques that produce quantitative data on the fibril characteristics produced under different synthesis process conditions.

The primary tools for characterization are the various microscopic techniques, including optical microscopy, scanning electron microscopy (SEM), and transmission electron microscopy (TEM). The characterization work has been performed at Carborundum and the High Temperature Materials Laboratory (HTML) facilities at Oak Ridge National Laboratory. Optical microscopy was used primarily for preliminary product screening and identification of the presence of undesirable fibril morphologies. SEM was used for more detailed product evaluation, including the identification of surface characteristics like bambooing and the presence of very fine diameter fibrils. TEM was used to characterize the fibril crystal structure and identify potential causes for non-needle growths.

Characterization of the fibril morphology has been critical for interpreting the effects of synthesis process conditions. Process conditions impact growth rate, yield, and production cost. This results in trade-offs between production cost and product characteristics. Process conditions which promoted the highest growth rates did not produce fibrils with desirable physical characteristics.

The VLS process is capable of producing perfect single crystal needles as the prime product. There appears to be a perception that the process produces all needles. This does not appear to be the reality; under all growth conditions, varying amounts of nonneedle fibrils were found. Under proper growth process conditions, these nonneedle morphologies can be minimized.

The present study has focused on the characterization of the most frequently found nonneedle morphologies, including branching, bambooing, and bent needles. These general classes of morphologies have been reported elsewhere[2,14,18]. Figures $20-24$ show examples of prime needle product and several of the more common by-product structures. Formation of these structures appeared to be enhanced by specific process conditions. For example, high methane partial pressures enhanced the appearance of fibril balls. A semi-quantitative technique was developed to measure the concentration of branched and bambooed fibrils by counting these structures during diameter analysis. Preliminary semi-quantitative analysis indicated that the total percentage of nonneedle product was of the order of $10 \%$ of the total fibrils produced at the baseline process conditions. 

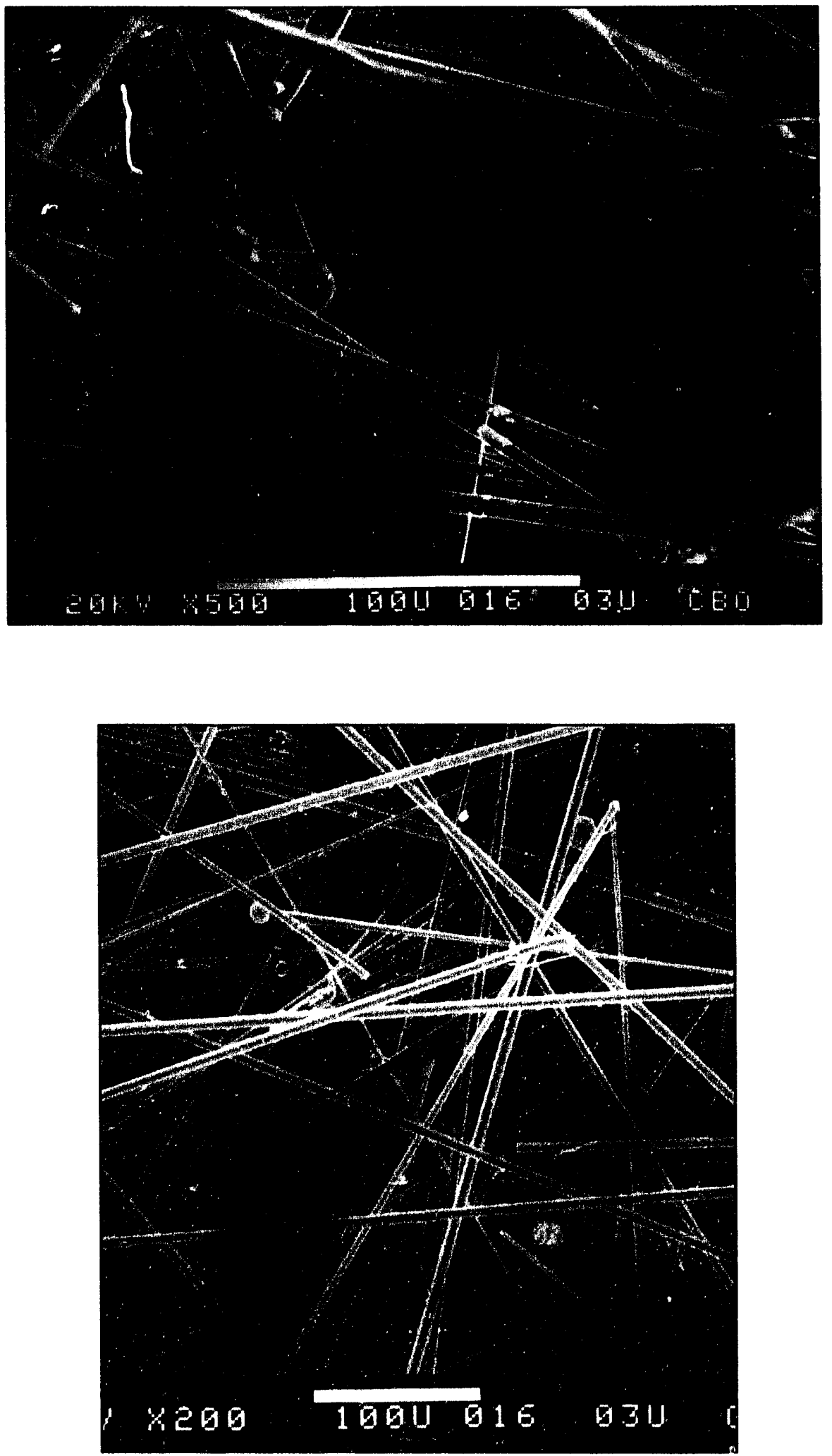

Figure 20 Prime SiC Fibrils 


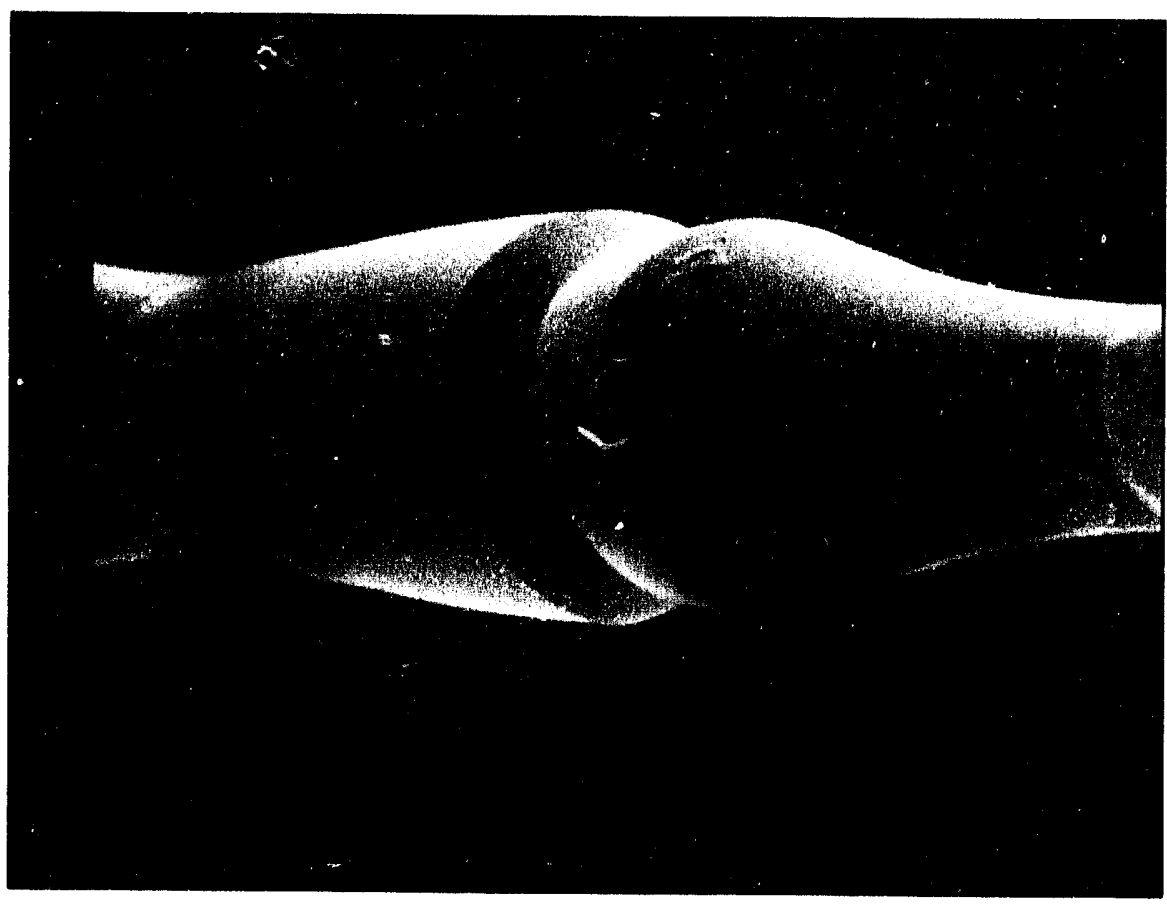

Figure 21 Bambooed SiC Fibrils

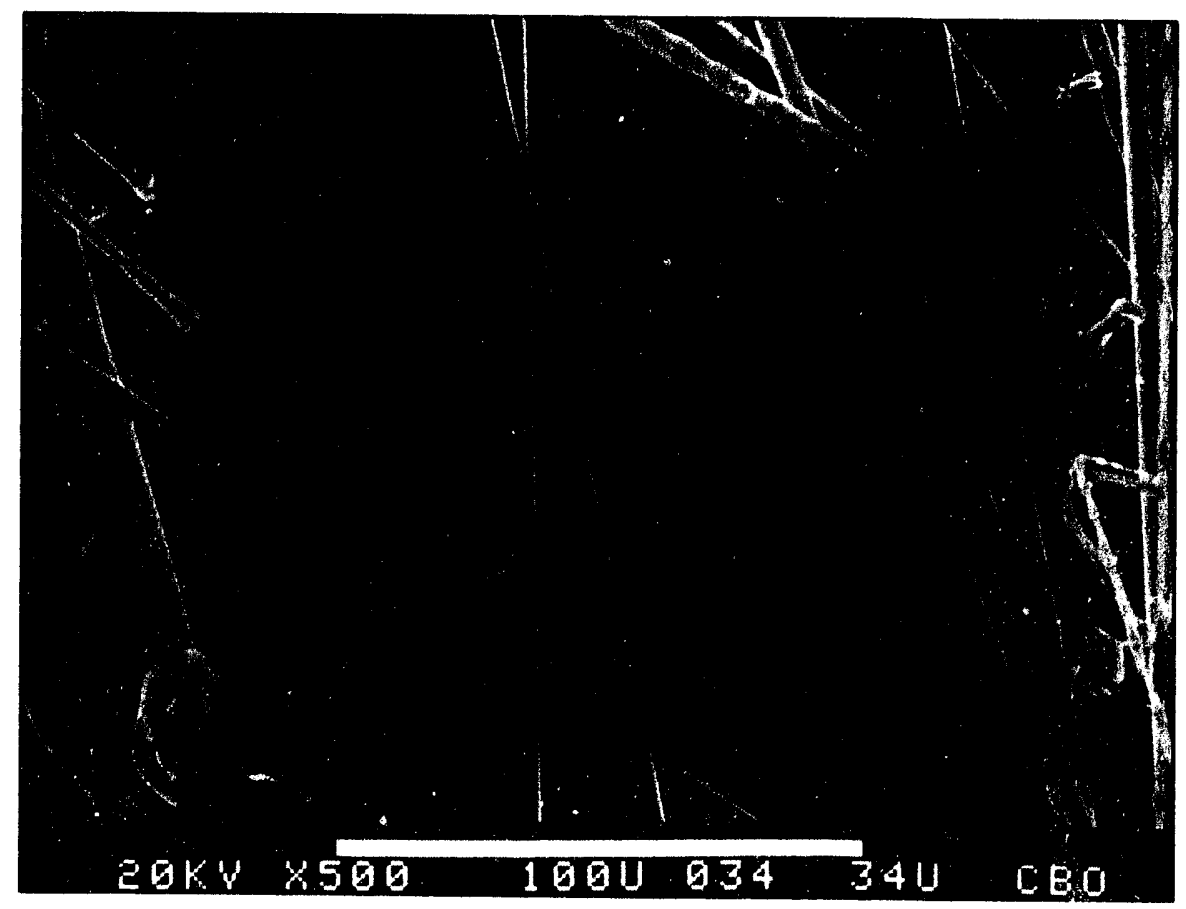

Figure 22 Branched SiC Fibrils 

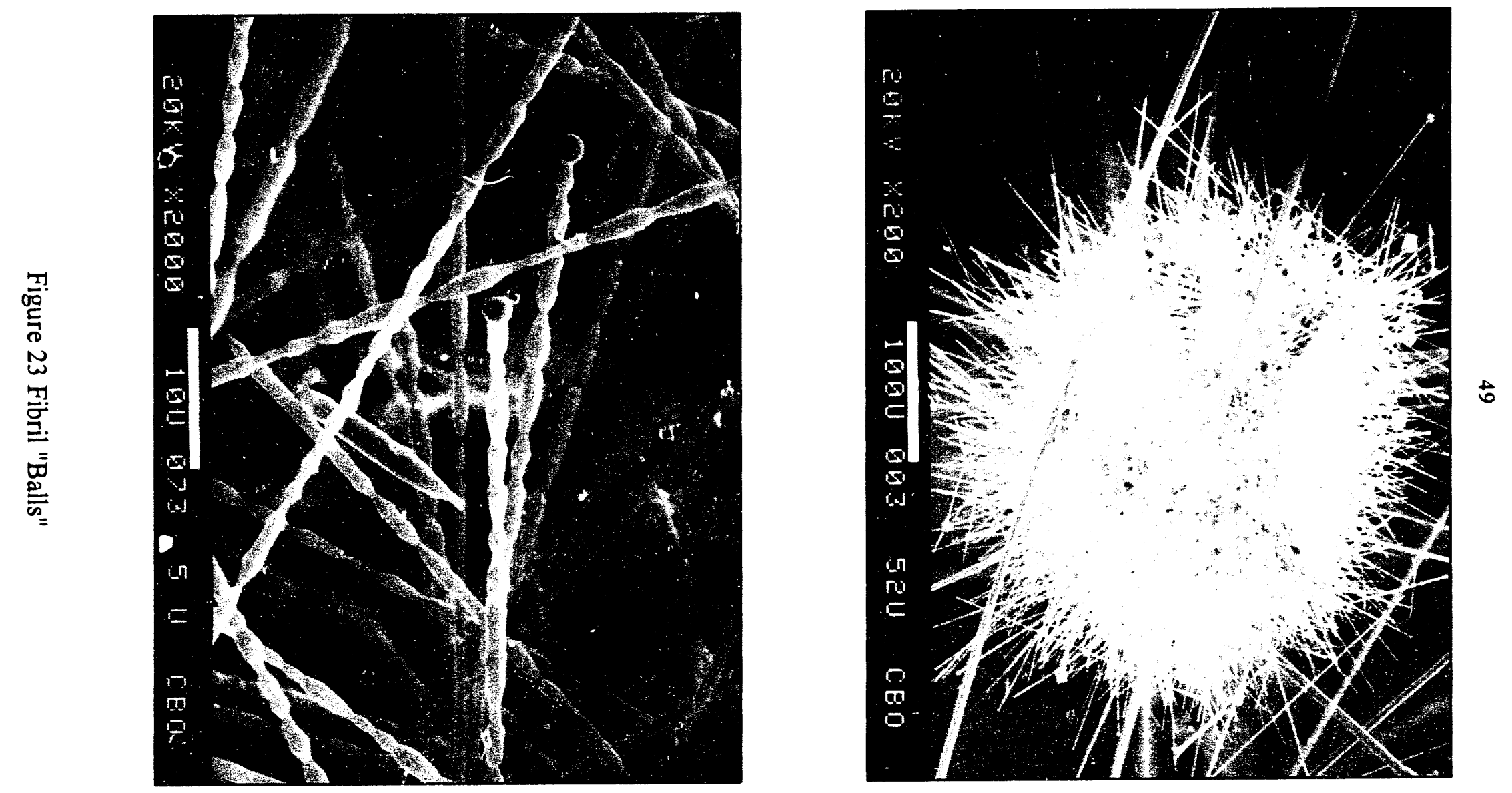

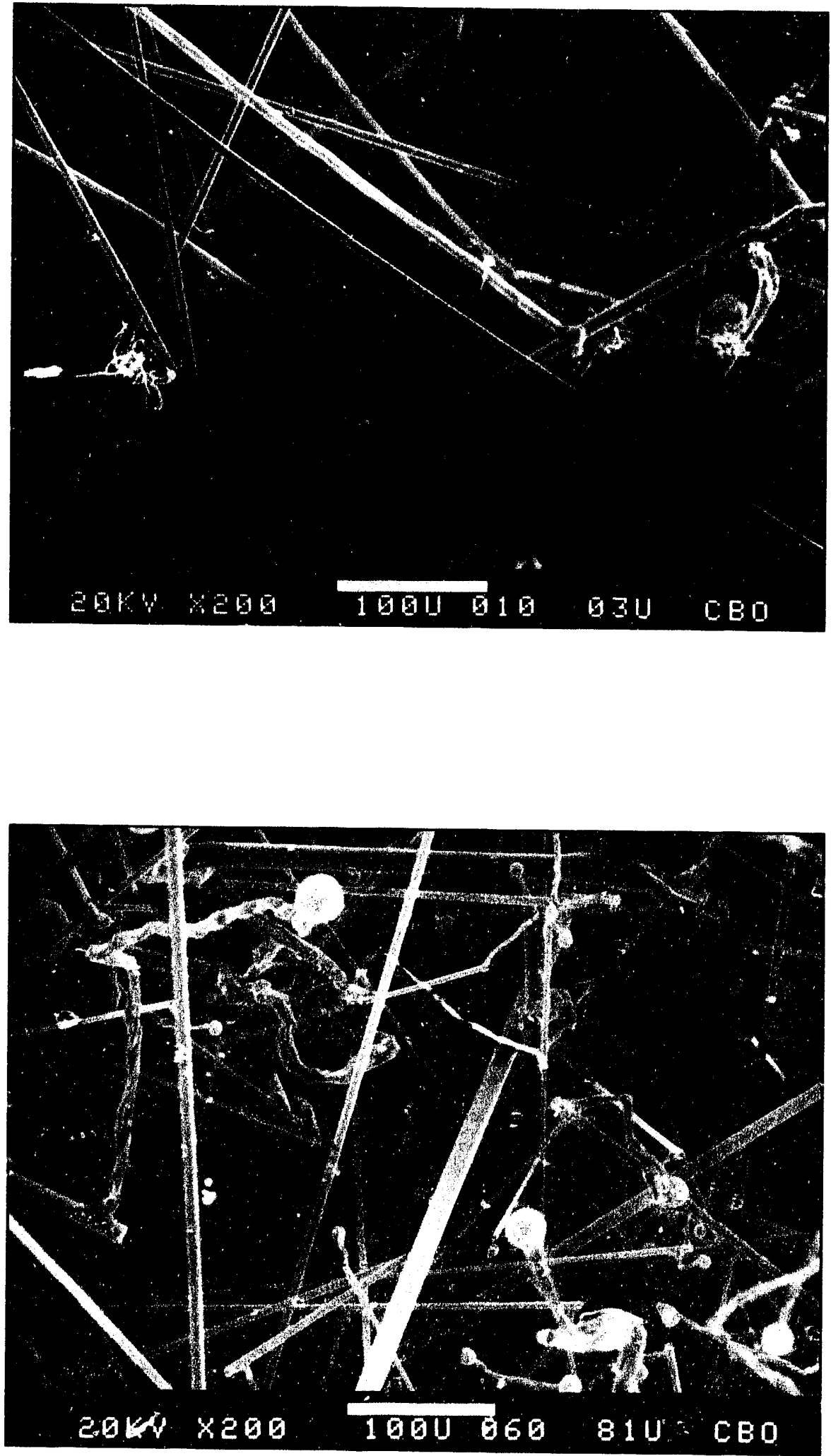

Figure 24 Bent Needle Fibrils 


\subsection{Diameter Analysis}

The fibril diameter has important ramifications on the commercial viability of the VLS SiC fibril process. The diameter distribution may affect composite performance. The potential health hazard associated with small diameter fibrils is another concern. These factors have promoted efforts to characterize and improve control of the product diameter. A quantitative measurement technique based on optical microscopy combined with automated image analysis was used to guide this task.

Fibril samples were prepared by obtaining a small tuft of fibrils by tweezers. This sample was shortened by cutting with razor blades. The cut fibrils were dispersed on a glass slide using an index oil with a refractive index of 1.518. Two sampling techniques were used. Initially, sampling was performed by grab sampling from the as-harvested fibril mass. The modified sampling procedure consisted of a grab sampling from a dispersed and settled batch of fibrils taken from an entire substrate or set of substrates. It was felt that the second technique led to a more representative sample.

The diameter measurements were made with an optical microscope interfaced to a personal computer. A magnification of $1250 \mathrm{x}$ was used in all measurements. The slide was scanned across the viewing area and 100 diameter data points were accumulated. The diameter was automatically measured by the image analysis software. The diameter and its distribution were calculated by the computer software. Bambooed and branched fibrils were tallied by the operator during the diameter measurement.

To aid in data interpretation, the diameter distribution was correlated using the Rammler-RosinBennett (RRB) equation[23]. This equation was originally developed to correlate powder particle size distributions. The RRB equation is given by:

$$
Y=1-\left[\exp \left(-\left(X / X^{\prime}\right)^{n}\right)\right]
$$

$\begin{array}{ll}\text { where } & Y=\text { cumulative fraction less than diameter } X \\ X=\text { diameter } \\ X^{\prime}, n=\text { equation constants }\end{array}$

Parametric sensitivity calculations were performed to identify the relationship between model parameters and diameter distribution width. These results have been sumınarized in Appendix 9 . Equation constants $X^{\prime}$ and $n$ are linearly related to the average diameter and the width of the distribution, respectively. 
Figure 25 shows an example of model predictions of a typical fibril diameter distribution. The RRB equation produced a reasonable correlation of the fibril diameter distributions. It reproduced critical features such as the width of the distribution and the S-shaped curve typically exhibited by the fibril product. A simpler equation was evaluated for correlating the diameter data--the GGS equation[23]. This equation produced poorer predictions of experimental data, particularly in the limits of small and large diameters.

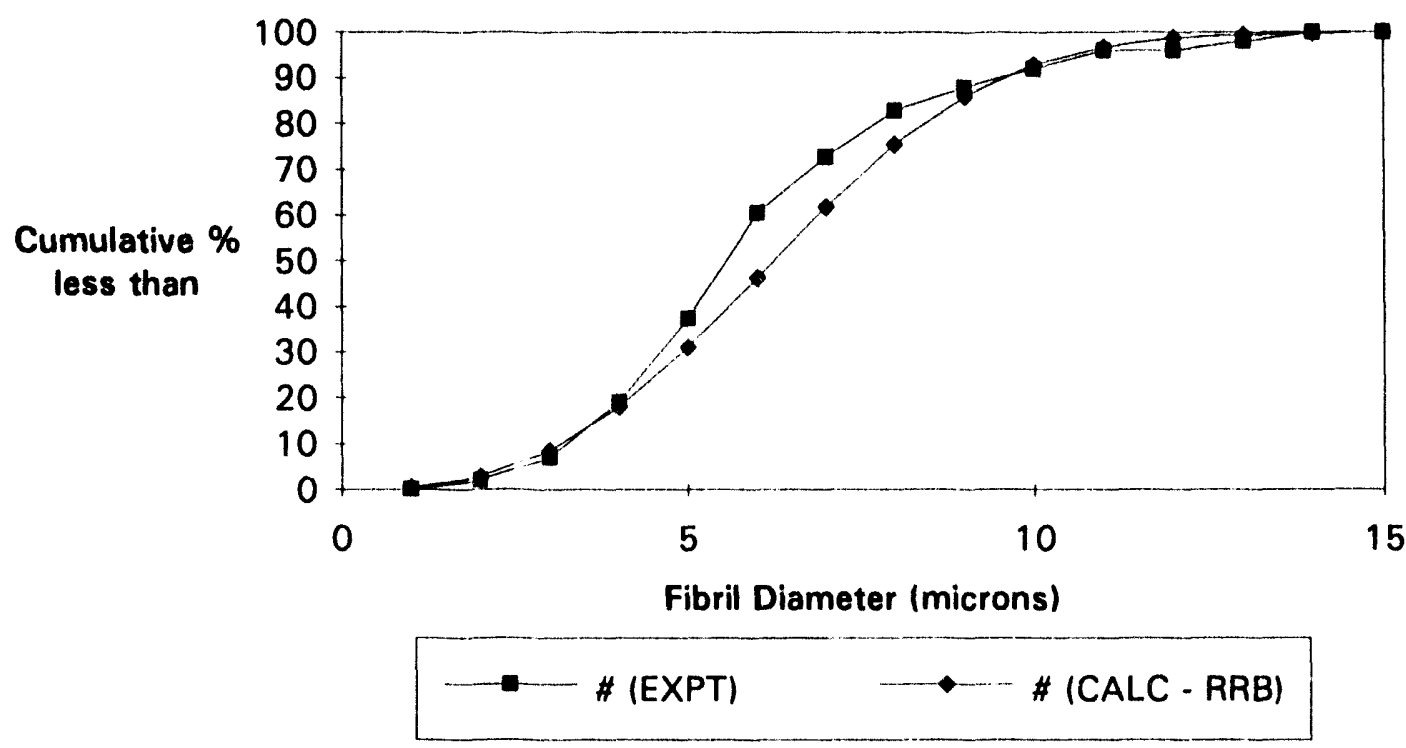

Figure 25 Experimental and Calculated Fibril Diameter Distributions

This analysis procedure was used to analyze the impact of temperature and methane partial pressure on the diameter distribution. The results are shown in Figures 26 and 27. Baseline process conditions promoted higher average diameters and narrower distributions, as evidenced by the larger values of $\mathrm{X}^{\prime}$ and $\mathrm{n}$ under these process conditions.

Diameter measurements were useful for evaluating the impact of postprocessing on the product diameter. Figure 28 shows that air harvesting appeared to have a beneficial effect on the product diameter distribution, increasing the average diameter by several $\mu \mathrm{m}$. The residual fibrils left on the substrate had a smaller average diameter. 


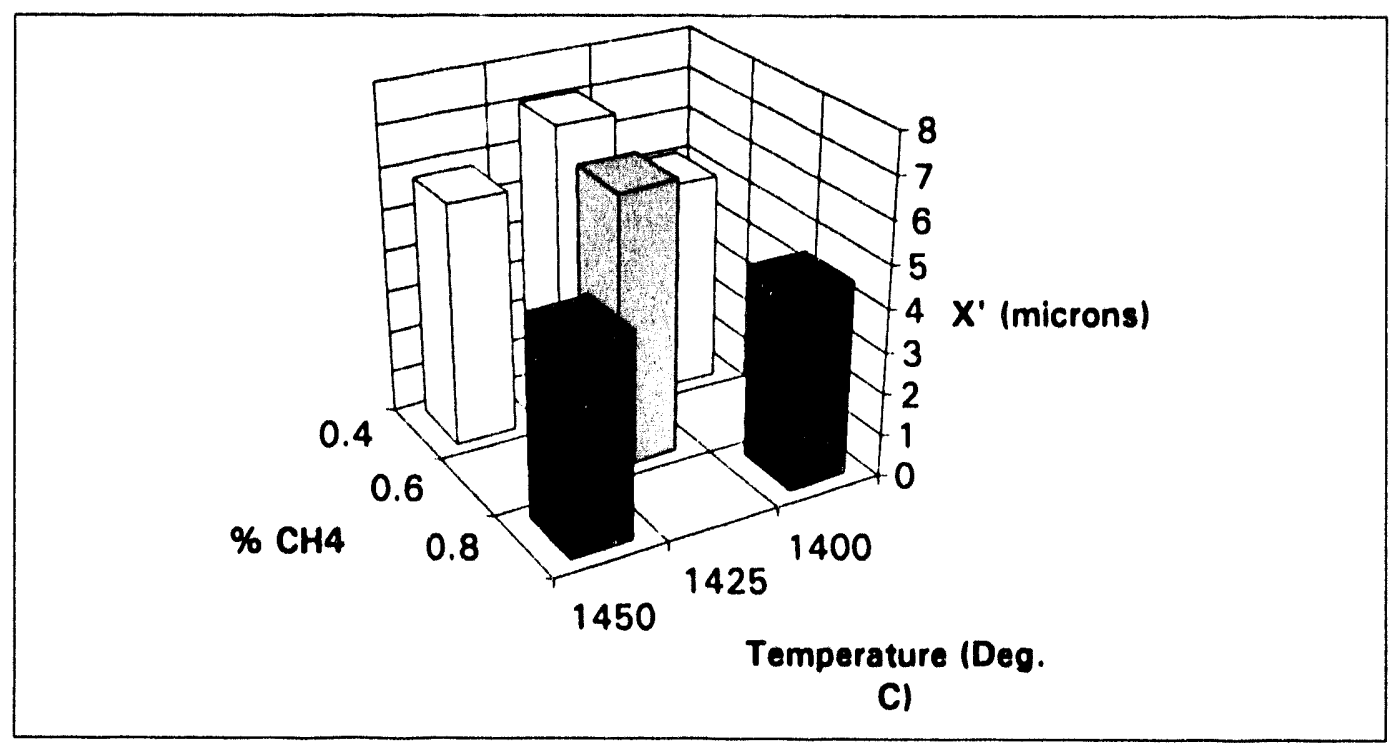

Figure 26 Effect of Synthesis Process Conditions on Average Diameter Parameter (X')

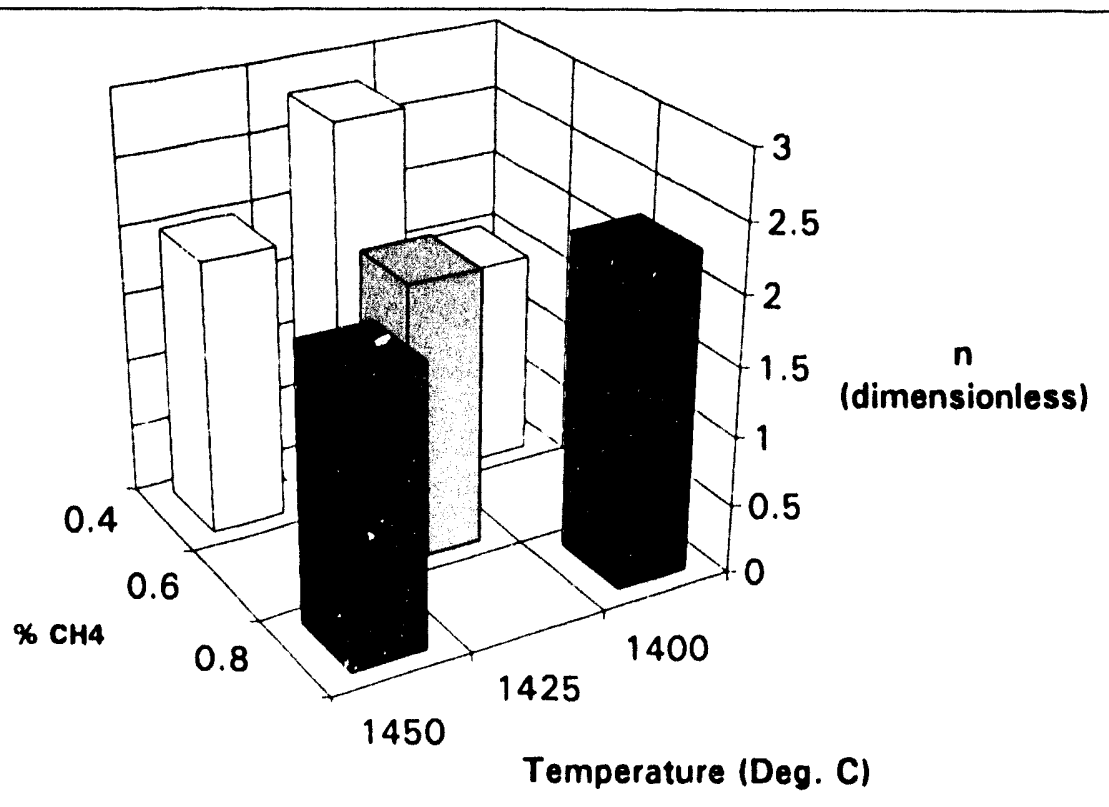

Figure 27 Effect of Synthesis Process Conditions on Diameter Dispersion Parameter (n) 


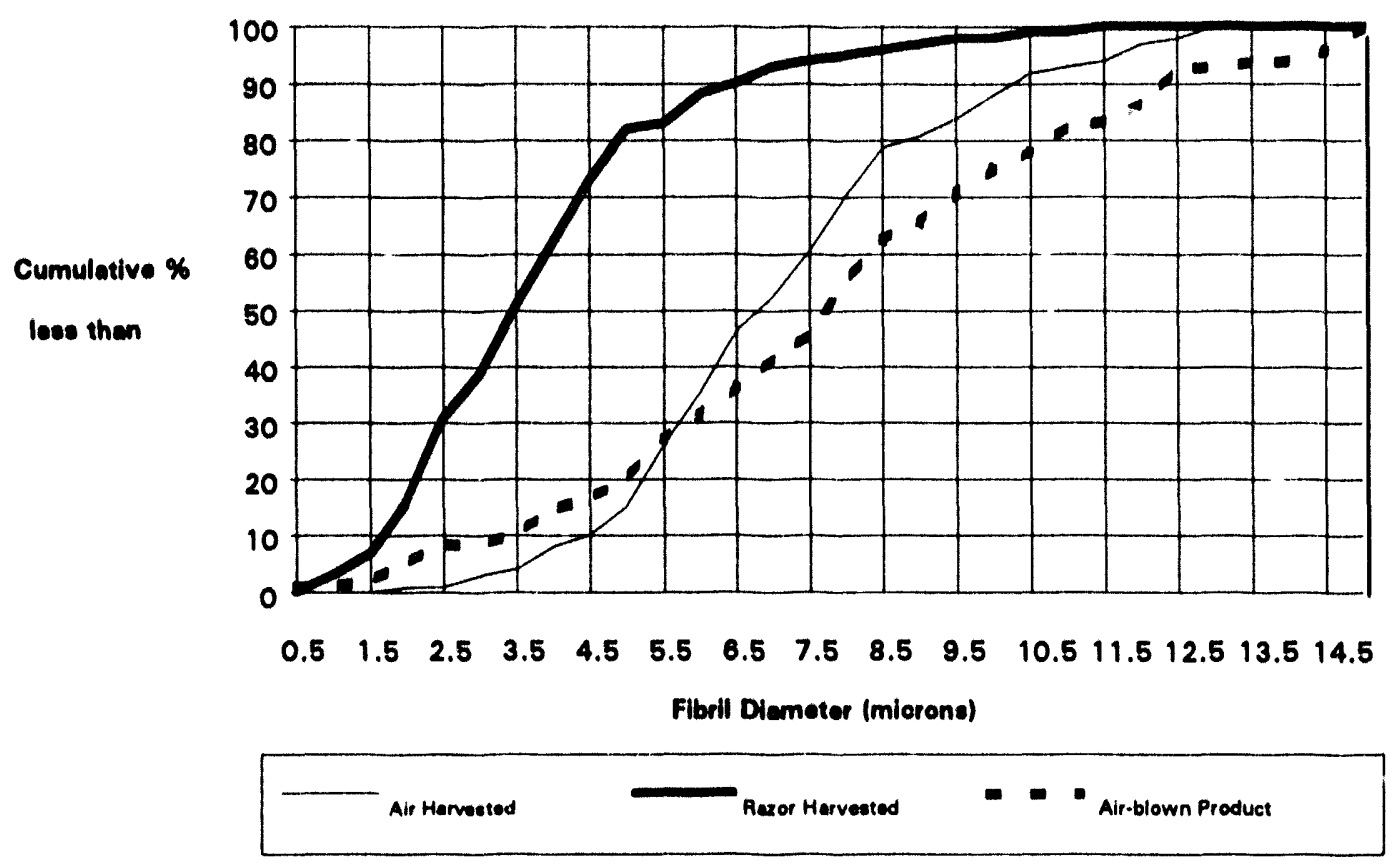

Figure 28 Effect of Air Harvesting on Diameter Distribution

\subsection{Length Evaluation}

Fibril length is another important physical characteristic. Quantitative length measurement was made difficult by two facts:

- the extreme asymmetry between length and diameter made simultaneous characterization nearly impossible

- the sample preparation technique can modify the length distribution by fracture of the fibrils

Fibril length was estimated by three techniques:

- maximum/typical lengths of as-synthesized fibrils

- fibril length via settled density

- air harvesting

Each technique had its own advantages and disadvantages. The first technique was the easiest to perform. It consisted of ruler measurements of the maximum and typical lengths of the fibrils as a function of position on the growth substrate. This method was the simplest procedure but it yielded the least amount of useful information.

The basis for the measurement of length (aspect ratio) by settled volume has been described by other authors $[24,25]$. The fibril aspect ratio was evaluated by measurement of the settled volume of a fixed mass of dispersed fibrils. Its major drawbacks were:

- the procedure required dispersion of the fibrils in a liquid medium which can shorten the fibrils

- knowledge of the diameter was required to determine the length

- the effect of diameter distribution has not been defined 
Some preliminary results of settling experiments for several different fibril products are summarized in Table 12. The longest product resulted in larger settled volumes (reduced settled densities). Continued effort will be required to establish the accuracy and reproducibility of this technique.

Table 12 Settled Density of Different Length Fibril Product

\begin{tabular}{|c|c|c|}
\hline Product Description & Maximum Length $(\mathrm{cm})$ & Settled Density $(\mathrm{g} / \mathrm{cc})$ \\
\hline Air harvest (long) & $2-3$ & 0.003 \\
\hline Air harvest (short) & $1-1.5$ & 0.009 \\
\hline $\begin{array}{c}\text { Razor harvest (mix of long } \\
\text { and short product) }\end{array}$ & $0.1-1.0$ & $0.013-0.025$ \\
\hline Short fibrils & 0.2 & 0.05 \\
\hline
\end{tabular}

The last technique used the relative amount of material obtained by air harvesting to determine the average length. The air harvesting procedure yields products of three distinct lengths--long product, which comes off in a coherent mat; medium/short length fibrils, which are blown loose for the mat but are not carried away by the process; and the shortest product, which remains attached to the substrate. Air harvesting can provide useful insights into the mass distribution of the fibril lengths because of this apparent product separation. This technique is still under development and may eventually be useful for guiding development and analysis of fibril product for specific composite applications.

\subsection{Chemical Analysis}

Table 13 summarizes the results of chemical analyses performed in this study and by LANL[5]. The SiC fibrils produced in this study are similar in purity to LANL fibril product. Trace impurities were evaluated after leaching in the present study and after shortening/screening in the Gac reference. Differences in the amount of impurity concentrations are mainly due to the different catalysts used in the two studies.

\section{Table 13 Chemical Analysis of SiC Fibrils}

\begin{tabular}{||c|c|c|}
\hline Species & This Study & Gac [5] \\
\hline $\mathrm{Si}$ (total) (wt \%) & 69.5 & \\
\hline $\mathrm{C}$ (total) (wt \%) & 29.3 & 30.0 \\
\hline $\mathrm{Si}$ (free) (wt \%) & 0.02 & 0.74 \\
\hline $\mathrm{O}(\mathrm{wt} \%)$ & & 1.05 \\
\hline $\mathrm{N}(\mathrm{wt} \%)$ & & 0.2 \\
\hline $\mathrm{Fe}(\mathrm{wt} \%)$ & 0.75 & - \\
\hline $\mathrm{Al}$ (wt \%) & 0.12 & $2.5(0.1)^{*}$ \\
\hline Other (total, wt \%) & 0.03 & \\
\hline
\end{tabular}

* After chemical leaching 


\subsection{Mechanical Properties of SiC Fibrils}

The attractiveness of VLS SiC fibrils can be attributed to their high strength and unmatched thermal resistance which result from the single crystal structure of the fibrils. Several previous studies have measured crucial VLS SiC fibril mechanical properties[3,26]. Important results are summarized in Table 14. These efforts have demonstrated the SiC fibril's extremely high strengths--approaching as high as $16-20 \mathrm{GPa}$ for selected specimens. The average strength for forty $5-\mathrm{mm}$ samples was found to be $8.4 \mathrm{GPa}$; the data exhibited a high degree of scatter[4].

Table 14 Literature Data on SiC Fibril Mechanical Properties

\begin{tabular}{|c|c|c|}
\hline Property & Measured By & Result \\
\hline Tensile strength & LANL [4] & $8.5 \mathrm{GPa}(1,200 \mathrm{ksi})$ \\
\hline Elastic modulus & LANL [4] & $580 \mathrm{GPa}(85,000 \mathrm{ksi})$ \\
\hline Creep resistance & NASA-LRC [3] & $\mathrm{m}=1$ @ 1673 K for 1 hour \\
\hline
\end{tabular}

Initial single fiber tensile testing at Carborundum produced widely scattered data ranging from 2 - $5 \mathrm{GPa}$. Alternative testing techniques were explored due to concerns regarding the accuracy of the single fiber testing procedure.

Single fiber composite (SFC) testing was evaluated for measuring fibril strength and strength distribution[27]. In this technique, a single fibril is embedded in an epoxy matrix. This sample is stressed, and the number and location of breaks as a function of the stress level is measured. The resulting data can be used to predict the fibril strength as function of gauge length and simultaneously determine the statistical strength distribution. A model has been developed for analysis of the test results[28]. Appendix 10 contains the relevant test data results and analysis. The results have been summarized in Table 15 .

Single fiber composite testing results were in excellent agreement with previous studies[4,26]. The major advantage of the technique was that a single experiment was used to generate the data typically generated by multiple single fiber tensile tests.

Table 15 Single Fiber Composite Testing Results

\begin{tabular}{|c|c|c|}
\hline Sample & 1 & 2 \\
\hline Tensile strength (25.4 mm gauge length) & $6 \mathrm{GPa}$ & $9 \mathrm{GPa}$ \\
\hline Weibull modulus & 3.0 & 3.5 \\
\hline
\end{tabular}




\section{Composite Development}

A primary interest of the present program was the production of fibrils that could be aligned into oriented yarns. Fibril yarns should allow for directional loading of long fibrils for composite applications. Long fibrils have the potential to achieve continuous composite behavior (i.e., toughness enhancement of a brittle matrix dominated by pullout of the fibrils). Hand forming of fibril tow was evaluated as a means of producing samples for composite fabrication and testing.

Hand forming of tows to $0.1 \mathrm{~m}$ in length and $1-2 \mathrm{~mm}$ in diameter was demonstrated. Figure 29 shows $35 \mathrm{~mm}$ and low magnification SEM micrographs. These tows were produced by alignment of fibrils directly harvested from a growth substrate. A variant of this technique was developed to form tows from air-harvested product. Tow forming was facilitated by wetting the fibrils with a dilute aqueous solution containing polyvinyl alcohol. The solution improved the formability and handleability of the tows.

There are two important characteristics which describe tow properties--alignment and volume loading. It was found that the degree of alignment varied from good to poor. Composite mechanical testing also revealed that the volume loading varied along the length of the tow. This variability was most likely the result of the hand forming procedure.

\subsection{Epoxy Tow Composites}

Several samples of epoxy reinforced with SiC fibril tows were fabricated. The purpose of these experiments was two-fold:

- evaluate tow properties (loading/alignment)

- determine the feasibility of bundle testing to determine fibril strength

Initial testing of epoxy samples reinforced with a single fibril tow revealed the presence of low volume fraction sections within the tow. This was probably due to the hand-forming technique, which was not optimized for producing a uniform sample. These samples did not show improved mechanical properties because of extremely low volume fraction of fibrils in the area of the break.

Additional epoxy composites containing multiple strands of VLS SiC fibril tow were prepared. In this case, an increase in the fracture strength over the epoxy matrix was observed. SEM analysis of the fracture surface indicated that fibril loading remained low and highly localized despite this attempt to increase the loading. Figure 30 shows several SEM micrographs of the fracture surface. Appendix 11 shows the epoxy and epoxy composite stress-strain curves, which showed unusual behavior. The most significant result was the existence of fibril pullout at the fracture surface. This behavior was an indication that the fibrils have the potential to behave similarly to a continuous fiber reinforcements in a composite. 

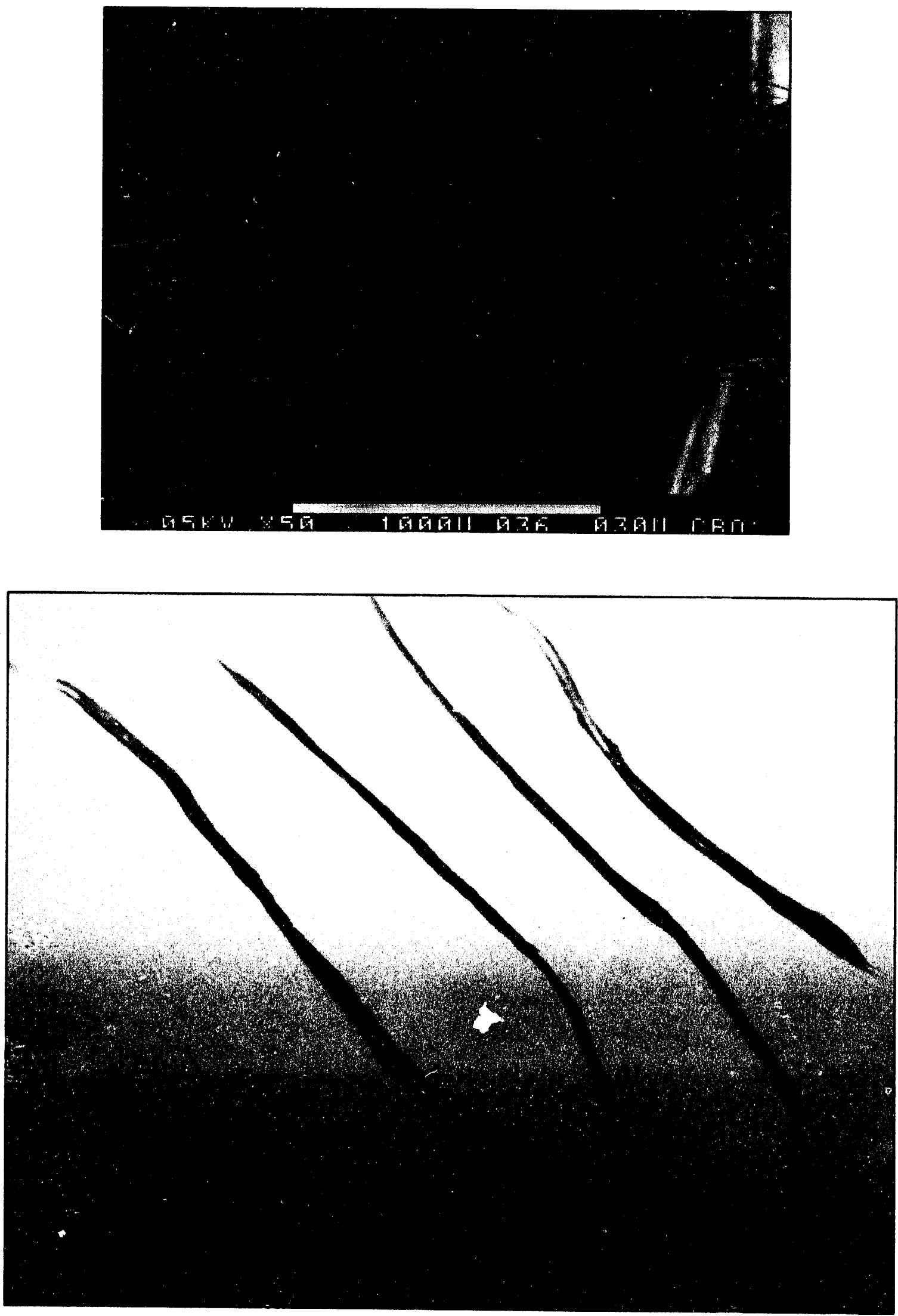

Figure 29 Hand-Formed SiC Fibril Tows 

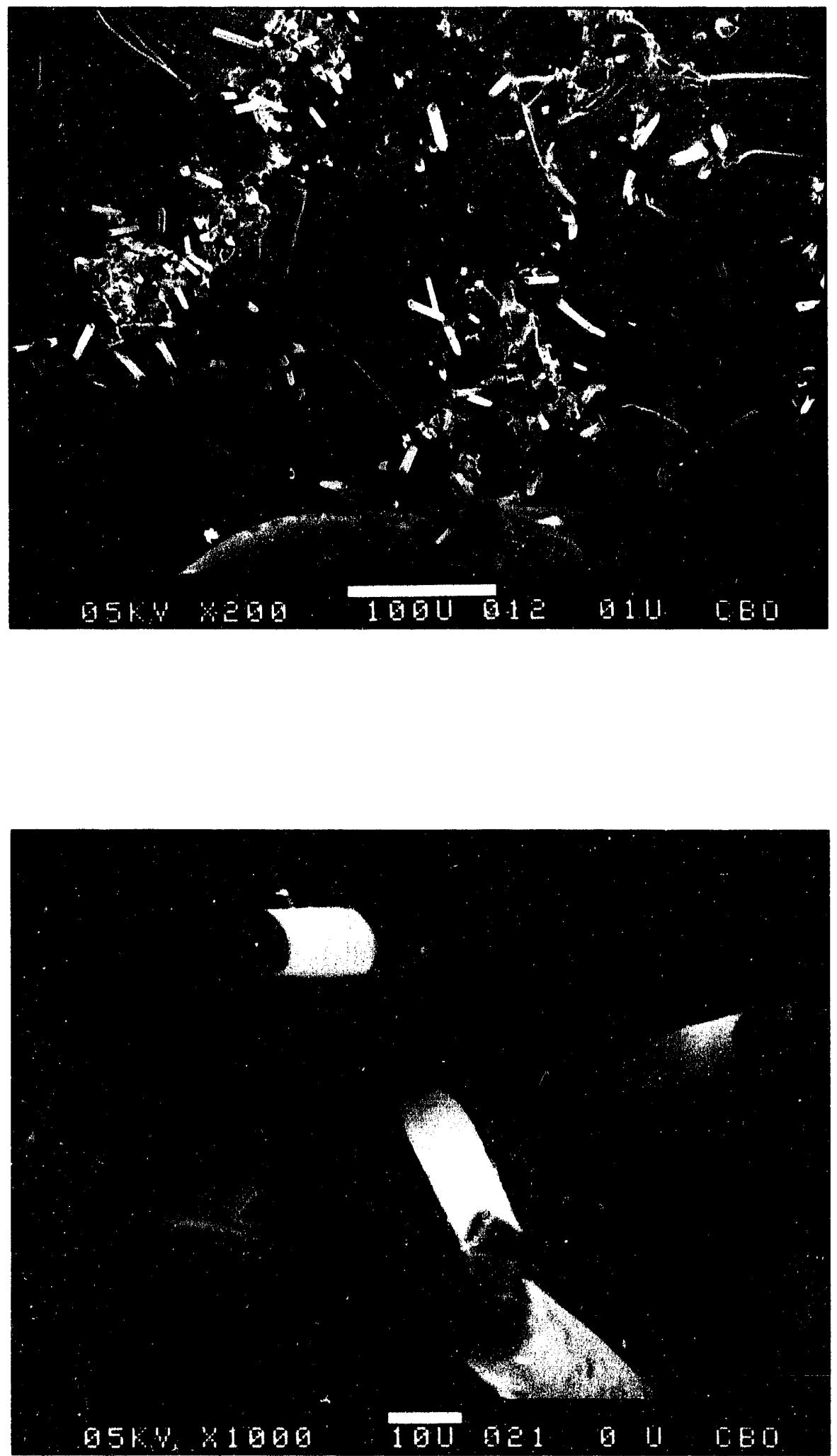

Figure 30 Fracture Surface of Epoxy-Fibril Composites 


\subsection{Ceramic Matrix Composites}

Preliminary ceramic matrix composite fabrication experiments were performed to evaluate the behavior of fibril tows in a brittle matrix. A primary goal was to determine whether fibril tows in a ceramic matrix could demonstrate pullout similar to a continuous fiber-reinforced composite. Mullite was chosen as the matrix material since:

- other researchers have examined mullite matrix composites[28]

- hot pressing could be used to fabricate the sample

- the difference in the mullite-SiC thermal expansion coefficients should reduce matrix clamping of the reinforcement

\subsubsection{Procedure}

A commercial mullite powder was used (Aremco - Fused $1-5 \mu \mathrm{m}$ ) with a typical particle size of $1-5 \mu \mathrm{m}$. An aqueous mullite slurry was prepared by roll milling with $6-\mathrm{mm}$ alumira media. A dispersant was used to aid in the dispersion process and to improve the stability of the sluriy. Fibril tows were dipped into the slurry and placed in a circular plaster mold until the mold was filled with aligned tows. Mullite slurry was used to fill the voids between tows and within each tow. During this step, bubbles were observed evolving from the uncoated fibril tows indicating displacement of residual air by the slurry. The coated fibril tow appeared to be poorly wet by the slurry, and intrusion of the slurry into the tow voids occurred less effectively. The resulting green body was dewatered and dried in an oven at $85^{\circ} \mathrm{C}$. The dried preform was placed in a graphite hot press mold. For experiments using larger hot press molds, excess mold volume was filled with as-received mullite powder. Hot pressing conditions and green body characteristics are summarized in Table 16. Fibril loading of $1-3$ volume $\%$ were typical. No attempt was made to increase loading, since these experiments were focused on demonstrating fibril pullout.

\section{Table 16 Hot Pressing Conditions and Fibril Composite Properties}

Hot pressing conditions:

$$
\begin{aligned}
& \text { Temperature }=2023 \mathrm{~K} \\
& \text { Pressure }=11.5 \mathrm{MPa} \\
& \text { Hold time }=1.3 \text { hour }
\end{aligned}
$$

\begin{tabular}{|c|c|c|c|c|}
\hline Sample \# & Fibril Coating & $\begin{array}{c}\text { Fibril Loading } \\
(\%)\end{array}$ & $\begin{array}{c}\text { Final Density } \\
(\mathrm{g} / \mathrm{cc})\end{array}$ & $\begin{array}{c}\% \text { Theoretical } \\
\text { Density }\end{array}$ \\
\hline $1^{\mathrm{a}}$ & None & 3.0 & 3.09 & 97.7 \\
\hline 2 & None & 1.4 & 3.05 & 96.5 \\
\hline 3 & BN: $2-6 \mu \mathrm{m}$ & 2.7 & 2.99 & $94.6^{\mathrm{b}}$ \\
\hline
\end{tabular}

a - broke during demolding b - \% theoretical density does not take into account BN, actual is above $95 \%$

The densified sample was polished and cut into flexure samples. Mechanical testing was performed using four-point bend testing on a MTS Model 810 . 


\subsubsection{CVD Coating of Fibril Tows}

$1.5 \mathrm{~g}$ of fibril tow, consisting of several dozen individual tows, was coated with a BN debond coating by General Atomics (San Diego, CA). Several examples of SEM micrographs of the tow and individual coated fibrils are shown in Figure 31. The debond coating was several microns thick, ranging from $2-6 \mu \mathrm{m}$. It can be seen that individual fibrils were fully coated throughout the thickness of the tow. The coating thickness was excessive and adversely impacted the coated fibril composite. This experiment did demonstrate that hand-formed fibril tows could be coated by a CVD technique.

\subsubsection{Composite Results}

Table 16 summarizes the hot pressing experimental results. Composite samples with theoretical densities $>95 \%$ were achieved.

Figure 32 compares the mechanical behavior of the monolithic, uncoated fibril composite and coated fibril composite. Figure 33 shows the fracture surfaces of the uncoated fibril composite sample. The uncoated fibrils increased the stiffness of the sample but did not increase the overall strength. The fracture surface shows no pullout of fibrils. This was expected, since the surface of the fibrils can react with the matrix to produce strong bonding in oxide matrix composites[28]. An important result was the acceptable distribution of the mullite matrix between individual uncoated fibrils and the minimal porosity in the reinforced regions. These two observations indicate that the composite fabrication procedure has the potential to produce an acceptable composite sample.

The coated fibril composite exhibited unusual behavior. In Figure 34, the fracture surface shows that there are essentially two regions in the sample--mullite matrix and $\mathrm{BN}$ rich areas containing $\mathrm{SiC}$ fibrils. The causes for this microstructure were:

- excessive BN coating thickness

- poor intrusion of the mullite slip between the coated fibrils

The overall result was that the $\mathrm{BN}$ regions acted like thick weak rods and probably led to the lower strength and stiffness observed for the coated fibril composite.

Recommendations for future composite fabrication experiments include:

- fabrication of a mullite CMC using fibrils with a thinner debond coating

- modification of the mullite powder slurry formulation to improve the wetting of the BN coated fibrils 

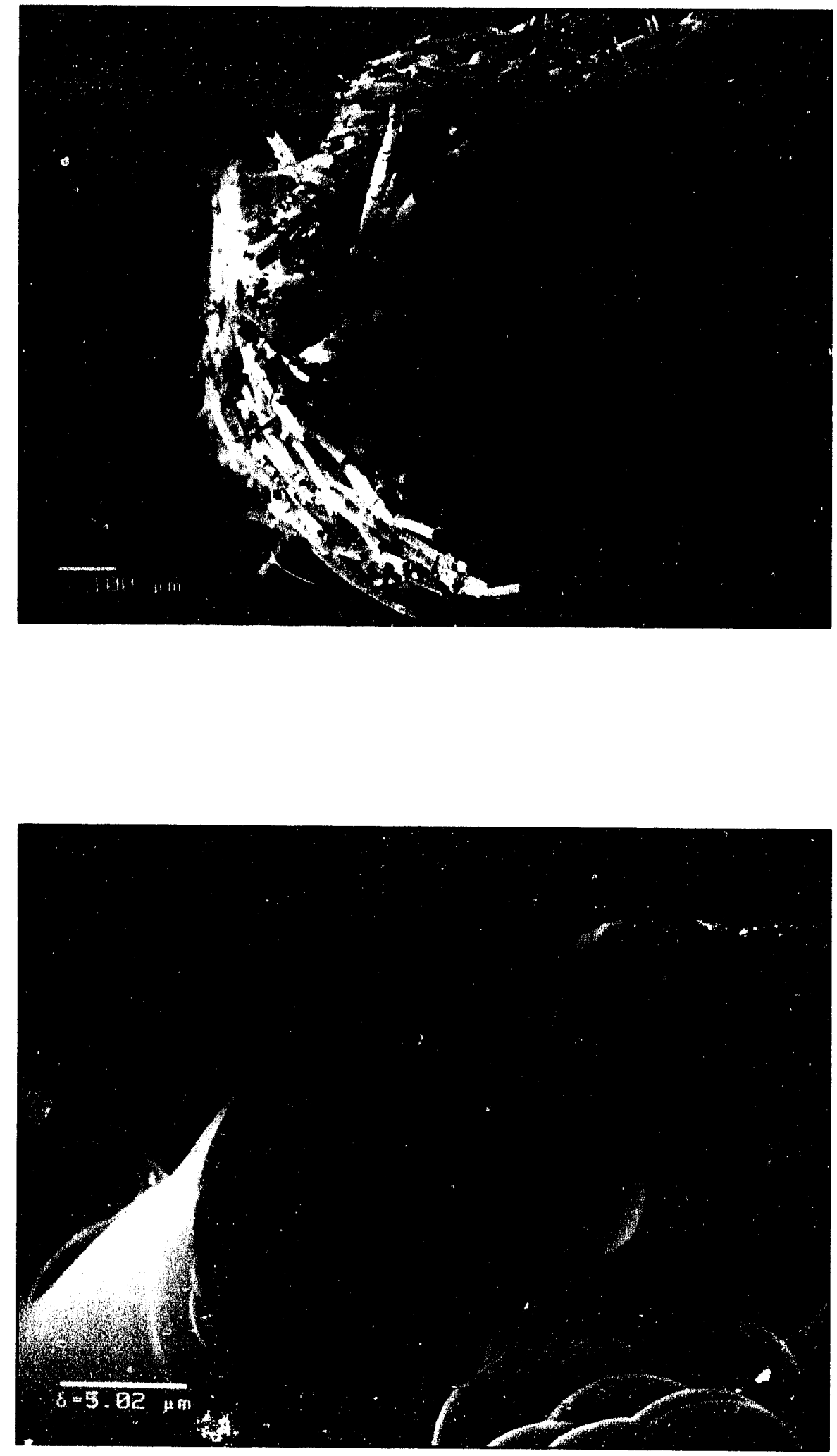

Figure 31 SiC Fibril Tows with BN Debond Coating 
63

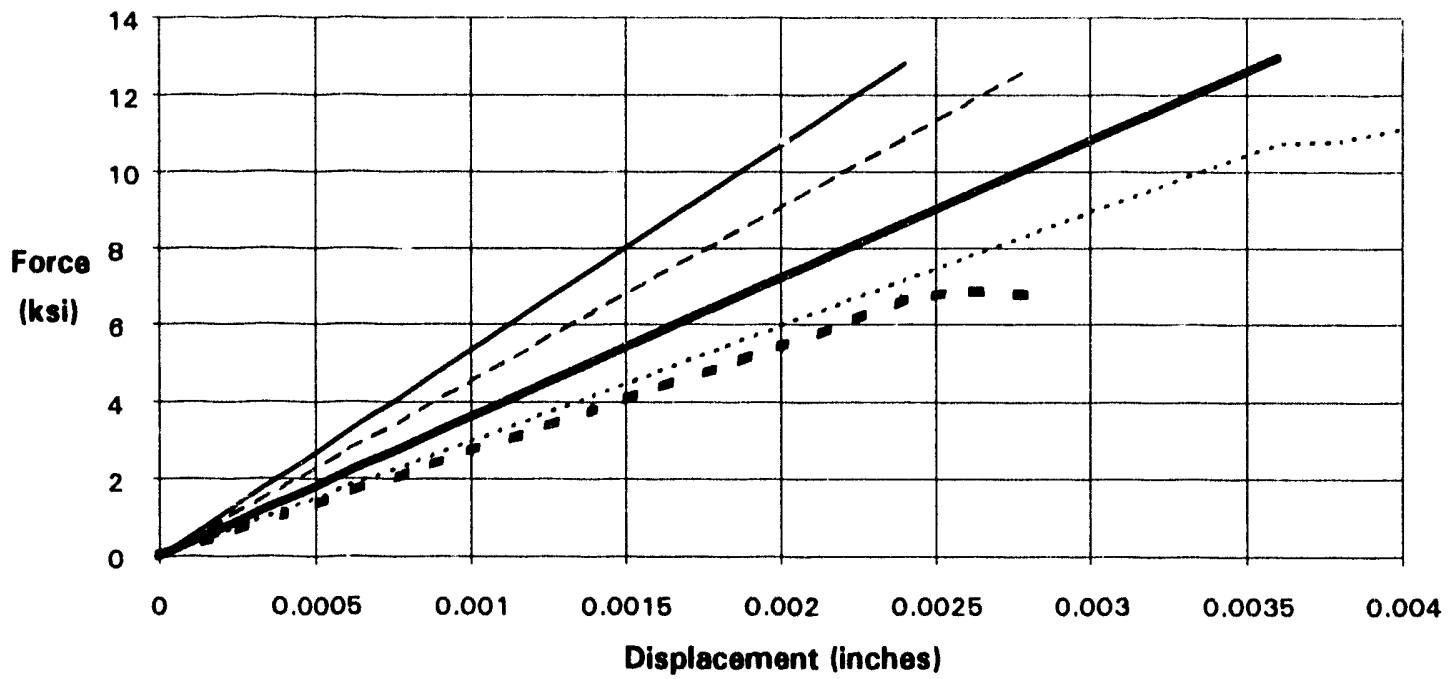

Mullite Uncosted - - - Uncoated a - Coated $\cdots$-... Coated

Figure 32 Four-Point Bend Testing Results on Monolithic Mullite and Fibril-Reinforced Mullite Composites Fabricated by Hot Pressing

It is felt these problems can be overcome with a more intensive effort directed toward coating the fibrils and consolidation of the composite. 

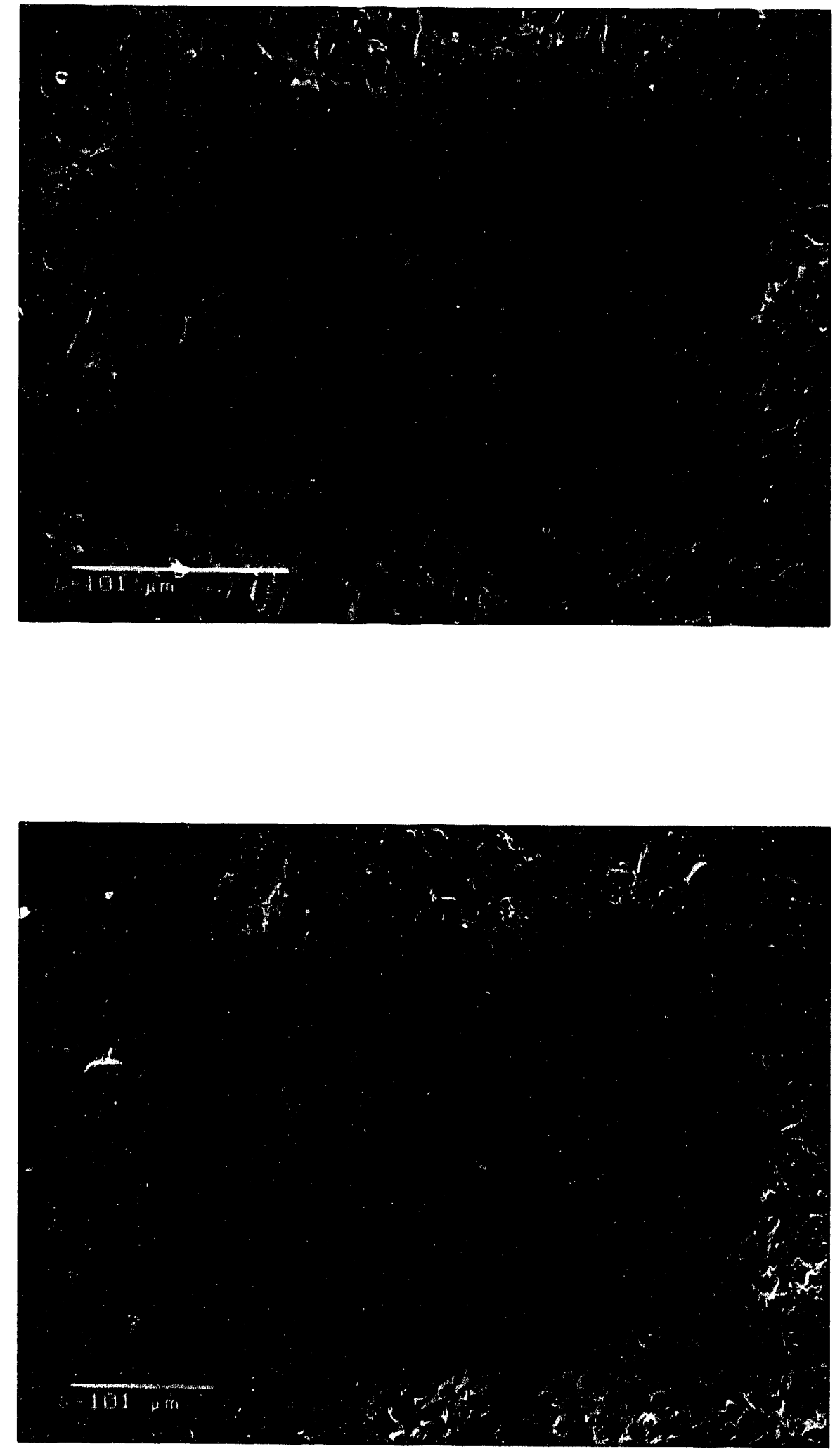

Figure 33 Fracture Surface of Uncoated Fibril Composite 

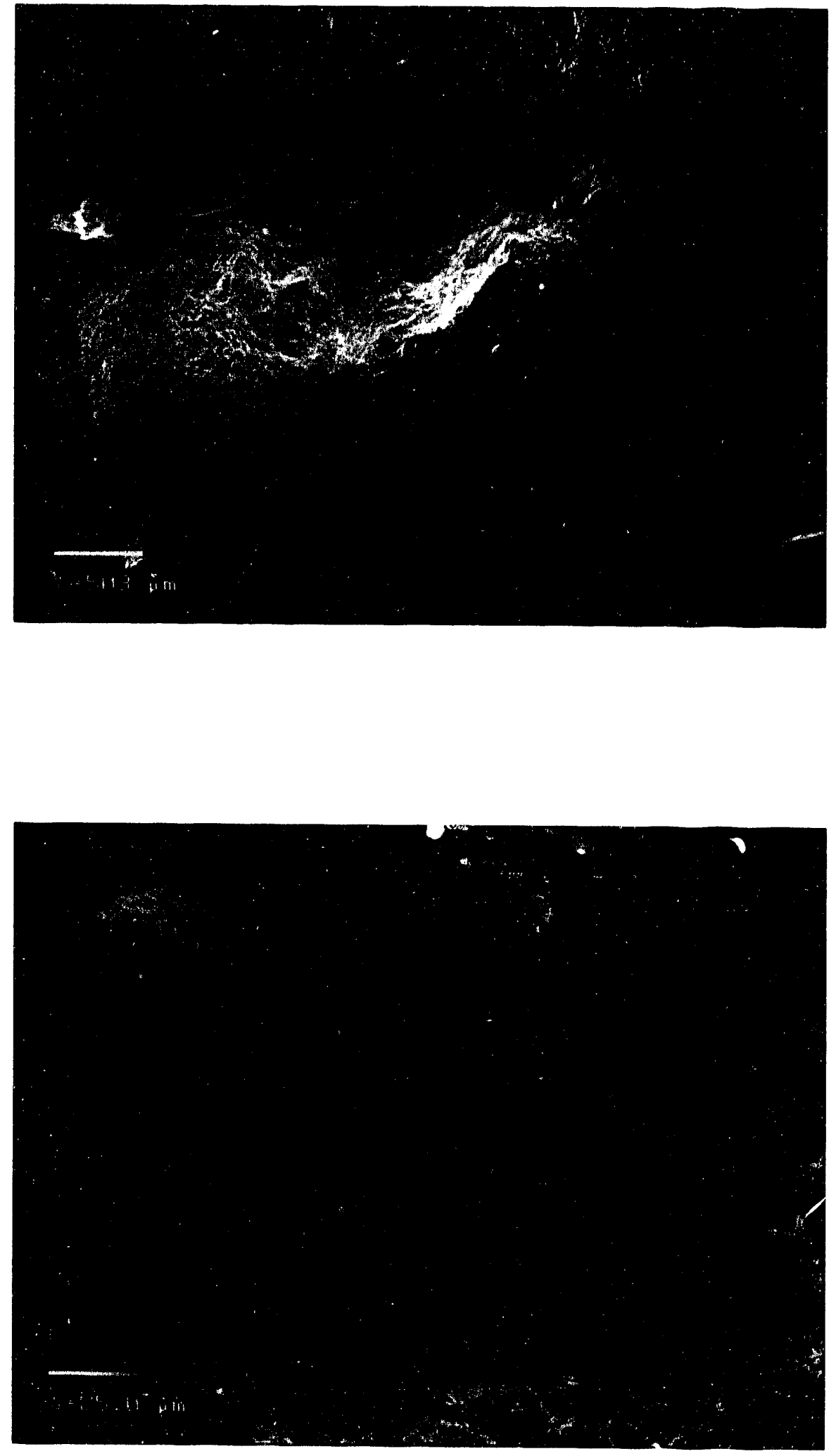

Figure 34 Fracture Surface of Coated Fibril Composite 


\section{Conclusions}

The Carborundum development reactor was used to obtain critical synthesis process scaleup data. The fibril growth rate was limited by the supply of $\mathrm{CH}_{4}$ and $\mathrm{SiO}$. Methane supply was strongly influenced by the decomposition of methane under typical process conditions. SiO was formed in-situ at locations through the reactor height via the carbothermal reduction of silica by carbon. The differences in the $\mathrm{CH}_{4}$ and $\mathrm{SiO}$ supply characteristics resulted in wide variations in the process gas composition as a function of height. The process gas composition was carbon rich in the bottom half of the reactor and silicon rich in the top half. Acceptable fibril growth rates and morphologies can be achieved throughout the reactor despite these variations. Average fibril growth rates up to $0.65 \mathrm{mg} / \mathrm{cm}^{2} /$ hour were achieved for the entire reactor. Primarily needle-like product was grown at these process conditions. Growth rates as high as $1 \mathrm{mg} / \mathrm{cm}^{2} /$ hour were achieved in the bottom half of the reactor during the growth portion of the cycle. Even higher growth rates were possible with higher methane partial pressures but the product characteristics were considerably poorer.

Important variables in the synthesis process were identified and evaluated. Time-series experiments confirmed that the growth process consisted of two stages: a nucleation period followed by steady-state growth period. Fibril nucleation and growth rates were affected by temperature, methane partial pressure, process gas flow rate, process gas composition, and catalyst chemistry/concentration. Kinetic expressions were obtained for $\mathrm{SiO}$ formation, $\mathrm{CH}_{4}$ decomposition, and $\mathrm{SiC}$ fibril formation.

Scaleup data obtained in the development reactor have been consolidated in the form of a computer simulation model. The model will eventually serve as the basis for scaleup reactor design and development. It correctly predicted trends in the fibril growth rates as a function of process conditions using rate constants obtained by experiment. The model will be useful for predicting reactor performance upon completion of model confirmation.

A process gas recycle system was demonstrated. SiC fibrils were successfully grown using a recycle ratio of $80 \%$. The preliminary experiments did not indicate any fundamental limitations in the recycle process concept. Use of recycled gas produced similar growth rates and fibril characteristics to the baseline process.

Harvesting and beneficiation process development identified several process steps for postprocessing of fibrils. Chemical leaching removed trace impurities without visibly attacking the fibril surface. Air harvesting appeared to be the best postprocessing step for harvesting long fibril product for use in yarn forming. Wet screening processes appear viable tor the beneficiation of medium-length and short fibrils.

Extensive fibril characterization was performed. This task focused on developing techniques to evaluate the effect of synthesis process conditions on fibril product characteristics. A procedure for analyzing fibril diameter distribution was used to identify baseline fibril diameter characteristics and strategies for improving diameter control. 
Several techniques were examined for evaluating fibril length. Single fiber composite testing was performed as an alternative to single fiber tensile testing for obtaining $\mathrm{SiC}$ fibril tensile strengths. The results of this test confirmed the extremely high strength of the VLS fibril-tensile strengths of 6 - $9 \mathrm{GPa}$ were measured for a $2.54 \mathrm{~cm}$ gauge length.

An important result of the fibril characterization effort has been to show that the fibril diameter is a function of both synthesis and postprocessing conditions. Modification of the synthesis conditions has led to substantial reductions in the fraction of small diameter fibrils. These techniques will be crucial for guiding future attempts at improving the fibril diameter through reduction in the fraction of small diameter product.

There are several aspects to consider relative to the possible health issues of small diameter, respirable VLS fibrils. The respirable fibrils are produced as a by-product of the fibril growth process. Process improvements have reduced the fraction of fibrils with a diameter below $3 \mu \mathrm{m}$ to less than $1 \%$ by weight. The utilization of proper engineering controls and work practices has been shown to limit exposures to concentrations less than those set for other respirable ceramic fibers. In addition, once the fibrils are incorporated in a dense matrix, the risk of airborne exposure to fibers is further minimized.

Preliminary composite evaluation was performed using hand-formed tows developed during this program. Epoxy and mullite matrix composites containing $\mathrm{SiC}$ fibrils were fabricated. The experiments showed two important results. Fibril pullout was observed in epoxy matrix composites, which indicates a potential for fibrils to act like a continuous reinforcement in composite applications. The mullite matrix composite showed that consolidation and intrusion of the matrix material in between individual fibrils was feasible. The coated fibril composite exhibited an unusual microstructure due to an excessively thick BN-debond coating and poorer wetting of the coating by the mullite slurry during green body fabrication. No fibril pullout was observed in the mullite matrix composite. 


\section{Acknowledgments}

The authors gratefully acknowledge the following individuals who made the successful completion of this program possible:

Project co-workers Jonathan Kim, Steve Chwastiak and G. DeMunda.

George Glijer, Mike Heath, Andy Park, and Wendy Kline of Carborundum for their efforts in performing and analyzing the experiments.

Steve Lacki of Carborundum for his SEM analysis of SiC fibrils.

Bora Mikic (MIT) and Iain Sommerville (University of Toronto) for their helpful suggestions and aid in interpreting the results of the program.

Jim Olson and Carborundum's Fibers Division for the use of their diameter analysis equipment.

Mike Manka and Chris Hawkins of BP Research for their useful discussions on the simulation model development and insight into the methane decomposition reaction.

Nancy Cole and Ernie Loing of DOE/ORNL for their support and encouragement throughout this program.

Larry Allard at the HTML for his analysis of SiC fibrils by SEM and TEM.

Rich McCormick and the MER Corporation for their work in evaluating the feasibility of adapting their whisker synthesis process for the growth of long fibrils. 


\section{References}

1. Bootsma, G. A., W. F. Knippenberg, and G. Verspui, J. Crystal Growth, 11, pp. 297 - 309 (1971).

2. Shyne, J., J.V. Milewski, R. G. Shaver, and A. L. Cunningham, "Development of Processes for the Production of High-Quality, Long-Length SiC Whiskers," AFML-TR-67-402 (1968).

3. Morscher, G. N. and J. A. DiCarlo, "A Simple Test for Thermomechanical Evaluation of Ceramic Fibers," J. Am. Cer. Soc., 75 [1], pp 136 -140 (1992).

4. Shalek, P. D., D.E. Christiansen, F.D. Gac, R.E. Honnell, G.F. Hurley, J.D. Katz, W.J. Parkinson, J.J. Petrovic, and D.S. Phillips, "Scale-up and Optimization of the VLS Growth Process for Beta-SiC Whiskers for the Period April 1982 - September 1989," DARPA Final Report \& DOE/OAR\&TD Topical Report, Los Alamos National Laboratory Report \# LA12119 (1992).

5. Gac, F.D., "Synthesis and Characterization of VLS Silicon Carbide Whisker Reinforced Reaction Bonded Silicon Nitride," Ph.D. Thesis, University of Washington (1989).

6. Rhodes, J. F. and H. M. Rootare, "Engineering Scale Development of VLS Whiskers," First Annual Report, October 1983 - September 1984 (1985).

7. Hollar, W.E. and J. J. Kim, "Review of VLS Whisker Growth Technology," Ceram. Eng. \& Sci. Proc., 12 [7-8], pp 979 - 991 (1991).

8. McCarthy, B. E., "Parameters Affecting Vapor-Liquid-Solid Growth of SiC Whiskers at $1450^{\circ} \mathrm{C}$," M.S. Thesis, MIT (1988).

9. Biernacki, J., "Formation of Silicon Monoxide and Application to the Growth of VaporLiquid-Solid Silicon Carbide Whiskers," Ph.D. Dissertation, Cleveland State University (1987).

10. Christiansen, D. E. and B. Van Eeckhout, Chem. Eng. Prog., 84, pp 18 - 22 (1988).

11. Fox, J. R. and D. A. White, "VLS Fiber Growth Process," U.S. Patent 4,911,781, March 1990.

12. Hollar, W. E., J. J. Kim, and W. H. Mills, "Engineering Scale Development of the VaporLiquid-Solid (VLS) Process for the Production of SiC Whiskers," Proceedings of the Fifth Annual Conference on Fossil Energy Materials, ORNL-FMP-91/1 (1991).

13. Manka, M., Personal Communication (1992).

14. Shalek, P. D., J. D. Katz, and G. F. Hurley, "Prealloyed Catalyst for Growing Silicon Carbide Whiskers," U.S. Patent No. 4,789,537, December 1988.

15. Shalek, P. D., "Process for Growing Silicon Carbide Whiskers by Undercooling," U.S. Patent No. 4,702,901, October 1987. 
16. Levenspiel, O., Chemical Reaction Engineering, John Wiley \& Sons, New York (1972).

17. Doehlert, D., Experimental Strategies for Process Variables, Edgeworks Inc., Seattle, WA (1988).

18. Milewski, J. V., F. D. Gac, J. J. Petrovic, and S. R. Skaggs, "Growth of Beta-Silicon Carbide Whiskers by the VLS Process," J. Mat. Sci., 20, pp 1160 - 1166 (1985).

19. Hollar, W. E. and J. D. Katz, "The Iron Sol Method of Catalyst Application for VLS SiC Whisker Process," Technical Report, Standard Oil Engineered Materials (1987).

20. Shalek, P. D., "Whisker Reinforced Structural Ceramics," Semi-annual Report for the Period April '87- September '87.

21. Rosten, H. I. and Spalding, D. B., The PHOENICS Reference Manual, CHAM Ltd., Wimbledon, England, TR/200, Oct. 1987.

22. Hollar, W.E., Unpublished results, (1989).

23. Perry, R.H. and C.H. Chilton, Chemical Engineers' Handbook, 5th Edition, Chapter 8, p 8-3, McGraw-Hill Book Co., New York, (1973).

24. Milewski, J. V., "The Combined Packing of Rods and Spheres in Reinforcing Plastics," Ind. Eng. Chem. Prod. Res. Dev., 17 [4], pp 363 - 366 (1978).

25. Starr, T. L., "Packing Density of Fiber/Powder Blends," Cer. Bull., 65 [9], pp 1293 - 1296 (1986).

26. Petrovic, J. J., J. V. Milewski, D. L. Rohr, and F. D. Gac, "Tensile Mechanical Properties of SiC Whiskers," J. Mat. Sci., 20, 1167 - 1177 (1985).

27. Netravali, A. N., L. T. T. Topoleski, W. H. Sachse, and S. L. Phoenix, "An Acoustic Emission Detection Technique for Measuring Fiber Fragment Length Distributions in the Single-Fiber-Composite Test," Comp. Sci. and Tech., 35, 13 - 29 (1989).

28. Becher, P. F., C-H Hsueh, P. Angelini, and T. N. Tiegs, "Toughening Behavior in WhiskerReinforced Ceramic Matrix Composites," J. Am. Cer. Soc., 71 [12], pp 1050 - 1061 (1988).

29. Curtin, W. A., "Fiber Strength Determination Using the Single Fiber Composite Test," presented at the 17th Annual Conference on Composites and Advanced Ceramics, Cocoa Beach, FL, January 12, 1993.

30. McCormick, R., "Feasibility of Adapting MER Whisker Technology to Produce Long SiC Whiskers, "Project Final Report, December 1992. 


\section{Appendix 1 Correction Procedures for SiC Formation at the Generator}

SiO generation via the carbothermal reduction of silica with carbon can be complicated by the formation of $\mathrm{SiC}$ at the generator. This reaction consumes $\mathrm{SiO}$ and reduces its availability for fibril formation. Primary determination of total SiO formation can be obtained from the weight loss of the individual generators[4]. Correction for the $\mathrm{SiC}$ formation at the brick represents an improved estimate of the $\mathrm{SiO}$ generation term[9]. The relative rates of the SiO formation and $\mathrm{SiO}$ consumption have not been well characterized.

In this program, two methodologies were developed for correcting the SiO generation rates for $\mathrm{SiC}$ formation. Both are based on the assumed reaction:

$$
\mathrm{SiO}(\mathrm{g})+2 \mathrm{C}(\mathrm{s})=\mathrm{SiC}(\mathrm{s})+\mathrm{CO}(\mathrm{g})(\mathrm{A}-1)
$$

Method 1 was based on gas chromatography measurement of the evolved $\mathrm{CO}$ (i.e., $\mathrm{CO}$ in excess of the process gas supply), which arises from three sources--SiC fibril formation, SiO formation and $\mathrm{SiC}$ formation at the brick. Figure A-1.1 shows the contributions to the evolved $\mathrm{CO}$ curve. The generator-evolved $\mathrm{CO}$ was obtained by integrating the total $\mathrm{CO}$ evolution and subtracting the contribution of the fibril formation reaction. The corrected $\mathrm{SiO}$ was then calculated using the assumption that the total generator weight loss was equal to the evolved mass of SiO and CO. This technique was most accurate with slow flow rates and high side reaction rates (cases where large amounts of $\mathrm{CO}$ evolution were evolved).

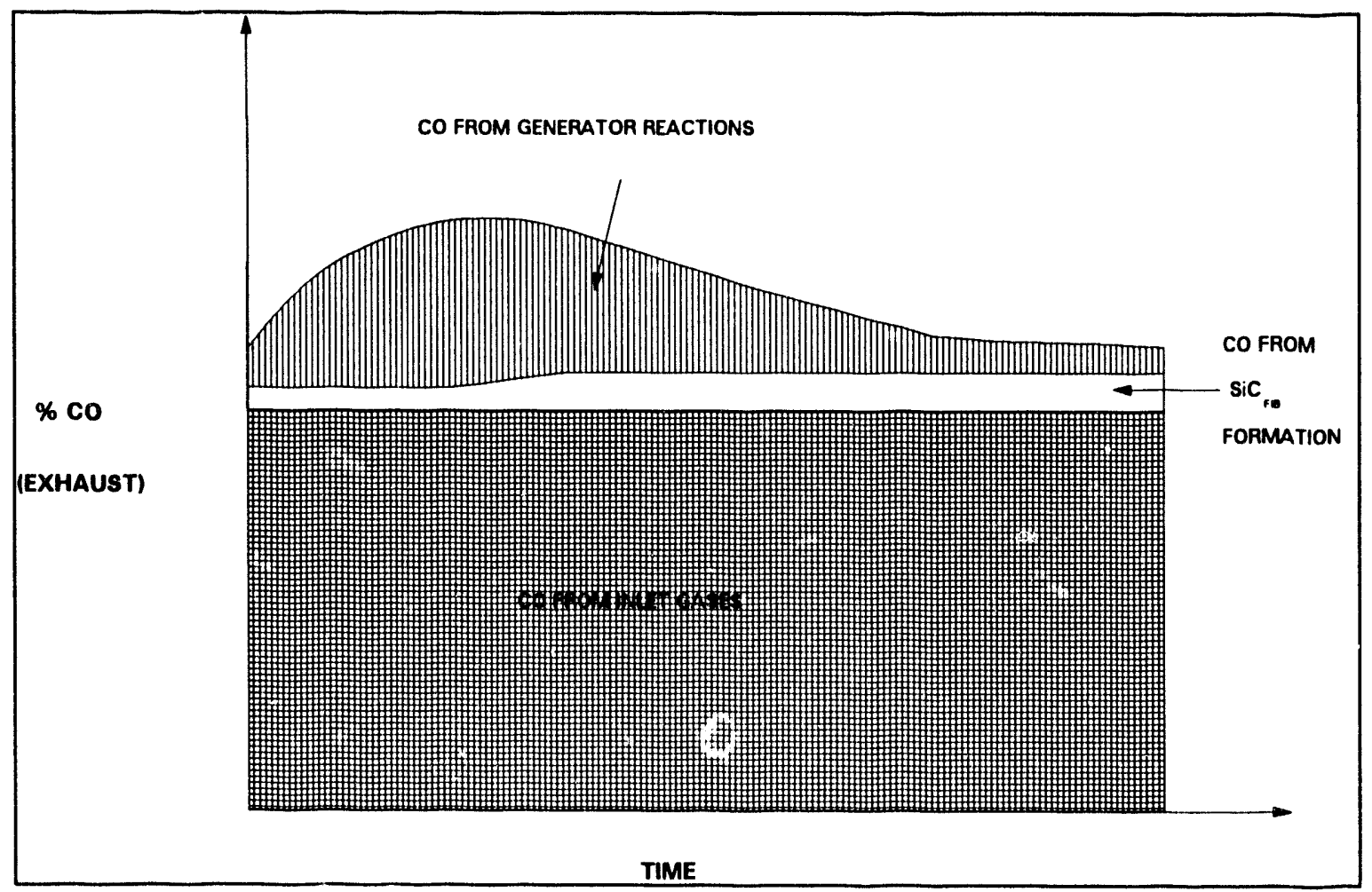

Figure A-1.1 CO Evolution During Fibril Growth Experiment 
There are several potential limitations with this technique. One limitation with this methodology was that it lumped the correction factors of the individual generators into a single correction. Another limitation was that the technique's accuracy decreased with increases in the process gas flow rate.

The stoichiometry of the $\mathrm{SiO}$ generation reaction provides a different route for measuring corrected total SiO formation. An approach was developed based on a simplified version of the experimental approach used by Biernacki[9]. In this approach the total and free carbon of the reacted generator were analyzed. Total carbon was contributed by the unreacted generator carbon and the carbon contained in the SiC. The free carbon measurement determined the amount of unreacted generator carbon. The combination of these measurements was used to determine the relative amount of $\mathrm{SiO}$ consumed by $\mathrm{SiC}$ formation at the generator. The method was less sensitive to the limitations of the first method but represented only an endpoint measurement.

Figure A-1.2 shows the spreadsheet calculation using the $\mathrm{CO}$ correction method. As described above, this approach used numerical integration of the $\mathrm{CO}$ by trapezoidal rule followed by subtraction of $\mathrm{CO}$ from known sources (process gas and $\mathrm{SiC}$ fibril formation). The remainder was assumed to be the $\mathrm{CO}$ formed by the $\mathrm{SiO}$ and $\mathrm{SiC}$ formation reactions at the generator and was subtracted from the total generator weight loss.

Table A-1.1 summarizes the corrected total $\mathrm{SiO}$ as a function of temperature. It c.in be seen that the ratio of $\mathrm{SiO}$ evolved (based on $\mathrm{GC}$ analysis) to $\mathrm{SiO}$ evolved (based on the generator weight loss) was 0.6 to 0.7 over the temperature range of $1673 \mathrm{~K}-1723 \mathrm{~K}$. This range was similar to the trend from generator carbon analy loss by up to $40 \%$. This correction $\mathrm{f}_{\bar{c}} \quad$ ed relatively constant over the temperature range used in this study $(1673 \mathrm{~K}-1723 \mathrm{~K})$. ᄂ... of the generator weight loss to predict trends in the SiO supply was a reasonable approximation, with the urderstanding that the weight loss calculation represented the maximum amount of $\mathrm{SiO}$ formed.

Table A-1.1 Corrected SiO Generation by CO Evolution

\begin{tabular}{|c|c|c|c|}
\hline $\begin{array}{c}\text { Temperature } \\
(\mathrm{K})\end{array}$ & $\begin{array}{c}\text { Run Time } \\
(\mathrm{min})\end{array}$ & $\begin{array}{c}\text { Moles SiO } \\
\text { (weight loss) }\end{array}$ & $\begin{array}{c}\text { Moles SiO } \\
\text { (corrected by CO) }\end{array}$ \\
\hline 1653 & 373 & 0.44 & 0.43 \\
\hline 1673 & 444 & 0.79 & 0.47 \\
\hline 1698 & 399 & 1.09 & 0.61 \\
\hline 1723 & 442 & 1.30 & 0.86 \\
\hline 1748 & 436 & 1.85 & 0.78 \\
\hline
\end{tabular}




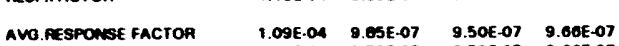

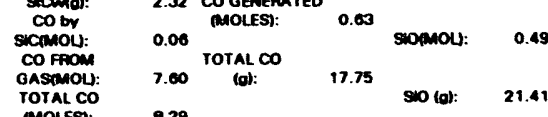

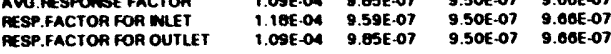

8.29

EXMAI : GAS:

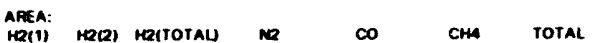

COMPOSTITON:

\begin{tabular}{lll}
$70.05 \times$ & 20.378 \\
$70.53 \times$ & $25.56 \%$ \\
$70.51 \%$ & 25.200 \\
\hline
\end{tabular}

CO CA TOTAL

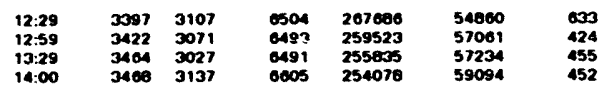

AVA.AAEA 34383000

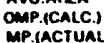

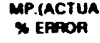

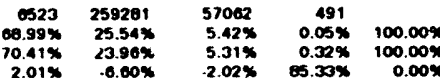

CORRECTED CO OAS: $\quad 5.02 \times$ apert

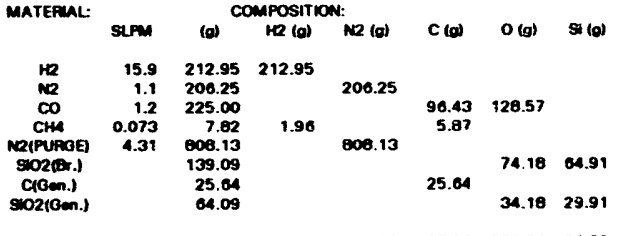

TOTAL $\quad \begin{array}{llllll}1008.97 & 214.90 & 1014.30 & 127.93 & 230.94 & 94.98\end{array}$

outpur

MATEFanL

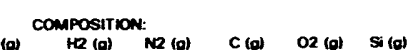

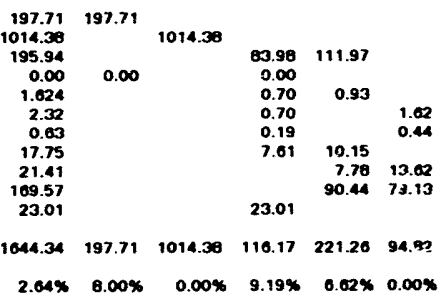




\section{A-4}

Table A-1.2 summarizes the effect of process conditions on generator carbon chemistry for a range of process conditions. These measurements confirmed the presence of $\mathrm{SiC}$ formation at the generator. A covering of small diameter VS type whisker growths on the generator surface was typically observed and probably contributed to the generator $\mathrm{SiC}$. These growths occurred under most process conditions. This correction procedure confirmed trends from the $\mathrm{GC}$ analysis.

Corrections based on the chemical analysis procedure were of a similar order of magnitude to the corrections based on the $\mathrm{GC}$ analysis procedure.

Table A-1.2 Effect of Process Conditions on Corrected SiO by Generator Chemical Analysis

\begin{tabular}{|c|c|c|c|c|c|c|c|}
\hline $\begin{array}{c}\text { Temp. } \\
\left({ }^{\circ} \mathrm{C}\right)\end{array}$ & $\begin{array}{c}\text { Generator } \\
\text { Location }\end{array}$ & Mixing & $\begin{array}{c}\text { Flow Rate } \\
(\text { slpm })\end{array}$ & $\begin{array}{c}\text { Gas } \\
\text { Comp. }\end{array}$ & Total C & Free C & $\begin{array}{c}\text { SiOc/ } \\
\text { SiOwt }\end{array}$ \\
\hline 1425 & Top & Standard & 18 & $\begin{array}{c}\text { Initial } \\
\text { baseline }\end{array}$ & 2.51 & 2.01 & 0.50 \\
\hline 1475 & Top & $"$ & 18 & $"$ & 1.60 & 0.15 & 0.72 \\
\hline 1450 & Top & Osc. & 18 & $"$ & 1.02 & 0.16 & 0.65 \\
\hline 1450 & Top & $"$ & 27 & " & 0.89 & 0.43 & 0.77 \\
\hline 1425 & Bottom & $"$ & 27 & $\begin{array}{c}\text { Final } \\
\text { baseline }\end{array}$ & 4.57 & 3.57 & 0.88 \\
\hline 1425 & next & $"$ & 27 & " & 3.28 & 2.58 & 0.82 \\
\hline 1425 & Middle & $"$ & 27 & $"$ & 2.86 & 2.05 & 0.71 \\
\hline 1425 & next & $"$ & 27 & $"$ & 2.55 & 1.96 & 0.57 \\
\hline 1425 & Top & $"$ & 27 & " & 3.33 & 2.58 & 0.52 \\
\hline
\end{tabular}

$1-7.6 \% \mathrm{~N}_{2}$

$2-15.0 \% \mathrm{~N}_{2}$ 


\section{Appendix 2 Methane Decomposition Kinetic Measurements}

Early model predictions indicated that the growth rate profiles could not be explained using the supply rates of $\mathrm{SiO}$ and $\mathrm{CH}_{4}$. There was also experimental evidence of methane disappearance in the exhaust stream above $1373 \mathrm{~K}$. These two results indicated the possibility that a methane decomposition reaction was occurring and impacting the methane supply to the reactor. Experiments were performed in which the disappearance rate of methane was evaluated as a function of temperature, flow rate, inlet methane partial pressure, and process gas composition.

Inlet and exhaust gas compositions were measured under typical synthesis process conditions. $\mathrm{SiO}$ generators were not included during these experiments to allow decoupling of the methane disappearance reaction from $\mathrm{SiO}$ and $\mathrm{SiC}$ fibril formation reactions. A spreadsheet was developed to calculate the fractional conversion of the methane as a function of the process conditions.

A kinetic equation for methane decomposition was analyzed using standard analysis procedures for integer order, homogenous gas phase reactions[16]. Methane decomposition data were evaluated assuming zero, first, and second order kinetic expressions. Figure A-2.1 illustrates the results. Both first and second order expressions gave similar correlation coefficients (around 0.82 ). The first order kinetic expression was chosen since it produced lower scatter than the second order equation and agrees with results measured by other researchers[13]. A first order kinetic equation provided a sufficiently accurate expression for the simulation model. Simulation model predictions of growth rate versus height and the effect of process gas flow rate improved with the addition of this mechanism.

Rate constants were calculated from methane conversions obtained at the baseline flow rate of $27 \mathrm{slpm}$ for a range of temperatures and process gas compositions. Temperature and gas composition had significant effects on the decomposition rate constants. The effect of nitrogen concentration and temperature on the reaction rate constant are shown in Figure A-2.2. 


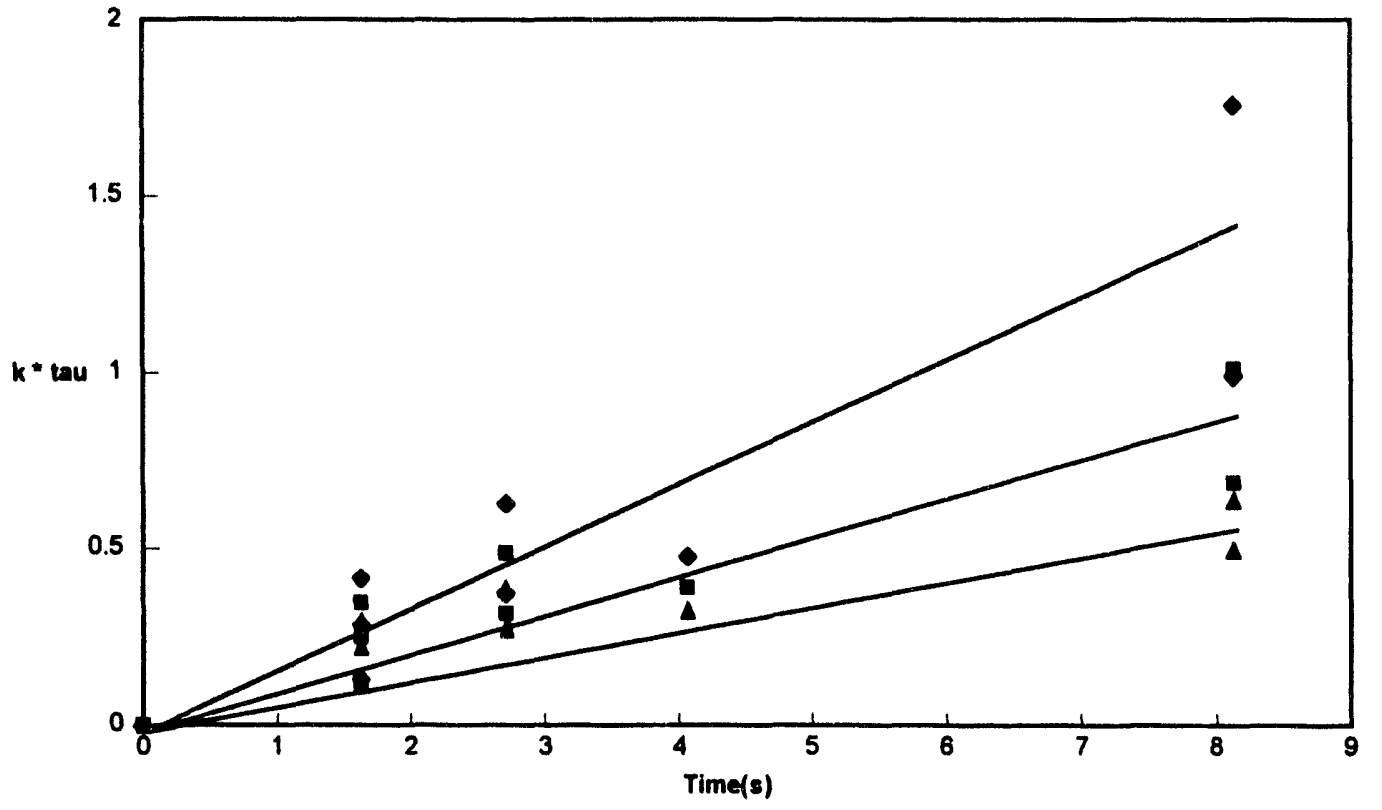

- 1st order $\quad$ 2nd order $\quad$ Oth order

Figure A-2.1 Methane Decomposition Kinetic Analysis

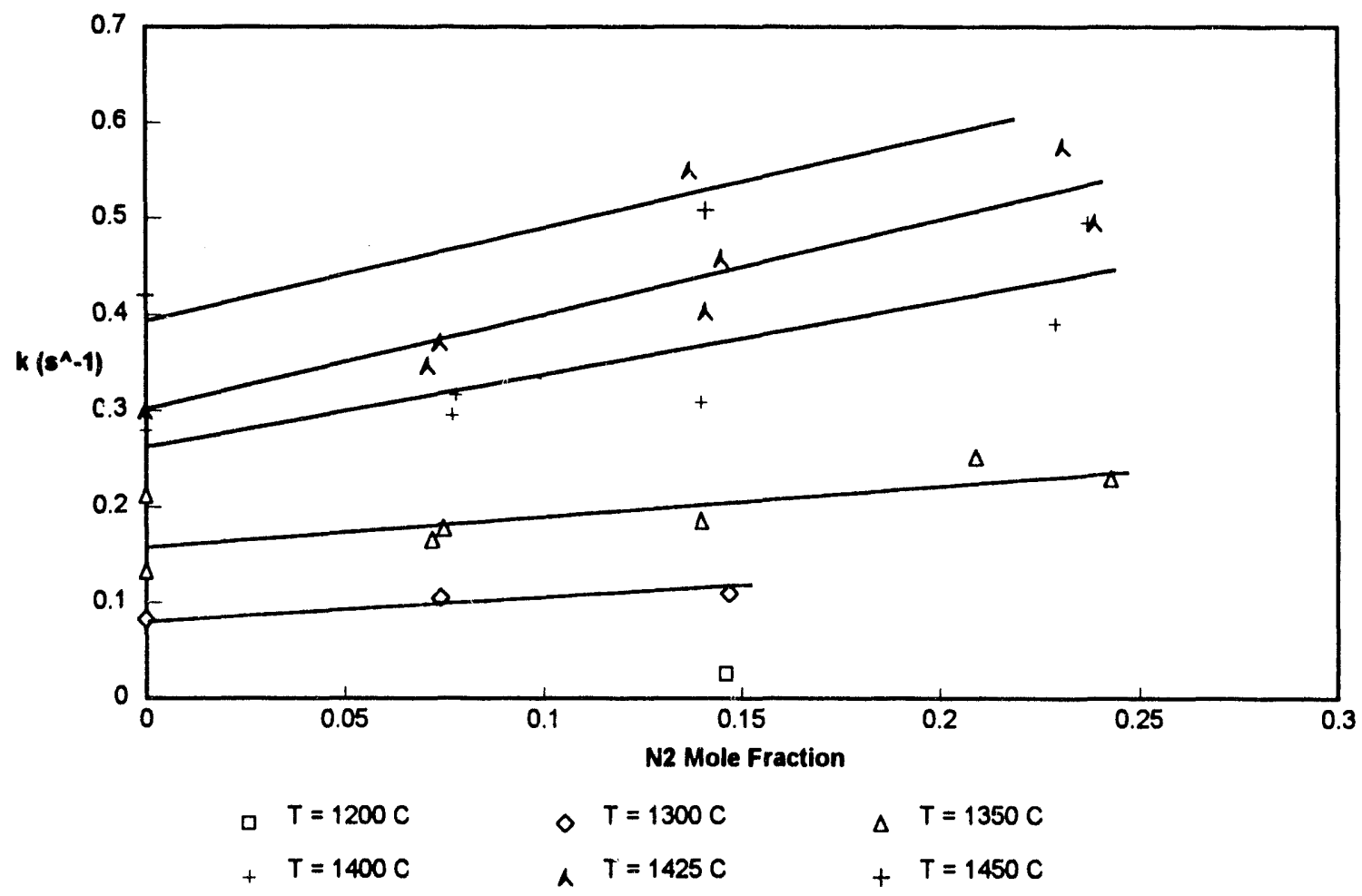

Figure A-2.2 Effect of Temperature and Process Gas Composition on Methane Decomposition Rate Constants 


\section{Appendix 3 Derivation of the Cell Model}

The cell model was developed to account for variations in the process gas composition through material balance calculations. Figure A-3.1 shows the assumed geometry of the cells. The reactor channel was divided into cells associated with individual $\mathrm{SiO}$ generators for a total of six cells. There was an inlet cell followed by five cells containing a generator site. A material balance was calculated for each cell based on the following input data:

- localized fibril growth rate

- individual generator weight loss

- methane decomposition rate constant

- inlet process gas flow rate

The average $\mathrm{SiO}$ and $\mathrm{CH}_{4}$ concentration for each cell were calculated from this data.

Figure A-3.2 shows an example of the spreadsheet calculations including input data and cell material balance results. Provisions for modifying the calculations for the SiO side consumption at the generator site were included. Preliminary data analysis assumed no side reaction at the generator. Output data included:

- total moles of each component within each cell

- reactant utilization

- total growth rate and generator weight loss

Cell model predictions of reactant concentrations were used to evaluate the kinetic equations for the $\mathrm{SiO}$ and $\mathrm{SiC}$ fibril formation reactions. The data regression procedure used the reactant concentrations from cells 2 - 5 to prevent errors caused by rapid changes in gas composition and temperature in cells 0 and 1 . This procedure also reduces the impact of reactant dispersion. The cell model was not sophisticated enough to take into account dispersion effects caused by diffusion processes, which would lead to small but significant changes in the SiO concentration at the bottom of the reactor. 


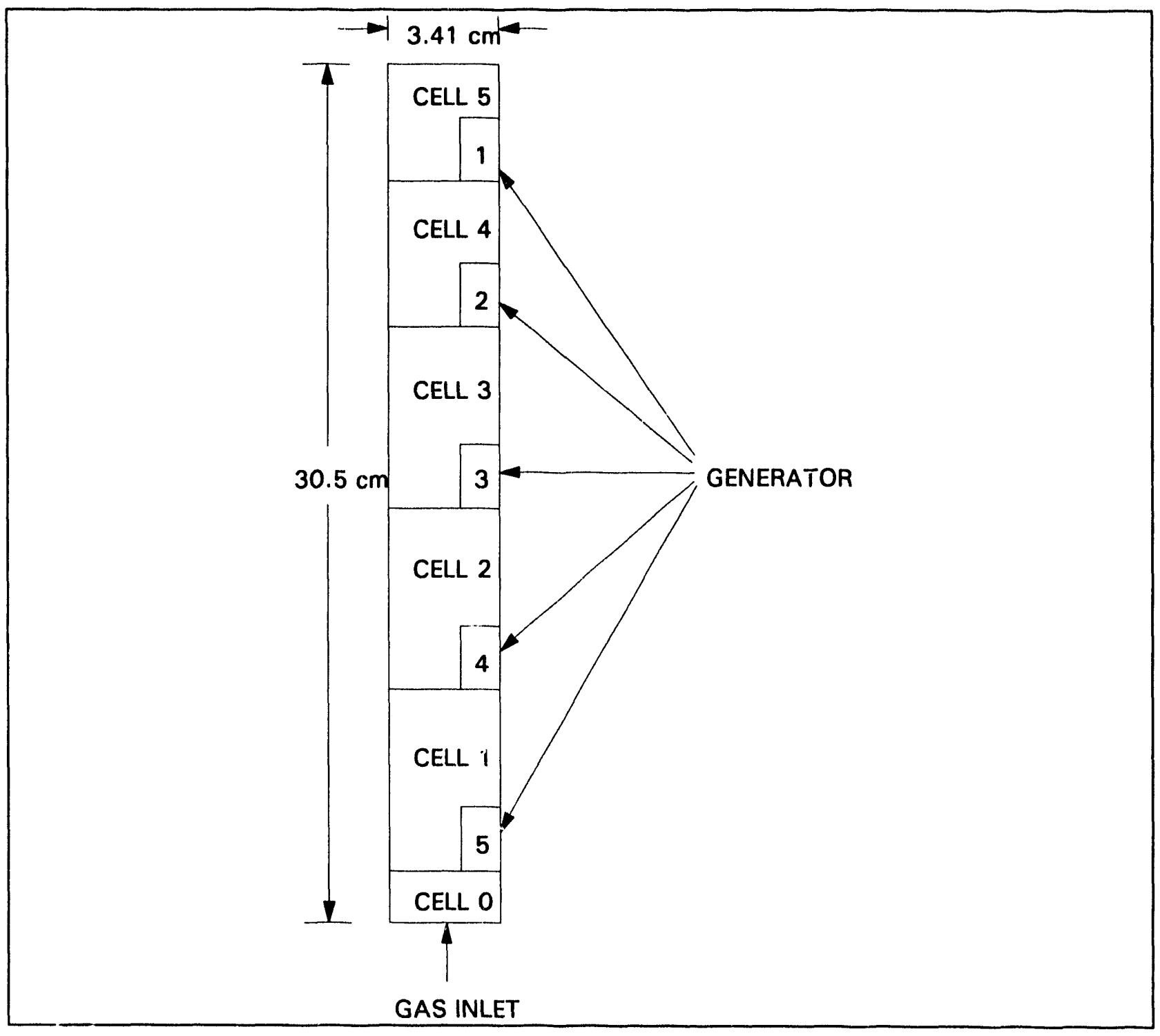

Figure A-3.1 Schematic Diagram of the Cell Model 
ExrT. 19

USES RES AS NUCLBATION RBSULT

call s:

\begin{tabular}{|c|c|c|c|c|c|c|c|c|c|c|}
\hline IN & & & & abs & & FDERL & & our & & \\
\hline ans smatas & $\operatorname{sen}$ & MOLEMaN & MOLE FR & speaks & MOLBMaN & speass & MOLBMAN & spaciss & MOLenms & MOLE \& \\
\hline HR & 3.4 & 0.201 & 0.700 & & & 브 & 0.00000 & H2 & 0.201 & $0.7 m$ \\
\hline N2 & 1.00 & 0.006 & 0.165 & & & $\sqrt{2}$ & & $\mathrm{N2}$ & $0.0 \mathrm{man}$ & 0.2060 \\
\hline$\infty$ & 0.4 & 0.0190 & 0.00 & $\infty$ & 0.00010 & $\infty$ & 0.00000 & $\infty$ & $0.00 \mathrm{n}$ & 0.000 \\
\hline $\mathrm{CH}$ & 0.01 & 0.0000 & 0.001 & $\mathrm{CH}$ & 0.00000 & $\mathrm{CHA}$ & 0.00000 & $\mathrm{CH}$ & 0.0000 & 0.0007 \\
\hline 10 & 0.01 & 0.0000 & 0.001 & 50 & 0.00010 & 10 & 0.00000 & 30 & 0.0000 & 0.0016 \\
\hline TOTAL & G.6. & 0.5007 & 1.000 & TOTAL & 0.00018 & TOTAL & 0.00000 & TOTAL & $0 . \operatorname{sen}$ & I.W \\
\hline
\end{tabular}

CEn Decomp

\begin{tabular}{|c|c|}
\hline CELI VOL (CC) & 17.10 \\
\hline RLOW (ACON) & 42060.13 \\
\hline TAU $(n$ & 0.25 \\
\hline R(DeC) $\left(8^{*}+1\right)$ & 0.40 \\
\hline $\mathrm{x}(\mathrm{CH})$ & 0.00 \\
\hline CHA (CONS) & 0.00000 \\
\hline
\end{tabular}

sOUD RXNs

\begin{tabular}{|c|c|c|c|c|c|c|}
\hline WT Lase & 3.06 & RATE (BOUD) & 0.36 & MONOM-2 HR & $\operatorname{Oos} \sin (\mathrm{Cr} y)$ & 2,20 \\
\hline sorco & 1.00 & RATB (OBN) & 0.36 & MOCOM'2.HR & mastux & $3.01 \mathrm{Bad}$ \\
\hline ZBTA & 0.00 & AREA (EOUD) & s.es & an:2 & & \\
\hline TEMP (DEO C) & 1423.00 & AREA (OBM) & 21.45 & an.2 & & \\
\hline $\operatorname{TEMP}(\boldsymbol{\alpha})$ & 1000.00 & FR(TOTAL) & 0.0004 & Gran & & \\
\hline & & PRectototal) & 0.0000 & O-MOLBEMAN & & \\
\hline
\end{tabular}

CELL 4:

\begin{tabular}{|c|c|c|c|c|c|c|c|c|c|c|}
\hline IN & & & & ENDDECON & & FPAUL & & our & & \\
\hline ans speciess & $\sin$ & MOLBMaN & MOLB $\mathrm{FR}$ & sprass & MOLBMaN & speciss & MOLEMAN & SPECABs & MOLBnaN & MOLB PR \\
\hline Ho & 3.4 & 0.2030 & 0.7805 & & & H2 & 0.00011 & HE & 0.2001 & 0.7001 \\
\hline $\mathrm{N}_{2}$ & 1.00 & 0.0046 & 0.1432 & & & $\mathrm{Nz}$ & & $N_{2}$ & 0.0006 & 0.1451 \\
\hline co & 0.4 & 0.019 & 0.0021 & $\infty$ & 0.0001 & $\infty$ & 0.00000 & co & 0.0195 & 0.0000 \\
\hline $\mathrm{CH}$ & 0.01 & 0.0004 & 0.0012 & $\mathrm{CH}$ & .0 .0001 & $\mathrm{CH}$ & .0 .00005 & $\mathrm{CF}$ & 0.0000 & 0.0000 \\
\hline so & 0.01 & 0.0003 & 0.0009 & $=0$ & 0.0001 & 10 & -0.000000 & 10 & 0.0000 & 0.0013 \\
\hline TOTAL & 6.0 & 0.3024 & 1.0000 & TOTAL & 0.0002 & TOTAL & 0.00000 & TOTAL & 0.2006 & 1.0000 \\
\hline
\end{tabular}

CWM DBCOMP

\begin{tabular}{|c|c|}
\hline YELL VOL (CO) & 259.60 \\
\hline FLOW (ACCA) & 42221.77 \\
\hline $\operatorname{TAU}(\Omega$ & 0.36 \\
\hline$K(D B C)\left(3^{*} \cdot 1\right)$ & 0.40 \\
\hline $\mathrm{X}(\mathrm{CHW})$ & 0.14 \\
\hline CHM (CONS) & 0.0001 \\
\hline
\end{tabular}

soLD RXN

\begin{tabular}{|c|c|c|c|c|c|c|}
\hline WT Loss & 4.12 & RATE (SOLD) & 0.50 & MO/CM-2-HIR & OBN AR $\left(C_{1} \cdot 2\right)$ & 20.20 \\
\hline 10,100 & 1.00 & RATE (OBN & 0.41 & $\operatorname{maran} \cdot 2$-HR & Mas FLUX & $4.005-04$ \\
\hline Zeta & 0.00 & ARRA (SOUD) & 210 & $\cos \cdot 2$ & & \\
\hline TEMP (DEA C) & 1425.00 & AREA (OBN) & 57.50 & con:2 & & \\
\hline TEMP $(x)$ & 1000.00 & PLE(TOTAL) & 0.0011 & aman & & \\
\hline & & FE(TOTAL) & 0.0000 & O.MOLBanaN & & \\
\hline
\end{tabular}

CELL 3:

\begin{tabular}{|c|c|c|c|c|c|c|c|c|c|c|}
\hline $\mathbf{I N}$ & & & & IEN/DACOM & & FRBRL & & OUT & & \\
\hline OAs SPBBCaBs & SLPM & MOLBMaN & MOLE FR & SPBCIES & MOLEMAN & SPBCJES & MOLRMIN & SPBCTES & MOLBMAN & MOLA Fr \\
\hline 12 & 3.4 & 0.2227 & 0.7906 & & & 102 & 0.00024 & HB & 0.2010 & 0.7000 \\
\hline $\mathrm{N2}$ & 1.00 & 0.006 & 0.1044 & & & $N_{2}$ & & $\mathrm{N2}$ & 0.000 & 0.1002 \\
\hline$\infty$ & 0.42 & 0.010 & 0.0614 & co & 0.0002 & $\infty$ & 0.00000 & $\infty$ & 0.019 & 0.0021 \\
\hline $\mathrm{CH}$ & 0.01 & 0.0000 & 0.0019 & $\mathrm{CH}$ & -0.0001 & $\mathrm{CH}$ & -0.0001 & $\mathrm{Cln}$ & 0.0004 & 0.0012 \\
\hline so & 0.00 & 0.0002 & 0.0006 & 10 & 0.0002 & 30 & -0.00006 & 10 & 0.0000 & 0.0009 \\
\hline TOTAL & 6.4 & 0.3000 & 1.0000 & TOTAL & 0.0002 & TOTAL & 0.00012 & TOTAL & 0.0074 & 1.0000 \\
\hline
\end{tabular}

CFH DBCOMP

\begin{tabular}{|c|c|c|}
\hline \multirow[t]{6}{*}{ CHW DECOMP } & \multirow{2}{*}{\multicolumn{2}{|c|}{ CBLL VOL (CO) }} \\
\hline & & \\
\hline & $\operatorname{TAU}(\Omega)$ & 0.45 \\
\hline & $K(D A C)\left(s^{\circ} \cdot 1\right)$ & 0.40 \\
\hline & $x(\mathrm{CH})$ & 0.17 \\
\hline & CH (CONS & 0.0001 \\
\hline
\end{tabular}

\begin{tabular}{|c|c|c|c|c|c|c|}
\hline wr Loss & 5.00 & RATB (SOLDD) & 0.93 & $\mathrm{MO}_{\mathrm{MOM}} \cdot \mathbf{2} \cdot \mathrm{HR}$ & OeN $\ln (\mathrm{Ca} \cdot 2)$ & 2.20 \\
\hline sorco & 1.00 & RATE (OBM) & 0.60 & MOMOM'2.HR & $\sim \operatorname{ses} \mathrm{FuXX}$ & $4.928-04$ \\
\hline ZETA & 0.00 & AREA (SOLUD) & 100.30 & $\mathrm{CM} \cdot 2$ & & \\
\hline TEMP (DBOC) & 1422.00 & AREA (OEM) & 76.10 & $\cos \cdot 2$ & & \\
\hline TEMF (X) & 100.00 & PBBCTOTAL) & 0.0024 & anan & & \\
\hline & & PBMTOTAL) & 0.0001 & G.MOLBSAMN & & \\
\hline
\end{tabular}

\begin{tabular}{|c|c|c|c|c|c|c|}
\hline wr Loss & 5.00 & RATB (SOLD) & 0.93 & $\mathrm{MO} / \mathrm{CM} \cdot 2 \cdot \mathrm{HR}$ & OEN $\operatorname{se}(\mathrm{CON} \cdot 2)$ & 20.20 \\
\hline so/co & 1.00 & RATR (OBN) & 0.09 & MOMOM'2.HR & $-\cos \mathrm{frux}$ & $4.928-00$ \\
\hline ZETA & 0.00 & ARRA (SOLD) & 100.30 & $\mathrm{CM}_{2} \cdot 2$ & & \\
\hline TEMP (DBO C) & 1423.00 & AREA (OBN) & 76.10 & $\cos =2$ & & \\
\hline TEMF $(\boldsymbol{X})$ & 100.00 & PB(TOTAL) & 0.0002 & laman & & \\
\hline & & PRBTOTAL) & 0.0001 & Q.MOLBSMAN & & \\
\hline
\end{tabular}

Figure A-3 ${ }^{\cap}$ Cell Model Spreadsheet 
CEL' 2:

\begin{tabular}{|c|c|c|c|c|c|c|c|c|c|c|}
\hline GAS SPRECIES & SLPM & MOLEMMN & MOLB FR & SPBCIES & MOLE/MIN & SPECIES & MOLE/MIN & SPBCTE & MOLEMIN & MOLB FR \\
\hline H2 & 3.43 & 0.2224 & 0.7906 & & & $\mathrm{H} 2$ & 0.0003 & $\mathrm{H} 2$ & 0.2127 & 0.79062 \\
\hline N2 & 1.00 & 0.046 & 0.1456 & & & $\mathrm{~N}_{2}$ & & N2 & 0.0446 & $0.145 \times 2$ \\
\hline co & 0.42 & 0.0186 & 0.0607 & co & 0.0002 & $\mathrm{co}$ & 0.0001 & co & 0.0169 & 0.0614 \\
\hline $\mathrm{CH}$ & 0.02 & 0.0000 & 0.0029 & $\mathrm{CHA}$ & .0 .0001 & $\mathrm{CH}$ & 0.0001 & $\mathrm{CHM}$ & 0.0006 & 0.0019 \\
\hline 10 & 0.00 & 0.0001 & 0.0002 & so & 0.0002 & so & .0 .0001 & so & 0.0002 & 0.00059 \\
\hline TOTAL & $6 . n$ & 0.3007 & 1.0000 & TOTAL & 0.0002 & TOTAL & 0.0001 & TOTAL & 0.3070 & 1.0000 \\
\hline
\end{tabular}

CHA DBCOMP

\begin{tabular}{|c|c|c|c|c|c|c|c|c|c|}
\hline CBLL VOL $(C C)$ & 321.80 & \multirow[t]{6}{*}{ SOLD RXNS } & WT Loss & 9.36 & RATE (SOLD) & 0.90 & $\mathrm{MO} / \mathrm{CM} \cdot 2 \cdot \mathrm{HR}$ & $\operatorname{aEN~AR~}\left(\mathrm{CM}^{-2} 2\right)$ & 20.20 \\
\hline FLOW (ACCM) & 42724.19 & & so/co & 1.00 & RATE (OEN) & 0.97 & $\mathrm{MO} / \mathrm{CM} \cdot 2 \cdot \mathrm{HR}$ & MASS FLUX & $5.278-04$ \\
\hline $\operatorname{TAU}(\Omega)$ & 0.45 & & ZETA & 0.00 & AREA (SOUD) & 100.30 & CM:2 & & \\
\hline$K(D B C)\left(s^{2}-1\right)$ & 0.40 & & TEMP (DBA C) & 1422.00 & ARBA (OEN) & 76.10 & $\mathrm{CM}_{2} \cdot 2$ & & \\
\hline$X(\mathrm{CH})$ & 0.17 & & $\operatorname{TEMP}(\mathbf{X})$ & 1698.00 & PIB(TOTAL) & 0.0027 & OMIN & & \\
\hline CHU (CONS) & 0.0001 & & & & FBB(TOTAL) & 0.0001 & G-MOLESMMN & & \\
\hline
\end{tabular}

Ceen:

\begin{tabular}{|c|c|c|c|c|c|c|c|c|c|c|}
\hline IN & & & & EN/DECOM & & FBRIL & & OUT & & \\
\hline OAS SPECIES & SLPM & MOLEMIN & MOLB PR & SPBCIBS & MOLEMIN & SPBCIES & MOLBMMIN & SPBCIES & MOLEMIN & MOLB FR \\
\hline $\mathrm{H} 2$ & 3.93 & 0.2122 & 0.7903 & & & H2 & 0.0003 & H2 & 0.2221 & 0.7906 \\
\hline $\mathrm{N}_{2}$ & 0.30 & 0.046 & 0.1457 & & & $\mathrm{~N}_{2}$ & & N2 & 0.040 & 0.1456 \\
\hline co & 0.41 & 0.014 & 0.0601 & co & 0.0001 & co & 0.0001 & co & 0.0186 & 0.0607 \\
\hline $\mathrm{CH}$ & 0.03 & 0.0012 & 0.0039 & $\mathrm{CH}$ & .0 .0002 & $\mathrm{CH}$ & -0.0001 & $\mathrm{CH}$ & 0.0009 & 0.0029 \\
\hline so & 0.00 & 0.0000 & 0.0000 & so & 0.0001 & so & .0 .0001 & so & 0.0001 & 0.0002 \\
\hline TOTAL & 6.8645 & 0.3065 & 1.0000 & & 0.0001 & & & TOTAL & 0.3067 & 1.0000 \\
\hline
\end{tabular}

CH DECOMP

\begin{tabular}{|c|c|c|c|c|c|c|c|c|c|}
\hline CBLL VOL (CC) & 321.80 & \multirow[t]{6}{*}{ SOLAD RXNS } & WT LOSS & 4.13 & RATE (SOLDD) & 0.8 & MO/CM'2.HR & ORN AR $\left(\mathrm{CM}^{\prime} \cdot 2\right)$ & 24.20 \\
\hline FLOW (ACCM) & 42693.68 & & so/co & 1.00 & RATE (OEN) & 0.91 & $\mathrm{MO} / \mathrm{CM} \cdot 2 \cdot \mathrm{HR}$ & MASS FLUX & 4.067 .04 \\
\hline TAU (S) & 0.45 & & ZETA & 0.00 & AREA (SOLUD) & 100.30 & $\mathrm{CM} \cdot 2$ & & \\
\hline $\mathbf{k}(\mathrm{DEC})\left(\mathbf{S}^{*}-1\right)$ & 0.40 & & TEMP (DEO C) & 1422.00 & AREA (OBN) & 76.10 & $\mathrm{CM}_{2} \cdot 2$ & & \\
\hline$x_{(\mathrm{CH})}$ & 0.17 & & $\operatorname{TEMP}(\mathbf{X})$ & 1608.00 & PIB(TOTAL) & 0.0026 & OMMIN & & \\
\hline CHA (CONS) & 0.0002 & & & & FIB(TOTAL) & 0.0001 & O-MOLES/MIN & & \\
\hline
\end{tabular}

\begin{tabular}{|c|c|c|c|c|c|c|c|c|c|c|}
\hline OAS SPBCIES & SLPM & MOLEMON & MOLB FR & SPECTRS & MOLEMMN & $\begin{array}{l}\text { PBBRLL } \\
\text { PPBCS }\end{array}$ & MOLEMIN & OIT & MOLEMIN & MOLB $\mathrm{FR}$ \\
\hline H2 & 5.43 & 0.2122 & 0.7903 & & & $\mathrm{H}_{2}$ & 0.0000 & $\mathrm{H}_{2}$ & 0.2222 & 0.790 \\
\hline N2 & 1.00 & 0.046 & 0.1457 & & & N2 & & $\mathrm{N}_{2}$ & 0.040 & 0.146 \\
\hline co & 0.41 & 0.014 & 0.0601 & co & 0.0000 & co & 0.0000 & co & 0.014 & 0.060 \\
\hline $\mathrm{CH}$ & 0.03 & 0.0012 & 0.0039 & $\mathrm{CHA}$ & .0 .0001 & $\mathrm{CH}$ & 0.0000 & $\mathrm{CHA}$ & 0.0012 & 0.004 \\
\hline so & 0.00 & 0.0000 & 0.0000 & so & 0.0000 & so & 0.0000 & mo & 0.0000 & 0.000 \\
\hline TOTAL & 6.8643 & 0.3065 & 1.0000 & & .0 .0001 & & & TOTAL & 0.3064 & 0.999 \\
\hline
\end{tabular}

CHA DECOMP

\begin{tabular}{|l|r|}
\hline CELL VOL (CC) & 7.50 \\
\hline PLOW (ACCM) & 12699.60 \\
\hline TAU (S) & 0.11 \\
\hline K(DEC) $\left(S^{*}-1\right)$ & 0.40 \\
\hline$X$ XCHA) & 0.04 \\
\hline CHA (CONS) & 0.0001 \\
\hline
\end{tabular}

SOLD RXNS

\begin{tabular}{|c|c|c|c|c|c|c|}
\hline WT Loss & 0.00 & RATE (SOLD) & 0.00 & $\mathrm{MO} / \mathrm{CM} \cdot 2 \cdot \mathrm{HR}$ & $\operatorname{OEN~AR~}\left(\mathrm{CM}^{\circ} 2\right)$ & 24.20 \\
\hline so/co & 1.00 & RATE (AEN) & 0.00 & MO/OM'2.HR & MASS FLUX & $0.00 E+\infty 0$ \\
\hline ZETA & 0.00 & AREA (SOLD) & 22.80 & $\mathrm{CM} \cdot 2$ & & \\
\hline $\operatorname{TEMP}(D B O C)$ & 1423.00 & AREA (GEN) & 22.80 & $\mathrm{CM}_{2}=2$ & & \\
\hline TEMP (K) & 1698.00 & FIB(TOTAL) & 0.0000 & aMMIN & & \\
\hline & & FIB(TOTAL) & 0.0000 & O-MOLESMMIN & & \\
\hline
\end{tabular}




\begin{tabular}{|c|r|r|r|}
\hline \multicolumn{3}{|c|}{ OVERALL BAL ANCE (REALITY CHECK) } & ACTUAL \\
\hline GR RATE & 0.00926 & (G/MIN) & \\
\hline WT. SS & 86.68 & G & 84.34 \\
\hline TOTAL B & 15.55 & G & 14.55 \\
\hline WT. LOSS & 86.68 & G & \\
\hline TOT SIO & 1.20 & G-MOLE & \\
\hline TOT SIO & 52.97 & G & \\
\hline SIO UTIL & 0.32 & & \\
\hline CH4 UTL. & 0.19 & & \\
\hline
\end{tabular}

PARTIAL PRESSURE PROFILE

\begin{tabular}{|c|c|c|c|c|c|c|}
\hline CELL & PSIO-OUT & PCH4 -OUT & PSIO - IN & PCH4 - IN & PSIO -AVG & PCH4 -AVG \\
\hline & (ATM) & (ATM) & (ATM) & (ATM) & (ATM) & (ATM) \\
\hline 5 & 0.0016 & 0.0007 & 0.0013 & 0.0009 & 0.0014 & 0.0008 \\
\hline 4 & 0.0013 & 0.0009 & 0.0009 & 0.0012 & 0.0011 & 0.0010 \\
\hline 3 & 0.0009 & 0.0012 & 0.0006 & 0.0019 & 0.0008 & 0.0016 \\
\hline 2 & 0.0006 & 0.0019 & 0.0002 & 0.0029 & 0.0004 & 0.0024 \\
\hline 1 & 0.0002 & 0.0029 & 0.0000 & 0.0039 & 0.0001 & 0.0034 \\
\hline 0 & 0.0000 & 0.0038 & 0.0000 & 0.0039 & 0.0000 & 0.0038 \\
\hline
\end{tabular}

INPUT DATA

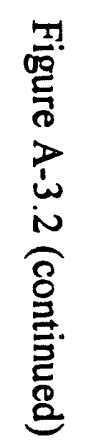

SIO GENERATION

\begin{tabular}{|c|r|c|r|}
\hline BRICK & WT. LOSS & BRICK & WT. LOSS \\
\hline & (G) & & (G) \\
\hline 1 & 6.14 & 6 & 6.12 \\
\hline 2 & 8.00 & 7 & 8.24 \\
\hline 3 & 9.80 & 8 & 10.00 \\
\hline 4 & 9.6 & 9 & 10.72 \\
\hline 5 & 7.39 & 10 & 8.26 \\
\hline
\end{tabular}

\begin{tabular}{|c|c|c|c|}
\hline LOCATION & AREA & FIBRIL MASS & RATE \\
\hline & $\left(\mathrm{CM}^{\wedge} 2\right)$ & MG & $\mathrm{MG} / \mathrm{CM}{ }^{-2} 2 \mathrm{HR}$ \\
\hline$s-1$ & 86.4 & 530.0 & 0.876 \\
\hline$s-2$ & 86.4 & 560.0 & 0.926 \\
\hline $5-3$ & 86.4 & 300.0 & 0.496 \\
\hline $6-1$ & 17.3 & 70.0 & 0.578 \\
\hline $6-2$ & 51.8 & 330.0 & 0.910 \\
\hline $6-3$ & 51.8 & 350.0 & 0.965 \\
\hline $6-4$ & 51.8 & 250.0 & 0.699 \\
\hline $6-5$ & 38.0 & 110.0 & 0.414 \\
\hline $6-6$ & 19.6 & 50.0 & 0.364 \\
\hline
\end{tabular}

\begin{tabular}{|c|c|c|}
\hline SUMMARY & STAGE 1 & STAGE 2 \\
\hline TEMP. C & 1425 & 1425 \\
\hline FLOW & $300 \%$ & $300 \%$ \\
\hline MIXING & OSC & OSC \\
\hline X CH4 & $0.4 \%$ & $0.4 \pi$ \\
\hline X N2 & $15 \%$ & $15 \pi$ \\
\hline CATALYST & FE SOL & FE SOL \\
\hline TMME (MIN) & 120 & 300.00 \\
\hline CYCLE & FULL & \\
\hline COMMENT & HIGH N2 & \\
\hline & & \\
\hline & RUN: & 139 \\
\hline
\end{tabular}




\section{Appendix 4 Activation Energies for SiO Formation}

The activation energy of the SiO generation reaction has been evaluated by several techniques. $\mathrm{SiO}$ formation rates based on generator weight loss and corrected $\mathrm{SiO}$ formation rates averaged over the entire growth cycle were used to determine the activation energy. Activation energies were obtained by plotting the natural logarithm of the rate versus the inverse of the temperature[16].

The SiO formation rate was also modeled using a mathematical expression consistent with a vaporization process. There were two model parameters: a kinetic constant $\left(\mathrm{k}_{\mathrm{gen}}\right)$, which should represent the mass transfer characteristics, and an "equilibrium" surface vapor pressure (pSiO*). This "vapor pressure" was actually an empirical parameter combining thermochemical and kinetic contributions to the $\mathrm{SiO}$ formation rate. Analysis of the temperature effects on these parameters revealed that the ( $\mathrm{pSiO}^{*}$ term had a strong temperature dependence. The kinetic constant $\mathrm{k}_{\mathrm{gen}}$ exhibited a very weak temperature effect (as determined by a low correlation coefficient). The activation energy was determined by analyzing the slope of the relationship between the natural logarithm of $\mathrm{PSiO}^{*}$ as a function of the inverse of the absolute temperature. This procedure is analogous to techniques used to correlate vapor pressure-temperature data.

Table A-4.1 compares the activation energy values obtained by each technique. It can be seen that the predicted activation energy ranged from 240 to $420 \mathrm{~kJ} / g m o l e$ and fell within the range of data in the published literature[9].

Table A-4.1 Activation Energies for the SiO Formation Reaction

\begin{tabular}{|c|c|c|}
\hline Calculation Method & $\begin{array}{c}\text { Temperature Range } \\
(\mathrm{K})\end{array}$ & $\begin{array}{c}\text { Activation Energy } \\
\text { (kJ/gmole) }\end{array}$ \\
\hline Weight loss & $1653-1748$ & $\frac{309}{242}$ \\
\hline Weight loss & $1673-1723$ & 293 \\
\hline Corrected by gas analysis & $1673-1723$ & $293-418$ \\
\hline Equilibrium vapor pressure & $1673-1723$ & $84-543$ \\
\hline Literature data range[9] & $1278-2038$ & 602 \\
\hline Literature data[9] & $1644-1736$ & \\
\hline
\end{tabular}




\section{Appendix 5 Kinetic Data for Fibril Formation Rate Constant}

Four kinetic equations were evaluated for their ability to model fibril formation kinetics. The analysis used data from the growth cycle decoupled from the nucleation period. First order equations produced universally poor correlation of the data. Table A-5.1 summarizes the regression results for second order expressions using data from the $27 \mathrm{slpm}$ statistical experimental matrix. Combined nucleation/growth rate constants from the reproducibility experimental series have also been included to show the parameter reproducibility at a fixed process condition. The second order expression in $\mathrm{PCH} 4$ was chosen since it produced slightly better correlation coefficients and also removed some of the uncertainty associated with the calculation of the equilibrium methane partial pressure. It can be seen that the rate constant for four out of five experiments falls within a similar range. The case with the high fibril growth rate constant exhibited low SiO generation, which may be related to this anomalous result (although the value is not excessive, considering the range exhibited in the second data set). A factor of two variations in the rate constant appeared in the case of the second data set, which is quite reasonable considering the procedure used to determine this parameter.

Table A-5.1 Regression Analysis for Fibril Formation Rate Constant

\begin{tabular}{|c|c|c|c|c|c|c|}
\hline Experiment & $\mathrm{T}(\mathrm{K})$ & $\% \mathrm{CH}_{4}$ & $\mathrm{Cycie}$ & $\begin{array}{c}\mathrm{k} \text { (growth) } \\
\left(\times 10^{-8}\right)\end{array}$ & $\begin{array}{c}\mathrm{r}^{2} \\
\left(\mathrm{p}_{\mathrm{CH}}\right)^{2}\end{array}$ & $\begin{array}{c}\mathrm{r}^{2} \\
\left(\Delta \mathrm{p}_{\mathrm{CH}}\right)^{2}\end{array}$ \\
\hline 120 & 1673 & 0.4 & $\mathrm{G}$ & 1.7 & 0.74 & 0.15 \\
\hline 125 & 1723 & 0.8 & $\mathrm{G}$ & 1.2 & 0.72 & 0.93 \\
\hline 128 & 1698 & 0.4 & $\mathrm{G}$ & 5.2 & 0.94 & 0.84 \\
\hline 130 & 1698 & 0.6 & $\mathrm{G}$ & 2.5 & 0.66 & 0.89 \\
\hline 132 & 1723 & 0.4 & $\mathrm{G}$ & 2.1 & 0.92 & 0.45 \\
\hline 139 & 1698 & 0.4 & $\mathrm{~N}+\mathrm{G}$ & 5.0 & 0.98 & 0.57 \\
\hline 140 & 1698 & 0.4 & $\mathrm{~N}+\mathrm{G}$ & 4.5 & 0.98 & 0.55 \\
\hline 145 & 1698 & 0.4 & $\mathrm{~N}+\mathrm{G}$ & 3.1 & 0.93 & 0.75 \\
\hline 146 & 1698 & 0.4 & $\mathrm{~N}+\mathrm{G}$ & 2.7 & 0.95 & 0.82 \\
\hline 147 & 1698 & 0.4 & $\mathrm{~N}+\mathrm{G}$ & 2.4 & 0.79 & 0.96 \\
\hline 148 & 1698 & 0.4 & $\mathrm{~N}+\mathrm{G}$ & 2.5 & 0.21 & - \\
\hline 153 & 1698 & 0.4 & $\mathrm{~N}+\mathrm{G}$ & 2.3 & 0.70 & 0.95 \\
\hline
\end{tabular}

$\mathrm{G}=$ growth cycle only

$\mathrm{N}+\mathrm{G}=$ nucleation + growth cycle 


\section{Appendix 6 Statistical Experimental Design Results}

A number of response variables for the statistical design experiments have been evaluated in addition to those reported in the body of the report. These include:

- Generator weight loss

- SiO utilization (average for the entire experiment)

- $\mathrm{CH}_{4}$ utilization (average for the entire experiment)

- Mean fibril diameter

These results are shown in Figures A-6.1 through A-6.4. 

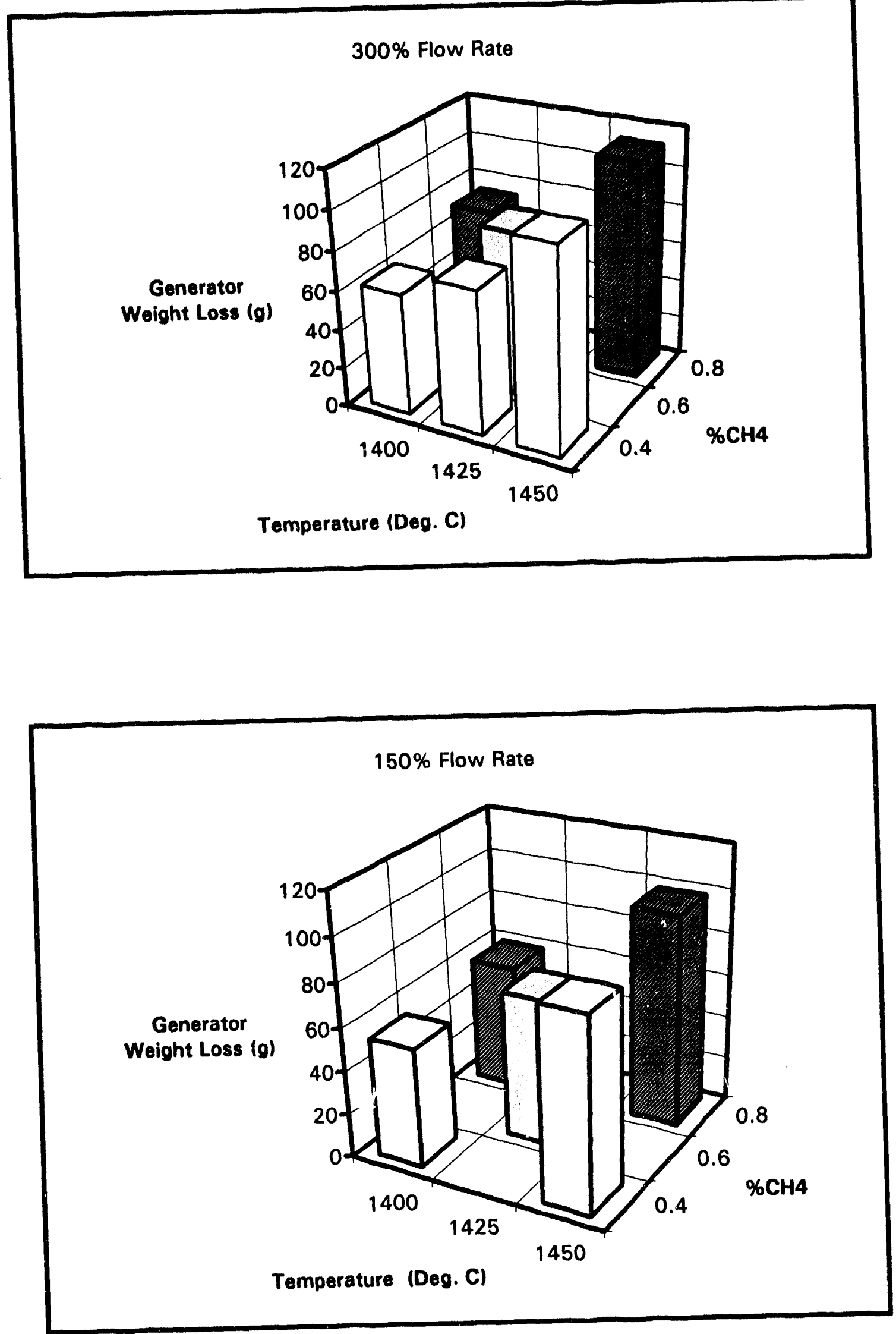

Figure A-6.1 Generator Weight Loss as a Function of Synthesis Process Conditions 


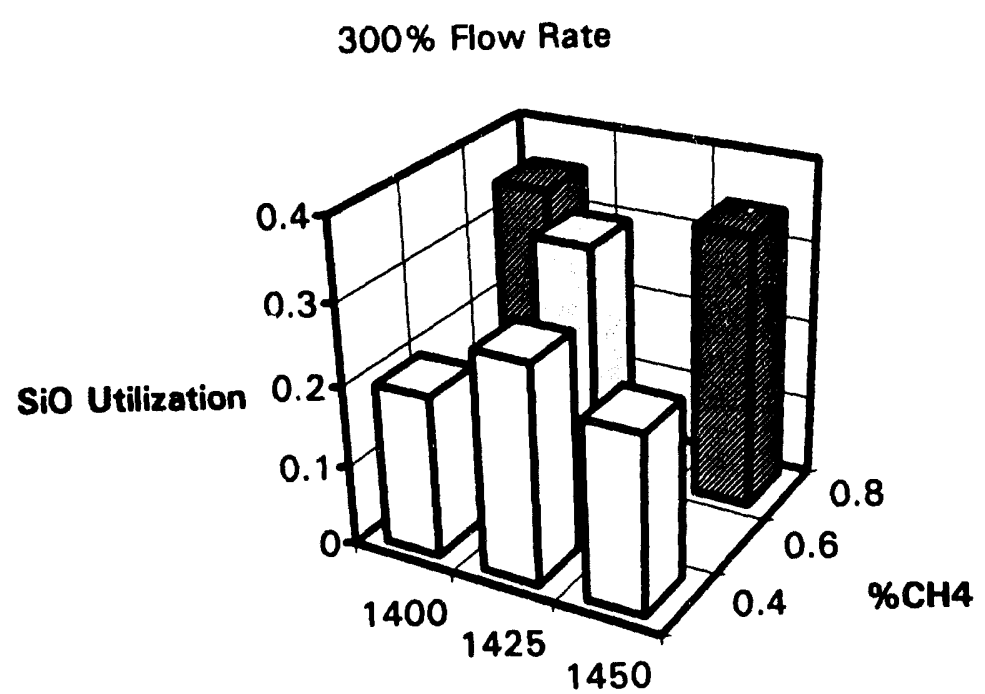

Temperature (Deg.

C)

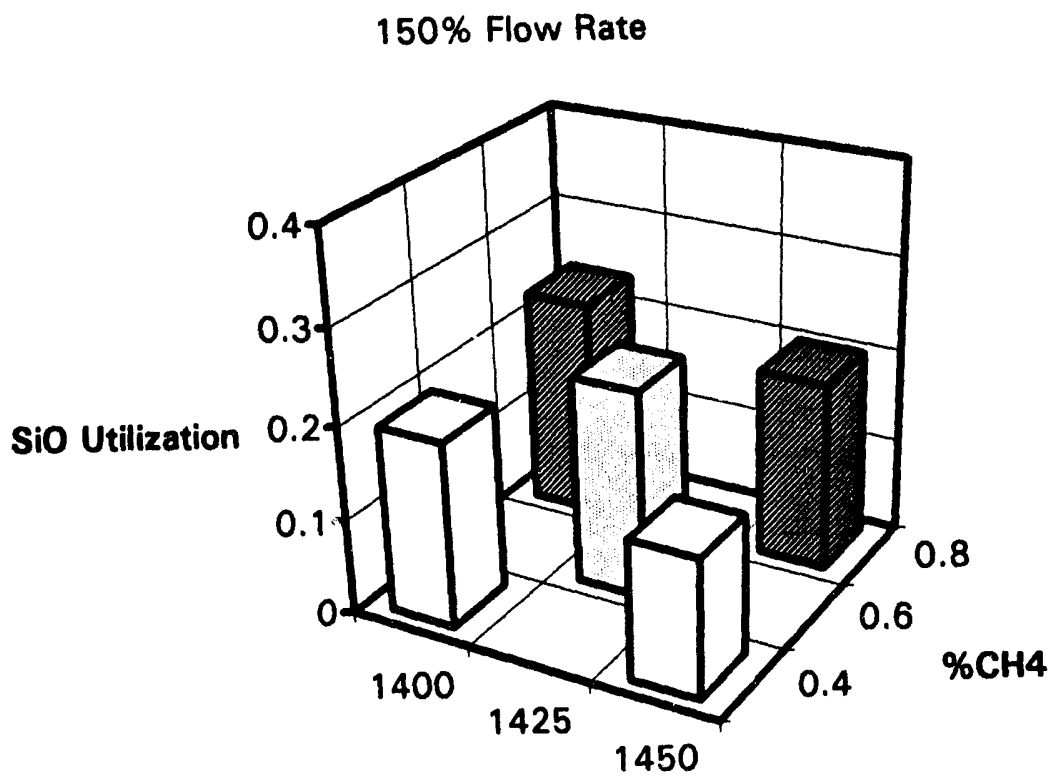

Temperature (Deg. C)

Figure A-6.2 SiO Utilization as a Function of Synthesis Process Conditions 

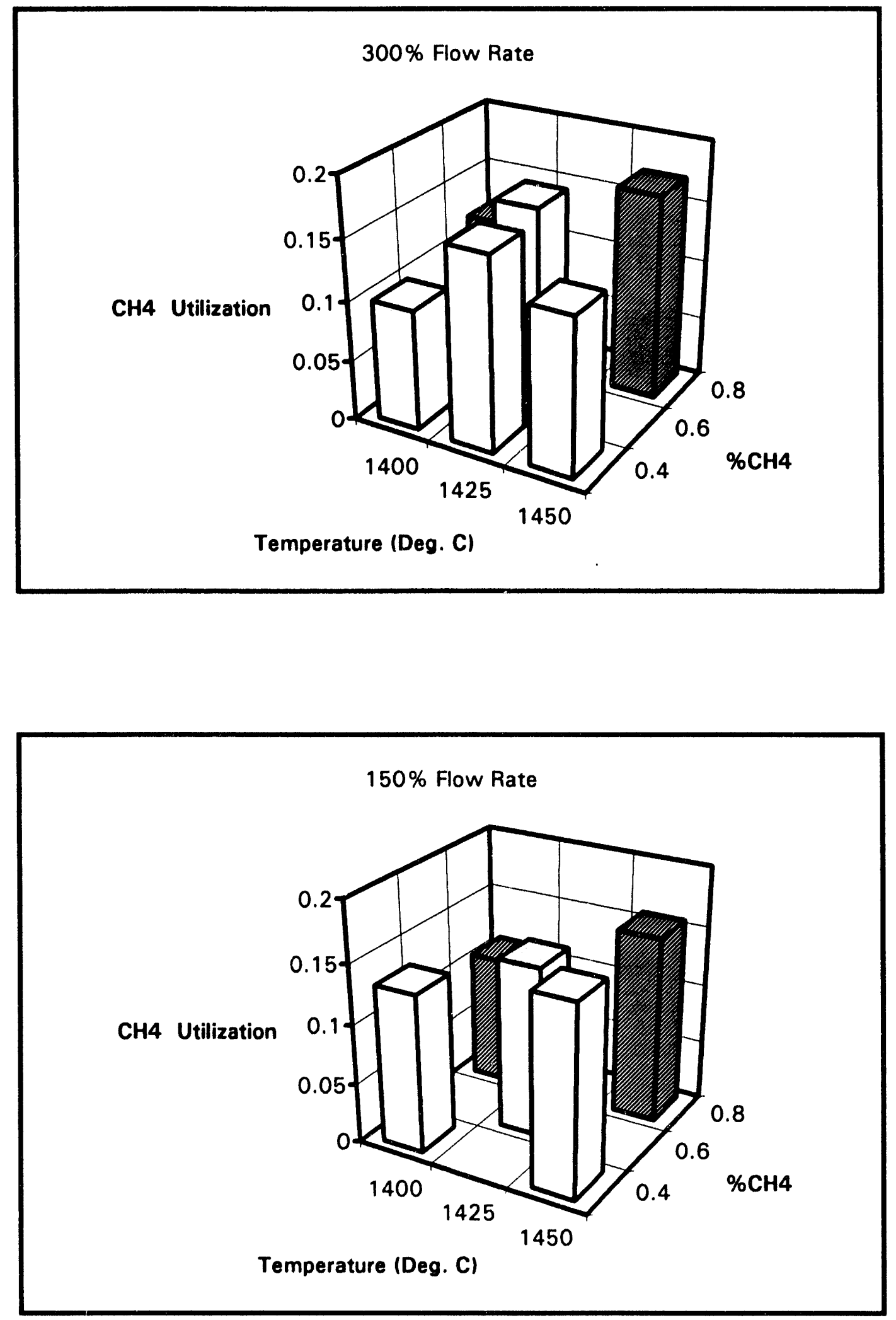

Figure A-6.3 $\mathrm{CH}_{4}$ Utilization as a Function of Synthesis Process Conditions 


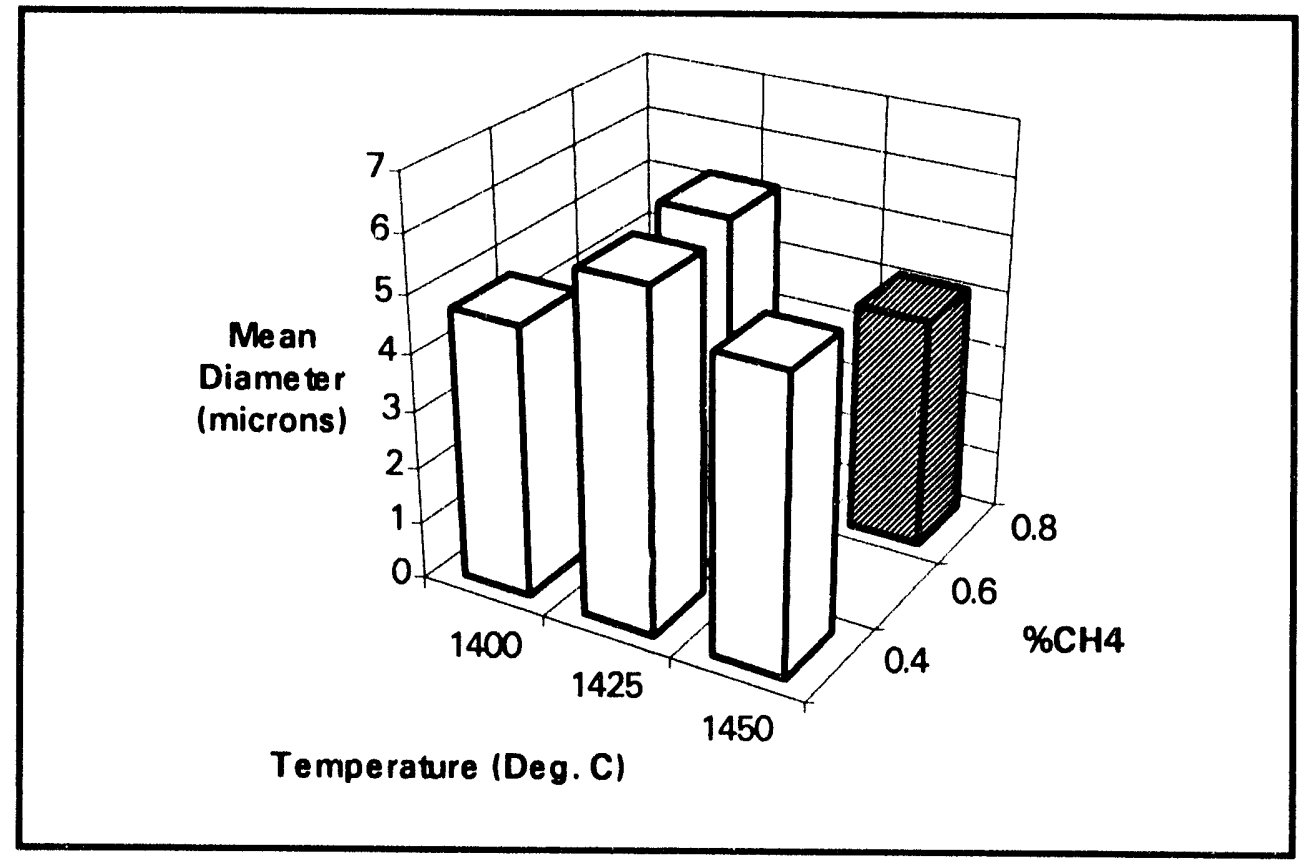

Figure A-6.4 Average Fibril Diameter as a Function of Synthesis Process Conditions 


\section{Appendix 7 Simulation Model Equations}

1. Momentum Convection-Diffusion

$$
\begin{gathered}
\nabla \cdot[\rho \mathbf{v} u-\mu \nabla u]=-\partial p / \partial x \\
\nabla \cdot[\rho \mathbf{v} v-\mu \nabla v]=-\partial p / \partial y+\rho g
\end{gathered}
$$

Boundary Conditions

$u, v$ specified at the inlet

laminar wall friction at all surfaces

$p$ specified at outlet

2. Continuity

$$
\nabla \cdot(\rho \mathbf{v})=0
$$

3. Species Reaction-Convection-Diffusion

$$
\begin{gathered}
\nabla \cdot\left[\rho \mathbf{v} \mathrm{x}_{\mathrm{i}}-\rho \mathrm{D}_{\mathrm{i}-\mathrm{m}} \nabla \mathrm{x}_{\mathrm{i}}\right]=0 \\
\mathrm{x}_{\mathrm{i}}=\text { mass fraction of species } \mathrm{i} \\
\mathrm{i}=\mathrm{SiO}, \mathrm{CO}, \mathrm{CH}_{4}, \mathrm{CH}_{4} \text { decomposition product }
\end{gathered}
$$

\section{Physical Properties}

\section{$\underline{\text { Viscosity }}$}

$$
\begin{gathered}
\mu=\Sigma y_{i} \mu_{i} /\left(\sum y_{j} \phi_{i j}\right)(i=1, N) \\
\mu_{i}=26.69\left(M_{i} T\right)^{0.5} /\left(\sigma_{i}\right)^{2} \Omega_{i}(\text { poise }) \\
\phi_{i j}=\left[1+\left(\mu_{i} / \mu_{j}\right)^{0.5}\left(M_{j} / M_{i}\right)^{0.25}\right]^{2} /\left[8\left(1+\mathrm{M}_{\mathrm{i}} / \mathrm{M}_{\mathrm{j}}\right)\right]^{0.5} \\
\Omega_{\mathrm{i}}=\mathrm{A} /\left(\mathrm{T} \mathrm{k}_{\mathrm{ei}}\right)^{\mathrm{B}}+\mathrm{C} / \exp (\mathrm{D} \mathrm{T} \mathrm{k} \mathrm{ei})+\mathrm{E} / \exp \left(\mathrm{F} \mathrm{T} \mathrm{k} \mathrm{k}_{\mathrm{ei}}\right)
\end{gathered}
$$

A, B, C, D, E, F, k $\mathrm{ei}_{\mathrm{i}}$ and $\Omega_{\mathrm{i}}$ constants 
Density

$$
\text { Ideal gas law }
$$

Diffusion

$$
\begin{aligned}
& D_{i-m}=\left(1-y_{i}\right) /\left(\Sigma\left(y_{i} / D_{i j}\right)\right)(j=1,5 ; j \neq i) \\
& \mathrm{D}_{\mathrm{ij}}=1.858 \times 10^{-3}\left(\mathrm{~T}^{1.5} / \mathrm{P}\right)\left(\left(\mathrm{M}_{\mathrm{i}}+\mathrm{M}_{\mathrm{j}}\right) /\left(\mathrm{M}_{\mathrm{i}} \mathrm{M}_{\mathrm{j}}\right)\right)^{0.5}\left(1 /\left(\left(\sigma_{\mathrm{ij}}\right)^{2} \Omega_{\mathrm{ij}}\right)\left(\mathrm{cm}^{2} / \mathrm{s}\right)\right. \\
& \sigma_{i j}=\left(\sigma_{i}+\sigma_{j}\right) / 2 \\
& \left(\sigma_{\mathrm{i}}, \Omega_{\mathrm{ij}}=\text { constants }\right)
\end{aligned}
$$




\section{Appendix 8 Recycle Material Balance}

A spreadsheet material balance was developed to arialyze the recycle experiments. An example of the spreadsheet is shown in Figure A-8.1. The recycle ratio and material balance were calculated using flow rates and input composition. Table A-8.1 summarizes the names and purpose of the important recycle gas streams.

Table A-8.1 Important Gas Streams in the Process Gas Recycle System

\begin{tabular}{|c|c|}
\hline Gas Stream & Purpose \\
\hline Inlet gas & Reactor supply \\
\hline Furnace purge & Mixture of inlet gas and purge \\
\hline Furnace exhaust & Total compressor output stream \\
\hline Compressed gas & Closed loop recycle stream \\
\hline Closed loop gas & Compressed gas minus closed loop \\
\hline Split gas & $\begin{array}{c}\text { Gas stream bled off to maintain gas } \\
\text { composition }\end{array}$ \\
\hline Bleed gas & Fraction of gas recycled to reactor \\
\hline Recycle gas & $\begin{array}{c}\text { Gas stream to restore inl } \text { t stream } \\
\text { composition }\end{array}$ \\
\hline Make-up gas & \\
\hline
\end{tabular}

Table A-8.2 compares predictions of gas compositions and flow rates based on the calculated and actual data. Good agreement was observed.

Table A-8.2 Comparison of Experimental and Calculated Gas Flow and Composition Parameters for a Recycle Experiment

\begin{tabular}{||c|c|c|}
\hline Stream & Experimental & Calculated \\
\hline Recycle (slpm) & 23.7 & 22.2 \\
\hline Make-up $\mathrm{H}_{2}($ slpm) & 4.8 & 4.4 \\
\hline Make-up CO (slpm) & 0.25 & 0.31 \\
\hline Make-up $\mathrm{CH}_{4}($ slpm) & 0.07 & 0.11 \\
\hline Bleed (slpm) & 6.7 & 6.7 \\
\hline Recycle ratio & - & 0.77 \\
\hline Exhaust composition & & 65 \\
\hline$\% \mathrm{H}_{2}$ & 63 & 30 \\
\hline$\% \mathrm{~N}_{2}$ & 32 & 5 \\
\hline$\% \mathrm{CO}^{\% \mathrm{CH}_{4}}$ & 4 & 0 \\
\hline
\end{tabular}




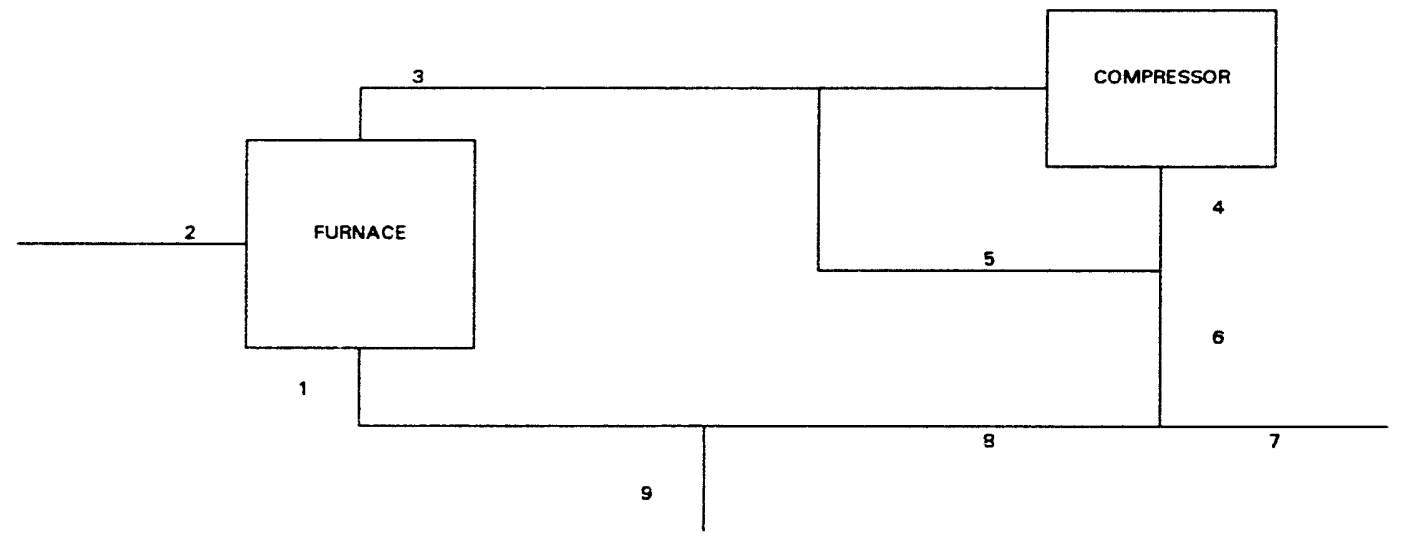

\section{INLET GA'S COMP. $\quad Y$ (N2) $=\quad 0.15$ PROCESS GAS FLOW $=\quad 36.00$} $\begin{array}{ll}\text { FURNACE PURGE }= & 1.00 \\ \text { RECYCLE RATIO }= & 0.84\end{array}$ 


\section{Appendix 9 Diameter Distribution Data and Correlation Results}

The analysis procedure for the fibril dianeter distribution was described in the report. Diameter analysis results for the $300 \%$ flow (27 slpm) experimental matrix are summarized in Table A-9.1.

Table A-9.1 Correlation of Fibril Diameter Distribution Data Using the RRB Equation

\begin{tabular}{|c|c|c|c|c|c|}
\hline $\begin{array}{c}\text { Temperature } \\
(\mathrm{K})\end{array}$ & $\% \mathrm{CH}_{4}$ & $\begin{array}{c}\text { Mean } \\
\text { Diameter } \\
(\mu \mathrm{m})\end{array}$ & $\begin{array}{c}\text { RRB - X' } \\
(\mu \mathrm{m})\end{array}$ & RRB - n & RRB - ${ }^{2}$ \\
\hline 1673 & 0.4 & 4.7 & 5.1 & 1.5 & 0.967 \\
\hline 1673 & 0.8 & 3.8 & 4.6 & 2.3 & 0.897 \\
\hline 1698 & 0.4 & 5.9 & 7.1 & 2.8 & 0.976 \\
\hline 1698 & 0.6 & 6.2 & 6.5 & 2.0 & 0.996 \\
\hline 1723 & 0.4 & 5.1 & 5.8 & 2.0 & 0.987 \\
\hline 1723 & 0.8 & 4.1 & 4.8 & 2.0 & 0.926 \\
\hline
\end{tabular}

Sensitivity calculations were performed to analyze the effect of equation parameters $X^{\prime}$ and $n$ on the calculated diameter distribution. These calculations are summarized in Figures A-9.1 through A-9.3.

Figures A-9.4 and A-9.5 compare calculated RRB parameters to the mean diameter and the width of the diameter distribution (defined by the difference in the 90 ind 10 percentile diameters). These figures st.ow an excellent correlation between $\mathrm{X}^{\prime}$ and the mean diameter. The parameter $\mathrm{n}$ correlates weli with the distribution width over limited ranges of $\mathrm{X}^{\prime}$. 


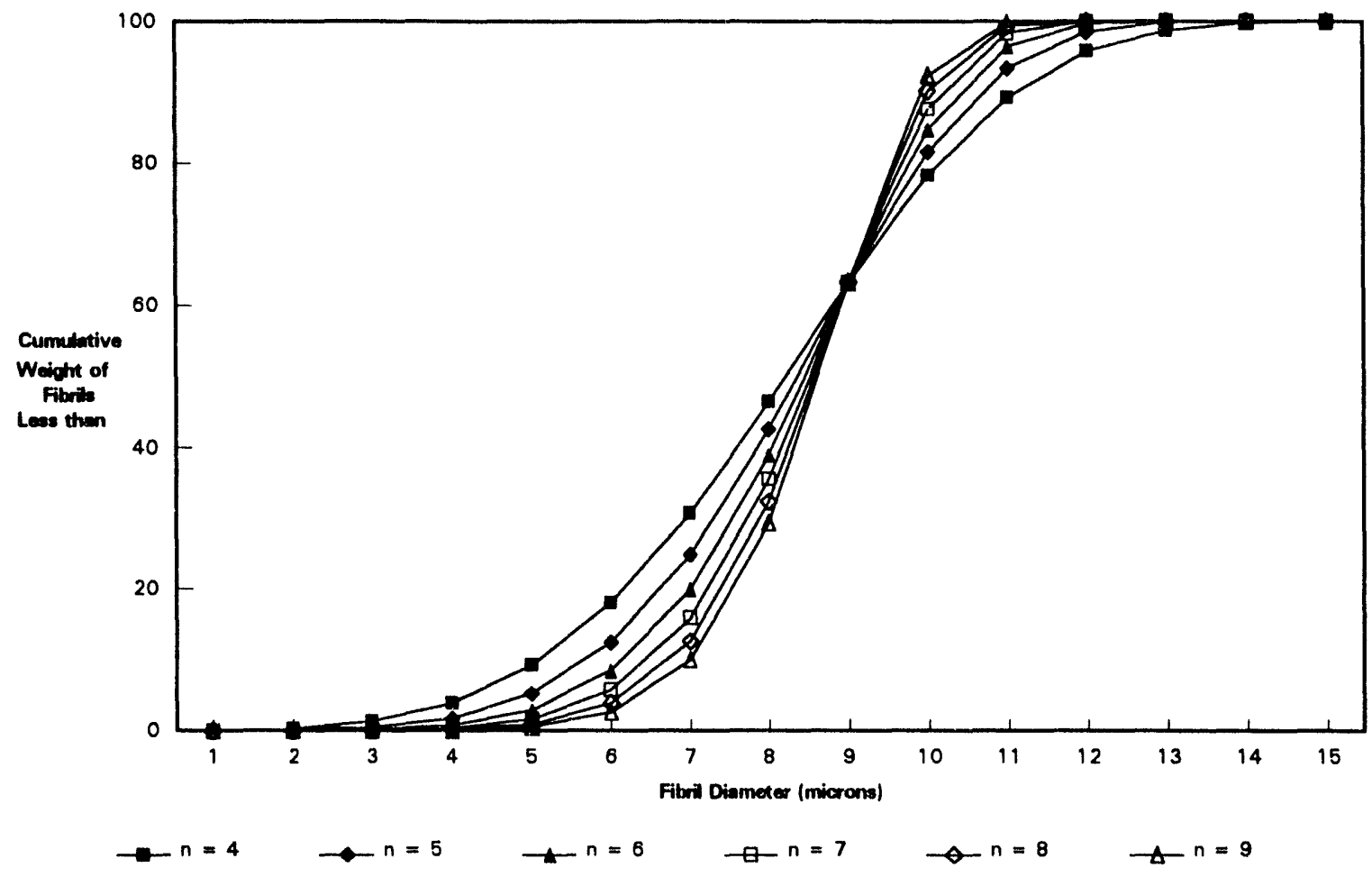

Figure A-9.1 Effect of $n$ on Diameter Distribution for Fixed $X^{\prime}$ Using the RRB Equation

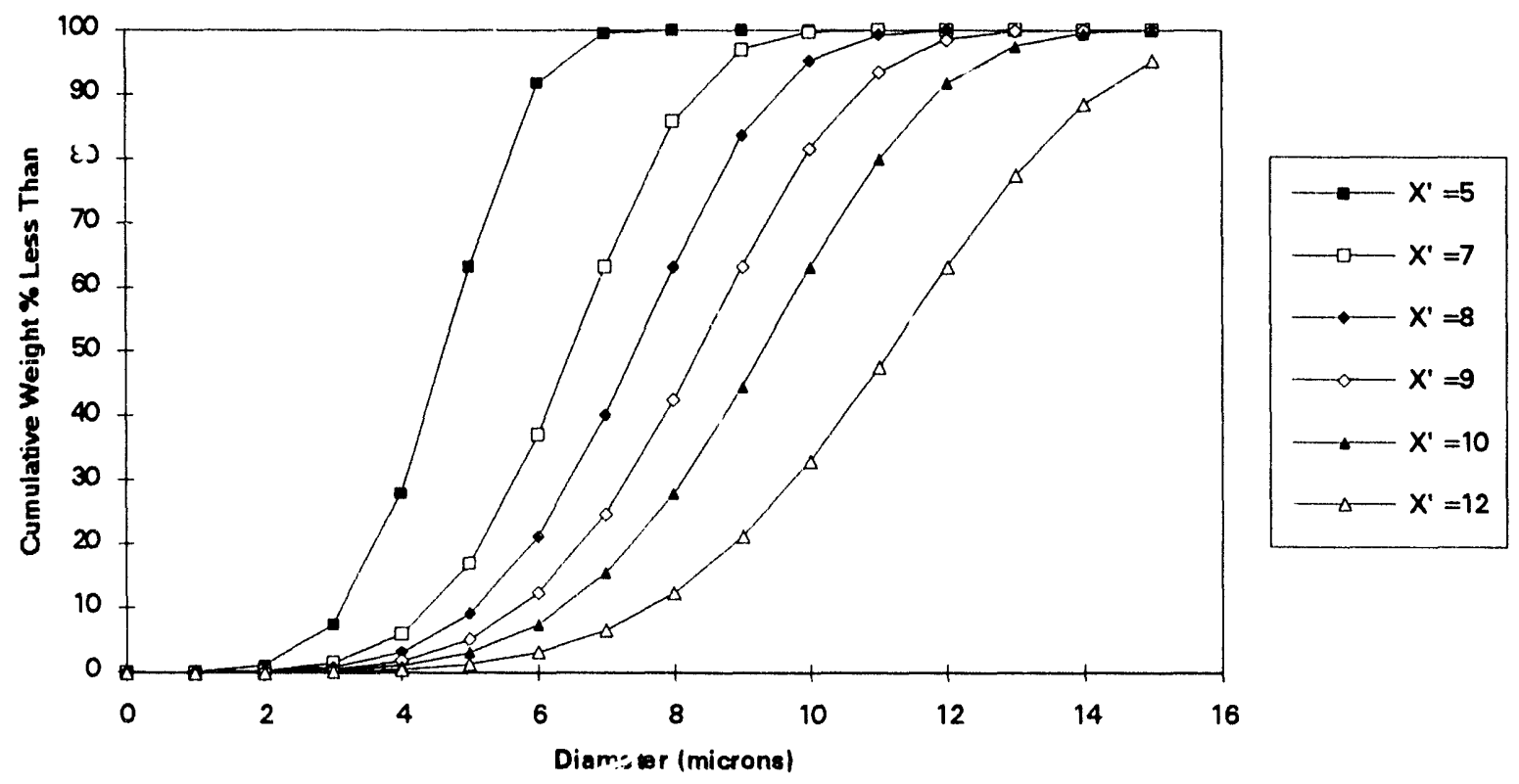

Figure A-9.2 Effect of $X^{\prime}$ on Diameter Distribution for Fixed $n$ Using the RRB Equation 

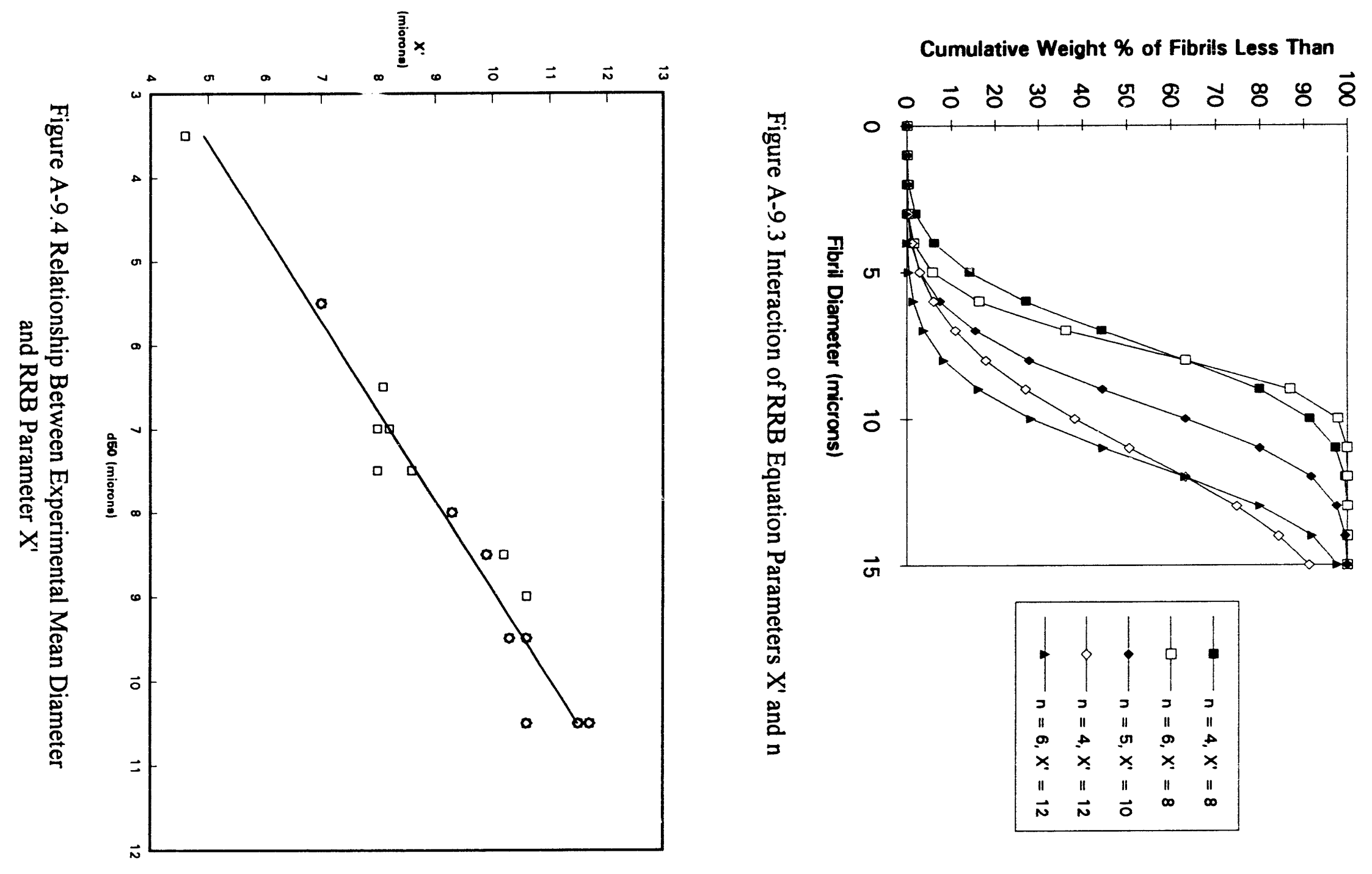
A-26

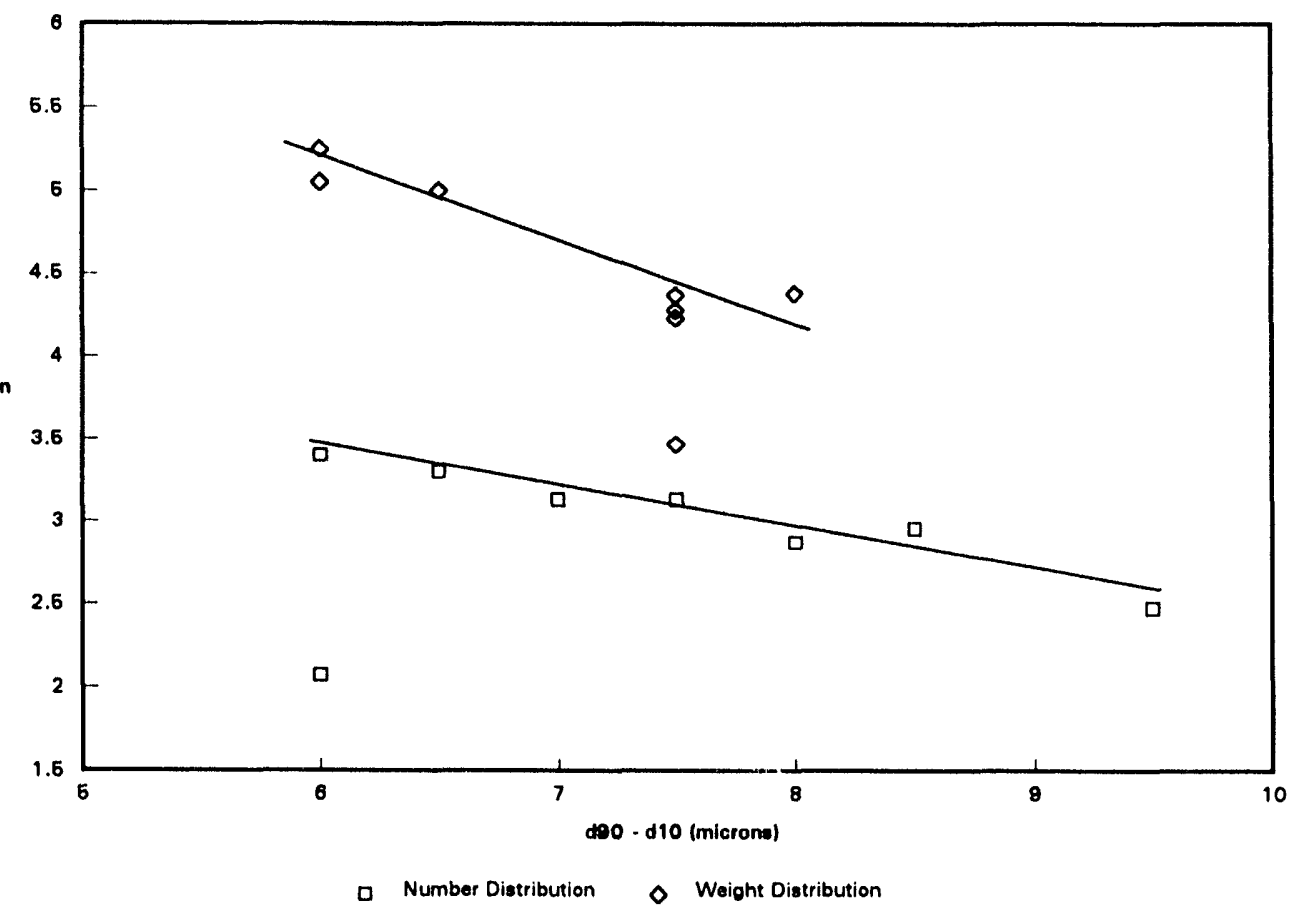

Figure A-9.5 Relationship Between Experimental Diameter Distribution Width and RRB Parameter $\mathbf{n}$ 


\section{Appendix 10 Single Fiber Composite Testing Results}

Figure A-10.1 shows the relationship between the number of breaks and the tensile force, along with the best fit model predictions[29].

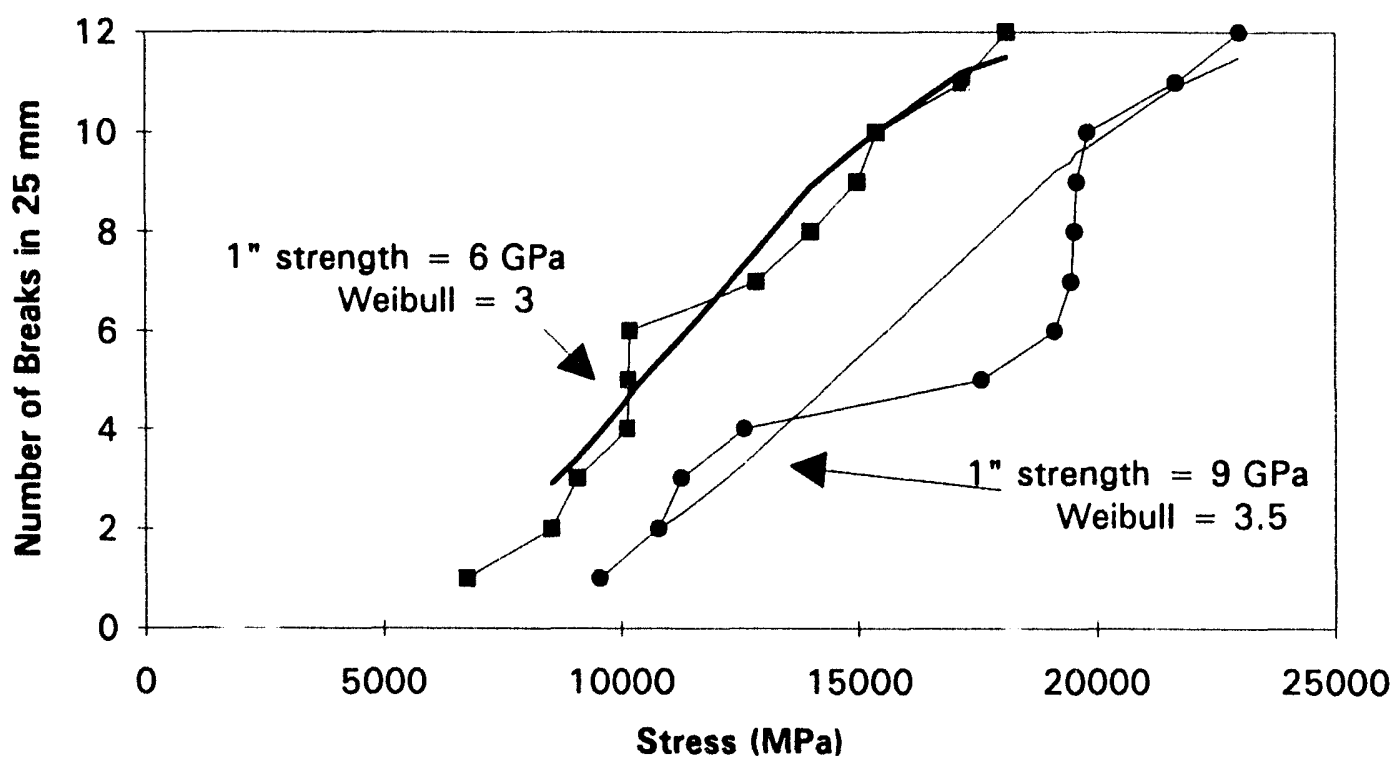

Figure A-10.1 Single Fiber Composite Test Results -

Experimental Data and Model Predictions 


\section{Appendix 11 Epoxy Composite Mechanical Testing Results}

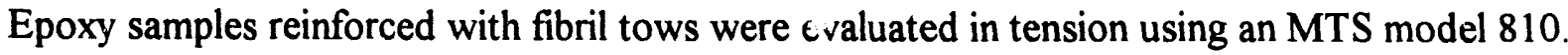
Figure A-11.1 shows the behavior. The fibril-reinforced samples' strength exceeded the unreinforced epoxy strength by approximately $25 \%$. The tensile test curves showed unusual behavior. There appears to have been some slippage of the sample in the grips, as indicated in the change in the slope during the testing and the excessive elongation of the sample.

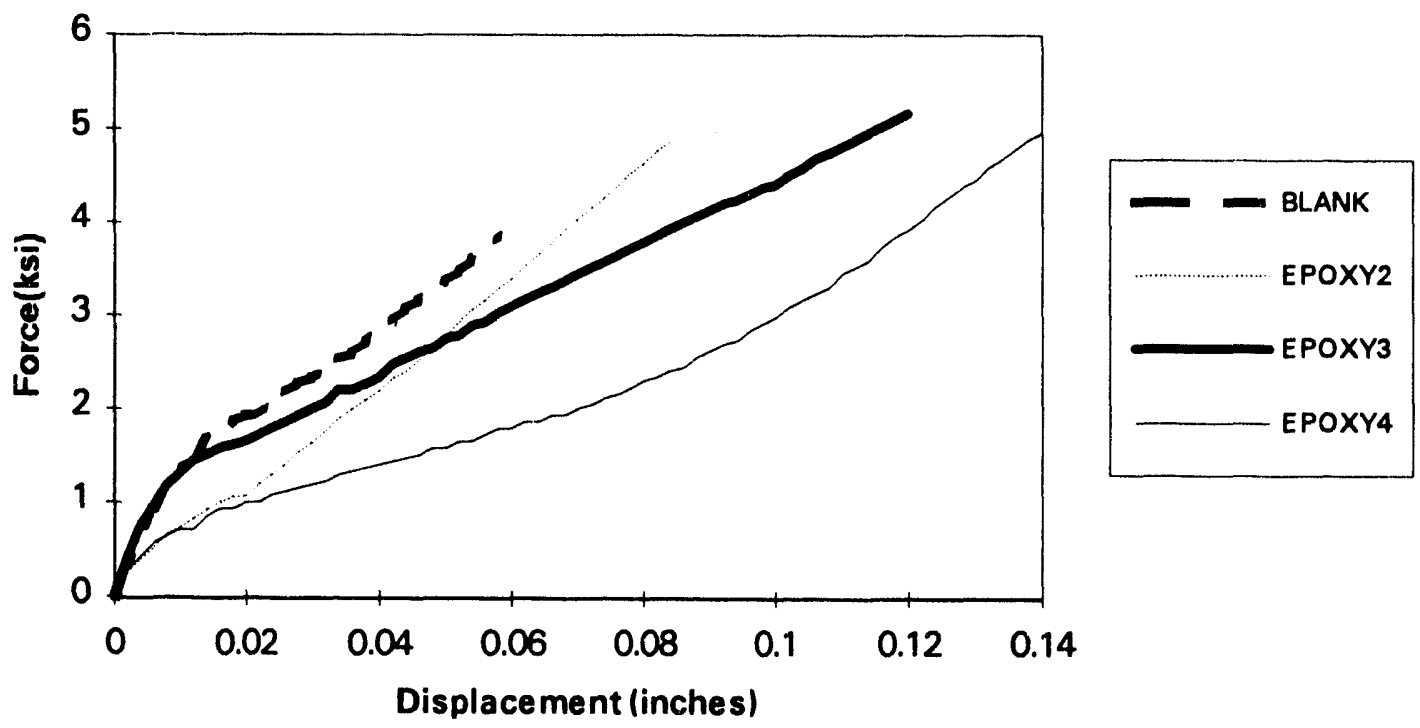

Figure A-11.1 Tensile Test Results for Fibril Tow Reinforced Epoxy 


\section{Appendix 12 Summary of MER Process Research Experiments}

by R. McCormick - MER Corporation

The MER Corporation has developed a novel process concept for the synthesis of VLS whiskers for composites based on discontinuous reinforcements[30]. The whiskers from this process had small diameters $(<3 \mu \mathrm{m})$ and short lengths (typically $<1 \mathrm{~mm}$ ). A subcontract with MER was performed with the purpose of evaluating the potential of converting their process concept to grow VLS SiC fibrils similar to those grown in the LANL process concept (i.e., lengths $>1 \mathrm{~cm}$, diameters $>3 \mu \mathrm{m}$ ) while maintaining the unique advantages of their process.

Experiments were performed in an attempt to produce VLS SiC whiskers over $3.0 \mu \mathrm{m}$ in diameter with lengths greater than or equal to $1.0 \mathrm{~cm}$. Variables explored included catalyst precursor particle size, carbon substrate particle size, the amount and reactivity of the SiO generator, the amount of carbon gas introduced into the furnace, the residence time, and the physical setup of the reactor. None of the variables explored allowed good control of the cataly st droplet size and hence the size of the whiskers. The catalyst precursor particle size and carbon substrate particle size did allow rough control over the catalyst drop size and hence over the whisker size distribution. The combination of catalyst and substrate that produced the best results was large flat graphite plates (5-10 mm across) combined with small sized catalyst precursor particles. Although whiskers grown in this combination reached the project size goals of diameter $>3.0 \mu \mathrm{m}$ and length greater than $1.0 \mathrm{~cm}$, no improvement appears to be offered over the Carborundum process.

A system was developed which allowed the quantitative measurement of whisker diameter and length. Although the process was not performed for all whisker runs, it confirmed the qualitative judgment that the large-sized carbon substrate particles and in particular the flat plates gave the largest average whisker sizes.

A harvesting system was also developed which allowed the determination of whisker yield per unit area per unit time. Although one of the two runs harvested with this system showed a yield of greater than $1.0 \mathrm{mg} / \mathrm{cm}^{2} / \mathrm{hr}$, the target figure, the run contained a significant amount of material that did not appear to be $\mathrm{SiC}$ although it was generally whisker shaped. Because the non-SiC material was not separated from the $\mathrm{SiC}$ whiskers, the process has not been conclusively demonstrated to produce whisker yields of greater than the target figure.

The best conditions of the identified MER process were found in run 0409 that used large flat plate carbon substrate, $-20 \mu \mathrm{m} \mathrm{FeCr}$ catalyst precursor, $1 \% \mathrm{CH}_{4}$, and $6.0 \mathrm{~g} \mathrm{SiO}$ generator to $1.0 \mathrm{~g}$ growth substrate. The results of this run are summarized in Table A-12.1.

Although there is a great deal more data that could be analyzed, it appears from the data so far compiled that there is no advantage in the MER system over that already employed by Carborundum.

Table A-12.1 Optimum Result - MER Process Research Program

\begin{tabular}{|c|c|c|c|}
\hline Run \# & Average Diameter & Average Length & Growth Rate \\
\hline 0409 & $11.9 \mu \mathrm{m}$ & $790 \mu \mathrm{m}$ & $0.88 \mathrm{mg} / \mathrm{cm}^{2} / \mathrm{hr}$ \\
\hline
\end{tabular}




\section{Appendix 13 Distribution}

M. Arnold

British Coal Corporation

Coal Research Establishment

Stoke Orchard, Cheltenham

Glochester, England GL52 4RZ

Assistant Manager for Energy

Research \& Development

DOE, DOE Oak Ridge Field Office

P.O. Box 2001

Oak Ridge, TN 37831

H. Atwell

Dow Corning Corporation

3901 S. Saginaw Road

Midland, MI 48686-0995

R. A. Bajura

DOE, Morgantown Energy

Technology Center

P.O. Box 880

Morgantown, WV 26505

W. T. Bakker

Electric Power Research Institute

P.O. Box 10412

3412 Hillview Avenue

Palo Alto, CA 94303

A. L. Baldwin

DOE, Pittsburgh Energy

Technology Center

P.O. Box 10940

Pittsburgh, PA 15236

C. P. Ballard

Allied Signal, Inc.

Ceramics Program

P.O. Box 1021

Morristown, NJ 07962-1021
R. C. Bedick

DOE, Morgantown Energy

Technology Center

P.O. Box 880

Morgantown, WV 26505

C. Bower

British Coal Corporation

Coal Research Establishment

Stoke Orchard, Cheltenham

Glochester, England GL52 4RZ

R. Bradley

Oak Ridge National Laboratory

P.O. Box 2008

Oak Ridge, TN 37831

P. T. Carlson

Oak Ridge National Laboratory

P.O. Box 2008

Oak Ridge, TN 37831

J. P. Carr (FE-14) GTN

DOE, Office of Fossil Energy

Washington, DC 20545

H. Cheung

Union Carbide Corporation

Linde Division

P.O. Box 44

175 East Park Drive

Tonawanda, NY 14151-0044

W. J. Chmura

The Torrington Company

Advanced Technology Center

59 Field Street

Torrington, CT 06790 
D. C. Cicero

DOE, Morgantown Energy

Technology Center

P.O. Box 880

Morgantown, WV 26505

W. S. Coblenz

U.S. Department of Defense

Advanced Research Project Agency

3701 North Fairfax Drive

Arlington, VA 22203-1714

N. C. Cole

Oak Ridge National Laboratory

P.O. Box 2008

Oak Ridge, TN 37831

N. Corbin

The Norton Company

High Performance Ceramics Division

Goddard Road

Northborough, MA 01532-1545

T. B. Cox

AMA Research \& Development Center 5950 McIntyre Street

Golden, CO 80403

F. W. Crouse, Jr.

DOE, Morgantown Energy

Technology Center

P.O. Box 880

Morgantown, WV 26505

J. B. Darby

DOE, Office of Basic Energy Sciences

Materials Sciences Division

ER-131 GTN

Washington, DC 20545

S. W. Dean

Air Products and Chemicals

P.O. Box 538

Allentown, PA 18105
L. W. R. Dicks

Shell Development Company

P.O. Box 1380

Houston, TX 77251-1380

DOE, Office of Scientific

$\&$ Technical Information

P.O. Box 62

Oak Ridge, TN 37831

For distribution by microfiche as shown in DOE/TIC-4500

Distribution Category: UC-114

(Coal Based Materials \& Components)

B. Draskovich

Allied Signal Aerospace

Garrett Engine Division

111 S. 34th Street

P.O. Box 5217

Phoenix, AR 85010-5217

J. DiCarlo

NASA-Lewis Research Center

21000 Brookpark Road

Cleveland, $\mathrm{OH} 44135$

J. J. Eberhardt

DOE, Office of Conservation and Renewable Energy

CE-12 Forrestal Building

Washington, DC 20545

W. A. Ellingson

Argonne National Laboratory

9700 S. Cass Avenue

Argonne, IL 60439

B. Emiliani

Pratt \& Whitney

P.O. Box 109600

West Palm Beach, FL 33410-9600 
A. G. Evans

Materials Department

College of Engineering

University of California at Santa Barbara

Santa Barbara, CA 93106

S. G. Fishman

Office of Naval Research

Code 431, 800 N. Quincy Street

Arlington, VA 22217

F. Gac

Los Alamos National Laboratory

P.O. Box 1663

Los Alamos, NM 87545

M. Gold

Babcock \& Wilcox

Domestic Fossil Operations

20 South Van Buren Avenue

Baberton, OH 44023

R. E. Green, Jr.

The Johns Hopkins University

Materials Science \& Engineering

Maryland Hall

Baltimore, MD 21218

T. D. Gulden

GA Technologies, Inc.

P.O. Box 85608

San Diego, CA 92138

P. W. Heitman

General Motors Corporation

Allison Gas Turbine Division

P.O. Box 420, MS: W-5

Indianopolis, IN 46206-0420

S. P. Henslee

Argonne National Laboratory-West

P.O. Box 2528

Idaho Falls, ID 83403-2528
J. L. Hill

A.P. Green Refractories Company

Green Blvd.

Mexico, MO 65265

E. E. Hoffman

DOE, DOE Oak Ridge Field Office

P.O. Box 2008

Building 4500N, MS 6269

Oak Ridge, TN 37831

N. T. Holcombe

DOE, Morgantown Energy

Technology Center

P.O. Box 880

Morgantown, WV 26505

C. M. Huang

Tennessee Valley Authority

Energy Demonstration \& Technology

MR2N58A

Chattanooga, TN 37402-2801

W. J. Huber

DOE, Morgantown Energy

Technology Center

P.O. Box 880

Morgantown, WV 26505

L. A. Johnson

G.E. Aircraft Engines

Engineering Materials Technology

Laboratories

One Neumann Way

Cincinnati, $\mathrm{OH}$ 45215-6301

T. I. Johnson

Babcock \& Wilcox

1562 Beeson Street

Alliance, $\mathrm{OH} 44601$

R. R. Judkins

Oak Ridge National Laboratory

P.O. Box 2008

Oak Ridge, TN 37831 
A. Katz

Wright Laboratory

Metals and Ceramics Division

WL/MLLM

Wright-Patterson AFB, OH 45433

J. Katz

Los Alamos National Laboratory

P.O. Box 1663

Los Alamos, NM 87545

D. W. Keefer

Idaho National Engineering Laboratory

P.O. Box 1625

Idaho Falls, ID $8 \quad 115$

D. J. Kenton

EC Technologies

3614 Highpoint Drive

San Antonio, TX 78217

P. Khandelwal (Speed Code W-5)

Allison Gas Turbine Division

P.O. Box 420

Indianapolis, IN 46206-0420

R. A. Lawson (8 copies)

Oak Ridge National Laboratory

P.O. Box 2008

Oak Ridge, TN 37831

M. A. Leitheiser

3M Company

Ceramic Materials Department

201-2C-12 3M Center

St. Paul, MN 55144

G. D. Linsey

Pratt \& Whitney

400 Main Street

East Hartford, CT 06108

E. L. Long, Jr.

Oak Ridge National Laboratory

P.O. Box 2008

Oak Ridge, TN 37831
R. B. Loop

DOE, Idaho Operations Office

P.O. Box 1625

Idaho Falls, ID 83415

S. G. Malghan

National Institute of Standards

\& Technology

Materials Building

Gaithersburg, MD 20899

M. J. Mayfield

DOE, Morgantown Energy

Technology Center

P.O. Box 880

Morgantown, WV 26505

G. V. McGurl

DOE, Pittsburgh Energy

Technology Center

P.O. Box 10940

Pittsburgh, PA 15236

D. R. Messier

Army Materials Technology Laboratory

SLCMT-MCC

Watertown, MA 02172-0001

T. Mulholland

LAVA Crucible-Refractories Co.

P.O. Box 278

Zelienople, PA 16063

H. Narita

New Energy \& Industrial Technology

Development

Sunshine 60 Building

P.O. Box 1151

1-1 Higashi-Ikebukuro 3-Chrome

Toshima-Ku, Tokyo, 170

Japan

B. North

Kennametal, Inc.

Philip McKenna Laboratory

1011 Old Salem Road

P.O. Box 639

Greensburg, PA 15601 
J. E. Notestein

DOE, Morgantown Energy

Technology Center

P.O. Box 880

Morgantown, WV 26505

T. E. O'Hare

Brookhaven National Laboratory

Department of Applied Science

Upton, Long Island, NY 11973

R. J. Pollina

Avco Research Laboratory

2385 Revere Beach Parkway

Everett, MA 02149

M. Prager

The Materials Properties Council, Inc.

United Engineering Center

345 E. Forty-Seventh Street

New York, NY 10017

K. M. Prewo

United Technologies Research Center

MS 24, Silver Lane

East Hartford, CT 06108

B. H. Rabin

Idaho National Engineering Laboratory

P.O. Box 1625

Idaho Falls, ID 83415

K. L. Reifsnider

Virginia Polytechnic Institute \& State University

Department of Materials Engineering

Blackburg, VA 24601

R. W. Revic

Canada Center for Mineral \& Energy Technology

568 Booth Street

Ottawa, Ontario

Canada K1A OG1
S. L. Richlen

U.S. Department of Energy

Office of Industrial Technologies

1000 Independence Avenue, S.W.

Washington, D.C. 20585

M. Sahoo

Canada Center For Mineral

\& Energy Technology

\$68 Booth Street

Ottawa, Ontario

Canada K1A OG1

R. Santore

DOE, Pittsburgh Energy

Technology Center

P.O. Box 10940

Pittsburgh, PA 15236

R. B. Schulz

DOE, Office of Vehicle and Energy R\&D

CE-151 Forrestal Building

Washington, DC 20585

J. E. Scott

British Gas Corporation

Westfield Development Center

Cardenden, Fife

Scotland KY50HP

V. K. Sethi

Western Research Institute

365 N. 9th Street

P.O. Box 3395

University Station

Laramie, WY 82071

T. W. Sigmon

Research Triangle Institute

P.O. Box 12194

Research Triangle Park, NC 27709 
J. P. Singh

Argonne National Laboratory

9700 S. Cass Avenue

Argonne, IL 60439

S. C. Singhal

Westinghouse Electric Corporation

Research and Development Center 1310 Beulah Road

Pittsburgh, PA 15235

T. L. Starr

Georgia Institute of Technology

Georgia Tech Research Institute

Atlanta, GA 30332

W. A. Steele

Lawrence Livermore Laboratory

P.O. Box 808, L-325

Livermore, CA 94550

C. Steven

Williams International 2280 West Maple Raod

P.O. Box 200

Walled Lake, MI 48088

T. G. Stoebe

University of Washington

Department of Materials Science and Engineering

101 Wilson, FB-10

Seattle, WA 98195

R. S. Storm (25 copies)

The Carborundum Company

Technology Division

P.O. Box 832

Niagara Falls, NY 14302

J. Stringer

Electric Power Research Institute

P.O. Box 10412

3412 Hillyiew Avenue

Palo Alto, CA 94303
P. T. Thornton

Oak Ridge National Laboratory

P.O. Box 2008

Oak Ridge, TN 37831

T. M. Torkos

DOE, Pittsburgh Energy

Technology Center

P.O. Box 10940

Pittsburgh, PA 15236

A. Twigg

British Coal Corporation

Coal Research Establishment

Stoke Orchard, Cheltenham

Glochester, England GL52 4RZ

S. Ueda

New Energy \& Industrial Technology

Development

Sunshine 60 Building

P.O. Box 1151

1-1 Higashi-Ikebukuro 3-Chrome

Toshima-Ku, Tokyo, 170

Japan

A. W. Urquhart

Lanxide Corporation

1300 Marrows Road

P.O. Box 6077

Newark, DE 19714-6077

D. Utah

General Electric

P.O. Box 156301

Cincinnati, $\mathrm{OH}$ 45215-6301

M. Van de Voorde

European Communities Joint Research Centre

Petten Establishment

P.O. Box 2

1755 ZG Petten

The Netherlands 
S. C. Weiner

Air Products and Chemicals

P.O. Box 538

Allentown, PA 18105

R. A. Wenglarz (Speed Code W-16)

Allison Gas Turbine Division

P.O. Box 420

Indianapolis, IN 46206-0420

J. S. Wilson

DOE, Morgantown Energy

Technology Center

P.O. Box 880

Morgantown, WV 26505

K. M. Zwilsky

National Materials Advisory Board

National Research Council

2101 Constitution Avenue

Washington, DC 20418 

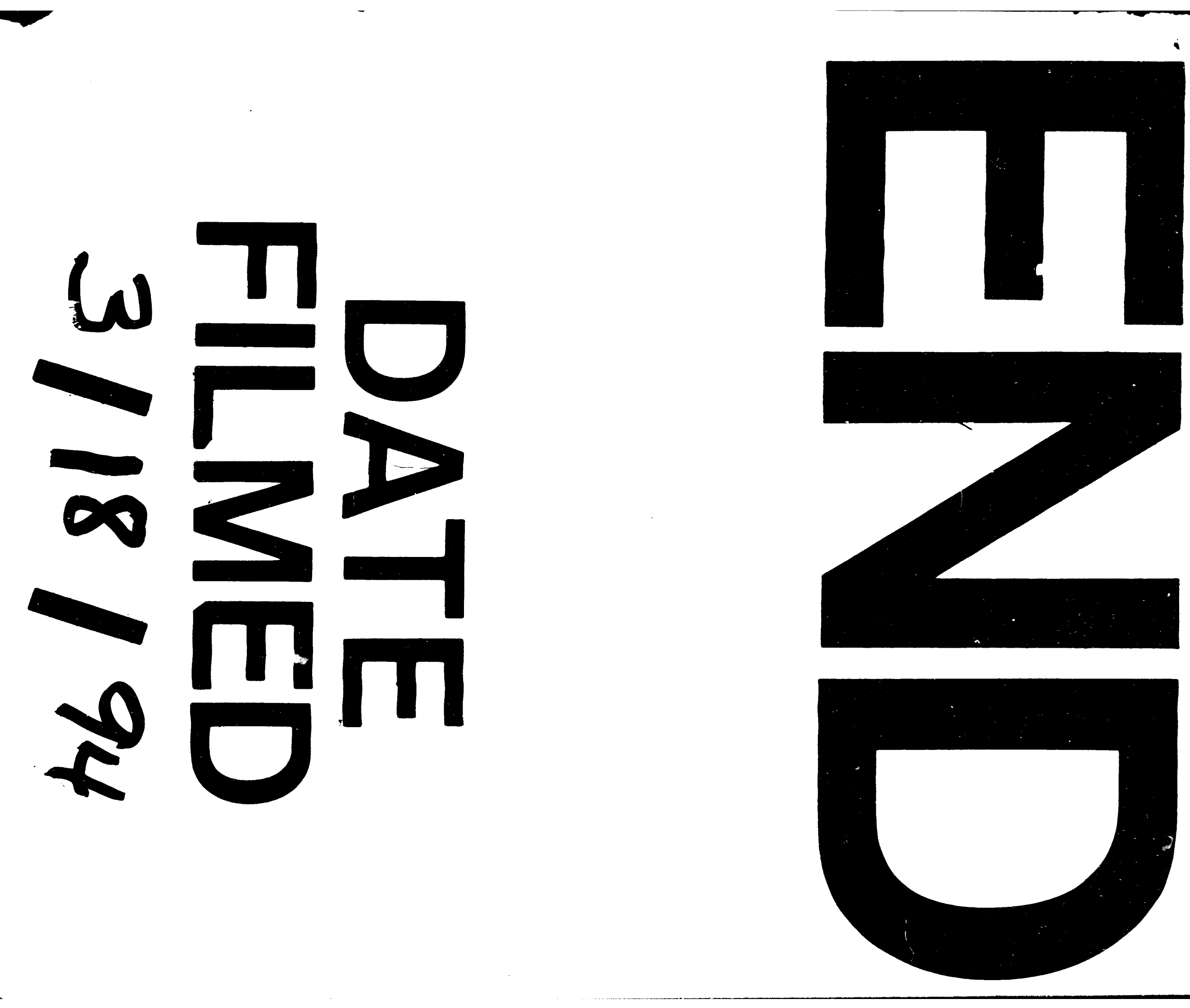
